\title{
Hydroclimatic Analysis of Rising Water Levels in the Great Rift Valley Lakes of Kenya
}

\author{
Mathew Herrnegger ${ }^{\mathrm{a}}$, Gabriel Stecher ${ }^{\mathrm{a}}$, Christian Schwatke ${ }^{\mathrm{b}}$, Luke Olang ${ }^{\mathrm{c}}$
}

${ }^{a}$ Institute for Hydrology and Water Management, University of Natural Resources and Life 5 Sciences (HyWa-BOKU), Vienna, Austria

${ }^{\mathrm{b}}$ Deutsches Geodätisches Forschungsinstitut, Technical University Munich (DGFI-TUM), Munich, Germany

${ }^{\mathrm{c}}$ Department of Biosystems and Environmental Engineering and Centre for Integrated Water Resources Management, Technical University of Kenya (CIWRM-TUK), Nairobi, Kenya

10 Corresponding author: Mathew Herrnegger - mathew.herrnegger@ boku.ac.at

This paper is a preprint submitted to EarthArXiv. It has been peer-reviewed and has been accepted in the Journal of Hydrology - Regional Studies.

@BOKU_HyWa 


\begin{abstract}
Study Region

The Great Rift Valley lakes of Kenya have recently experienced significant increases in their

20 water levels, negatively impacting the local communities. This has provoked renewed concerns about the causations, with various geological, anthropogenic and hydro-climatic influences hypothesized as potential causes of the water level rises.
\end{abstract}

\title{
Study Focus
}

This study analyses and documents water level fluctuations in Lakes Baringo, Bogoria, Nakuru,

25 Solai, Elementaita and Naivasha. Hydrometeorological analyses are undertaken to understand potential causes and lake volume data is used to derive the "Integrated Catchment Response" (ICR), a magnitude which allows to relate changes in water balance components to signals observed in the lake volume changes.

\section{New Hydrological Insights for the Region}

30 Compared to 1984-2009, the recent increases in lake areas range from $21 \%$ for Lake Naivasha to an extraordinary $123 \%$ for Lake Solai. Mean annual rainfall for 2010-2020 increased by up to $30 \%$. Actual evapotranspiration also increased, but to lesser extent compared to rainfall. The results illustrate that changes in catchment properties due to anthropogenic influences or changes in underground permeability are not necessary to explain the lake level rises. Based on the ICR only surprisingly minor changes in the water balance are necessary to explain the lake level rises, since an increase of only $0.4-2 \%$ of mean annual effective rainfall leads to the observed phenomena. 


\section{Introduction}

Water resource systems across the globe are today being affected by a number of natural and anthropogenic factors (Gownaris et al., 2018; Jenny et al., 2020; Salmaso et al., 2020). Changes in climatic and land use conditions, increased water demand from a growing human population and depletion of groundwater resources remain issues of key concern amongst water managers (du Preez and van Huyssteen, 2020; Fishman, 2018; Flörke et al., 2018). In sub-Saharan Africa, water resource systems are essential to local economies through supply of water for domestic and agricultural utilities, fishery, recreation and promotion of local tourism (Aura et al., 2020; Cowx and Ogutu-Owhayo, 2019; Minale, 2020). In Eastern Africa, the Rift Valley Lakes provide eco-regions of great biodiversity, considered today amongst the Global200 Freshwater ecoregions of the World (Fouchy et al., 2018; Olson and Dinerstein, 2002). However, the Rift Valley Lakes have witnessed upsurges in their lake water levels, areas and volumes, affecting not only the rich biodiversity but also the infrastructure and livelihoods of the local communities living within vicinity. The situation has been aggravated more recently, considering the continued above average rainfall being observed in the long rainy season (Wainwright et al., 2020). Lake Turkana, the largest permanent desert Lake in the world, has also shown substantial increases in water levels thereby affecting the local communities (Ojwang et al., 2016). These trends of Lake Turkana generally contradict the forecasted negative impacts of the ongoing water resources projects being carried along the Omo River in Ethiopia, which is considered the main water source for the lake (Avery and Tebbs, 2018).

Generally, Eastern Africa has shown substantial variability of its climate in the distant to the near past, where distinct wet and dry periods have been witnessed (Conway, 2002; deMenocal and Rind, 2019; Nicholson, 2019; Sutcliffe and Parks, 1999; Wainwright et al., 2020). This led not only to drastic changes in lake levels (Finney et al., 2019; Goman et al., 2017; Grove, 2019; Maina et al., 2018; McCall, 2010; Onywere et al., 2013; Richardson, 1966; Ricketts and Johnson, 2019; Sutcliffe and Parks, 1999; Verschuren, 2001, 2019; Whittaker, 2019), but also 
river flows (e.g. Grove, 2019; Sutcliffe and Parks, 1999). Between 1961 and 1964, for example, water levels in Lake Victoria rose by over two meters (Fig. 3.2 in Sutcliffe and Parks, 1999) and annual outflow from the lake through the Victoria or White Nile more than doubled in this same very short period of time (Fig. 3.8 in Sutcliffe and Parks, 1999).

The water level rises in the lakes of the Central Rift Valley of Kenya have begun to receive some scientific reflections in the recent past. Onywere et al. (2013) were the first to describe the phenomena of lake level rises, including detailed descriptions of the affected lake properties. Building up on these findings, Obando et al. (2016) illustrated the massive negative impacts of the flooding caused by the water level rises on the local population living within the riparian areas. Gichuru and Waithaka (2015) - similar to Moturi (2015) - focused their analyses on the trends of Lake Nakuru water surface variations between 1984 and 2013, concluding that no direct correlation between rainfall and changes in the lake surface area could be found. More recently, Kiage and Douglas (2020) assessed changes in land cover within the catchments of Lake Baringo, Bogoria, Nakuru, and Elementaita as a potential driver of the increasing lake water levels. Odongo et al. (2015) analysed time series of precipitation and flow, as well as annual mean lake volumes for the period 1960-2010 for Lake Naivasha to uncover possible abrupt shifts and gradual trends. For the covered years, which lie before the start of the recent lake level rises, most river gauging stations showed no evidence of trends in the annual mean and maximum flows as well as seasonal flows. RCMRD (n.d.) analysed the lake area increases for the period 06/2013-09/2020 and conclude that a "detailed investigation into the lake water balances, role of climatology, lake catchment land use change, land degradation and sediment yield into the lakes from the catchment as well as the role of geological activities including the status of the many geological fault and fissures in the region are key in understanding the underlying factors in the phenomenon." Although these studies show the development of the lake areas over time for single dates, the time series are incomplete and the methods of lake area delineation from satellite imagery differ. Rainfall data is partially analysed, however only for single ground 
stations and not necessarily for a longer period and no systematic hydroclimatic analysis exists. Additionally, developments in lake levels and lake volumes have not yet been documented.

Stimulated by country-wide media coverage, renewed increases in the lake water levels have recently provoked expert opinion and public debates on the potential causes of the water rises (e.g. Avery, 2020; Chebet, 2018; Chepkoech, 2020; Cherono, 2021; Njeri, 2020; Omondi, 2020; Wambua-Soi, 2020). The expert discourses revolve around potential geological, anthropogenic and hydro-climatic influences.

Geologically, it is argued that the affected Rift Valley lakes - all of which lie in closed basins without surface outlets - are located in a geologically highly active zone in the earth's crust (Gregory, 1896; Smith, 1989). Consequently, recent movement of tectonic plates in the region could have caused decreases in underground permeability, thereby decreasing sub-terranean outflow or seepage. This process could be described as hasty hydrogeological instationarity. The expert opinion is underlined by continued geothermal and volcanic activity witnessed within the entire region (Obando et al., 2016; Renaut et al., 2017; Smith, 1989; Tole, 1996).

105 The anthropogenic influences leading to hydrological changes consequent of land-use and landcover (LULC) change and degradation of the catchment areas has also been hypothesised as an important reason for the lake level rises by the Ministry of Environment, Water and Natural Resources and water resources managers from administration (Chepkoech, 2020). Here, it is argued that the potential sealing and clogging of the underground water paths due to higher sediment loads from the surrounding degraded catchments due to land use and land cover changes could have enhanced reduced permeability of the underground pathways in one way or the other. With this, it is further argued that increased sediment activation and erosion in the lake watersheds and in consequent higher siltation rates have impacted the lake volumes leading to the water levels rises. This theory follows recent independent studies that have shown dwindled forest cover in upstream headlands due to human encroachment, with agricultural 
land and peri-urban areas having almost proportionately increased (Boitt, 2016; Kiage and Douglas, 2020). Higher sediment inputs from the degraded lands, consequently, could probable be in favour of higher sediment yields.

Hydrologically, LULC changes often leads to higher surface runoff and less infiltration process, 120 thereby accelerating surface runoff and peak discharges on shorter time scales (Guzha et al., 2018). This in turn affects the overall water balance on a longer time scale through decreased actual evapotranspiration (Andréassian, 2004). Precipitation and actual evapotranspiration constitute major hydro-climatic drivers and components of the water balance, since they define the atmospheric boundary conditions. Rising water levels can therefore also be explained by a

125 deviation of inflow and on-lake precipitation and/or actual evapotranspiration from a magnitude that would result in an equilibrium in the lake water levels. Larger values in rainfall and/or lower actual evapotranspiration compared to the mean values, if the lake surfaces are in equilibrium, would be the rational.

Variations in lake volume is an integral response to potential changes, not only in the catchment,

130 but also in the lake water balance. Whatever the cause for the lake level changes is - Kiage and Douglas (2020) argue that all the above can potentially play a role in the lake level fluctuations - a quantifiable magnitude can be derived by analysing changes in lake volume, since they constitute an integrated catchment response. Changes in lake volume reflect potential influences due to deviations from an equilibrium regarding inflow and outflow, LULC changes,

135 or hydro-climatic changes. These are the options publicly debated.

For the analysis of hydroclimatic changes, time series of rainfall and actual evapotranspiration, ideally available as catchment values, are necessary. The limited rainfall observations on the ground are important, but exhibit some deficits related to uncertainties due to systematic and random errors in point measurements. Also, they do not sufficiently capture the spatio-temporal variability of rainfall in the drainage basins of the lake catchments (e.g. rainfall in the valley 
floors is only $30 \%$ compared to rainfall in the head water catchments, since the lakes are encircled by higher mountain ranges and escarpments (Kiage and Douglas, 2020)). Additionally - the lake level rises are acute at point of writing (03.2021) - the timely availability of time series from ground stations for a more or less online monitoring or rapid analysis is rarely given.

145 A number of reasons can be attributed to this, including a lack of consistent maintenance and lack of financial resources.

As an alternative, rainfall data estimated by remotely sensed satellite data and ideally corrected by local observations (e.g. Ashouri et al., 2015; Beck et al., 2019; Huffman et al., 2007; Joyce et al., 2004; Maidment et al., 2014; Tarnavsky et al., 2014) or meteorological reanalysis data

150 (e.g. Hersbach et al., 2020; Muñoz Sabater, 2019; Rienecker et al., 2011; Rodell et al., 2004; Saha et al., 2014) therefore constitute a potential alternative. Regarding actual evapotranspiration, hardly any measured information is available on the ground. This holds true not only for the study regions, but is still generally a global challenge with few areas as exceptions (Baldocchi et al., 2001). Modelled actual evapotranspiration rates from meteorological reanalysis data can provide an alternative in this case (e.g. Muñoz Sabater, 2019; Rodell et al., 2004b), although the data must be used with care considering the inherent associated uncertainties.

\subsection{Research questions and objectives}

Based on these guiding problems with respect to understanding the mechanisms behind the lake water level increases in the Central Kenya Rift Valley, the following research questions and answers as objectives are aimed to be investigated in this research:

1. What are the magnitudes in changes in lake characteristics, i.e. water surface area, water level and water volume over time, i.e. for 1984-2020, a period of 37 years?

2. How has catchment rainfall and actual evapotranspiration evolved over this period, thereby also considering spatio-temporal variability? 
3. What are the changes in lake water volume and how does this magnitude translate to changes in water balance components?

4. Are the derived changes in water volume observable trends in rainfall and actual evapotranspiration or are other causalities drivers for the lake level increases?

170 It is clear that the current fluctuations in lake levels have previously been there - probably with higher intensity. At the same time, the negative effects on the local population are not comparable. Higher population densities, especially in the riparian areas and generally higher damage potentials, i.e. the upper limit of the loss or damage, constituting all assets and affected persons which can potentially be damaged by the rising lake levels, are very different now.

175 This, in combination with widespread media coverage, gives the whole phenomena an unprecedent focus. Also different from previous lake level fluctuations is our ability to observe these changes - in space and time - in unknown detail. Although local observation networks have deteriorated, information based on remote sensing has exploded. This makes this investigation and descriptions possible. The main lakes in the Central Rift Valley with different spatial catchment characteristics but also water quality properties as investigated: Lake Baringo, Lake Bogoria, Lake Nakuru, Lake Solai, Lake Elementaita and Lake Naivasha.

\section{Materials and methods}

\subsection{Study lakes}

The study lakes are located in the Central Rift Valley of Kenya, which is part of the East African Rift System, ranging from the Gulf of Aden at the Horn of Africa to the South of Lake Malawi between Malawi and Mozambique. Also denoted in Figure 1, from North to South, are the investigated lakes: (a) Baringo, (b) Bogoria, (c) Nakuru, (d) Solai, (e) Elementaita, and (f) Naivasha. Apart from the larger scale feature of the East African Rift Valley, the Western Rift System running south in the Western border of Uganda is also visible from Figure 1. 


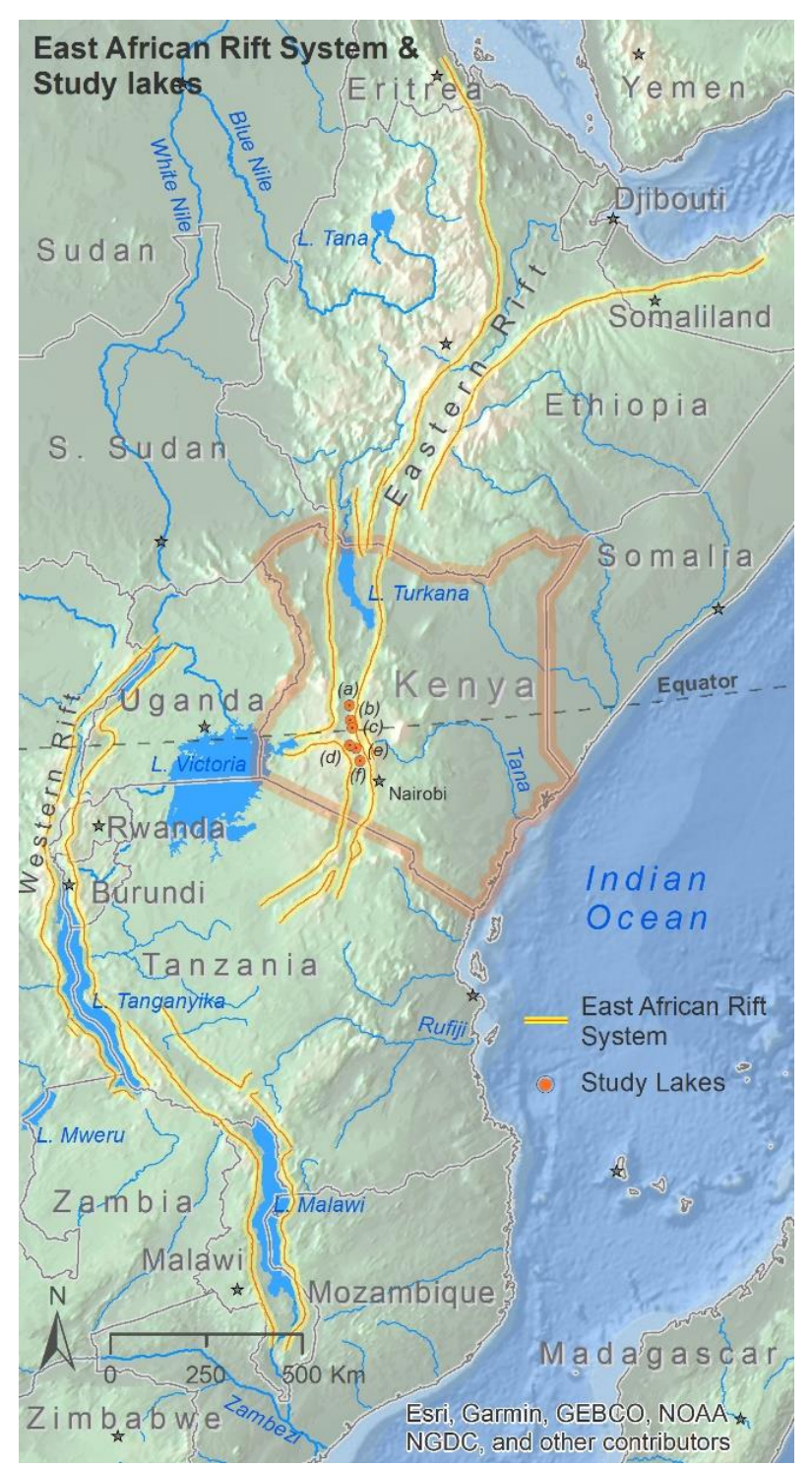

Figure 1: East African Rift System, including study lakes in Kenya depicted as red points. From North to South: (a) Lake Baringo, (b) Bogoria, (c) Solai, (d) Nakuru, (e) Elementaita, and (f) Naivasha. Lighter areas in the map, e.g. in Ethiopia, show higher elevation zones. Data sources for mapping: Esri, Garmin, GEBCO, NOAA, NGDC, hydrolk, naturalearthdata.com 
In total, the study area and lake basins cover an area of $13355 \mathrm{~km}^{2}$. The orographic catchment areas of the single lakes and other lake characteristics are summarized in Table 1.

Table 1: Lake characteristics, including references used for calculations.

\begin{tabular}{|c|c|c|c|c|c|c|}
\hline \multirow[t]{2}{*}{ 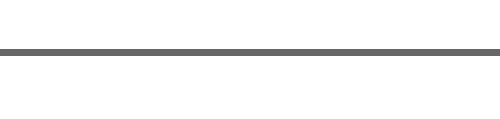 } & \multicolumn{6}{|c|}{ Lake } \\
\hline & Baringo & Bogoria & Nakuru & Solai & Elementaita & Naivasha \\
\hline $\begin{array}{l}\text { Orographic catchment area }\left[\mathrm{km}^{2} \text {; }\right. \\
\text { Yamazaki et al. (2019)] }\end{array}$ & 6608.7 & 1060.0 & 1470.6 & 214.1 & 771.9 & 3229.1 \\
\hline $\begin{array}{l}\text { Mean catchment elevation [m; } \\
\text { Yamazaki et al. (2019)] }\end{array}$ & 1721.6 & 1774.1 & 2186.7 & 1757.9 & 2054.9 & 2354.9 \\
\hline $\begin{array}{l}\text { Range in catchment elevation [m; } \\
\text { Yamazaki et al. (2019)] }\end{array}$ & $963-3014$ & $\begin{array}{l}980- \\
2872\end{array}$ & $\begin{array}{c}1751- \\
3085\end{array}$ & $\begin{array}{c}1508- \\
2456\end{array}$ & $1715-2816$ & $1879-3992$ \\
\hline $\begin{array}{l}\text { Mean annual catchment rainfall (1981- } \\
\text { 2020) [mm; Funk et al. (2015)] }\end{array}$ & 1023.7 & 1036.1 & 1012.7 & 1023.0 & 913.9 & 1029.2 \\
\hline $\begin{array}{l}\text { Mean annual lake area (1984-2020) } \\
\quad\left[\mathrm{km}^{2} ; \text { Schwatke et al. (2019)] }\right.\end{array}$ & 146.3 & 34.9 & 43.6 & 7.1 & 18.8 & $128.9^{\text {a }}$ \\
\hline $\begin{array}{c}\text { Standard deviation of annual lake area } \\
(1984-2020) \text { [\% of mean; Schwatke et } \\
\text { al. (2019)] }\end{array}$ & $\pm 19.3 \%$ & $\pm 9.1 \%$ & $\pm 20.7 \%$ & $\pm 34.6 \%$ & $10.8 \%$ & $\pm 8.7 \%$ a \\
\hline $\begin{array}{l}\text { Range in annual lake area (1984-2020) } \\
\qquad\left[\mathrm{km}^{2} ; \text { Schwatke et al. (2019)] }\right.\end{array}$ & $118.3-197$ & $\begin{array}{c}31.4- \\
41.2\end{array}$ & $33.1-62.3$ & $3.3-11.7$ & 15.121 .9 & $\begin{array}{l}104.9^{-} \\
147.7^{\text {a }}\end{array}$ \\
\hline $\begin{array}{l}\text { Mean lake level }(1984-2020)[\mathrm{m} ; \\
\text { Schwatke et al. }(2020,2019)]\end{array}$ & 973.8 & 994.4 & 1761.5 & 1510.1 & 1776.9 & $1884.1^{\mathrm{a}}$ \\
\hline $\begin{array}{l}\text { Range in lake level }(1984-2020)[\mathrm{m} ; \\
\text { Schwatke et al. }(2020,2019)]\end{array}$ & $\begin{array}{c}971.4- \\
979.6\end{array}$ & $\begin{array}{c}993.1- \\
998.1\end{array}$ & $\begin{array}{c}1759.8- \\
1766.2\end{array}$ & $\begin{array}{c}1505.9- \\
1514.4\end{array}$ & $1775.9-1778.2$ & $\begin{array}{l}1880- \\
1887.5\end{array}$ \\
\hline
\end{tabular}

200 Figure 2 shows spatial characteristics of the Central Rift Valley and gives an overview of the landscape the lakes are located. Panel (a) depicts the topography and elevation, including the orographic catchment areas, highlighting the fact that the lakes lie in closed basins, where the lake is the sink and where no surface outlets are present. The lakes are all located in the Rift floor, encircled by high mountain ranges and escarpments. The lowest lake regarding lake level 205 but also mean catchment elevation of $1722 \mathrm{~m}$ is Baringo in the North and the highest is Lake Naivasha $(2355 \mathrm{~m})$ in the South (Table 1). Both lakes are freshwater. Despite high potential evapotranspiration rates, the lakes have not become saline, indicating that there is substantial underground loss of water through seepage, which hinders the accumulation of dissolved solids through flushing (Becht et al., 2006; Darling et al., 1996, 1990; Derakhshan, 2017; Yihdego 
and Becht, 2013). The smallest lakes regarding water and catchment area, Lake Solai (De Bock et al., 2009; Goman et al., 2017; Nyaga et al., 2019) with a mean catchment elevation of 1759 m, also shows lower alkalinity, indicating some loss through the underground, probably leaking towards Lake Bogoria and Baringo, which lie in a downward elevation gradient to the North (Olago and Mavuti, 2017). Bogoria, Nakuru, and Elementaita are in contrast highly saline, 215 which however does not mean that no underground seepage is present. The magnitude of underground seepage will be lower, compared to the freshwater lakes (McCall, 2010). Generally, a falling elevation gradient is evident from South to North - from Naivasha to Baringo - as can also be seen from the mean catchment and lake level elevations in Table 1. Although Naivasha also leaks to the south towards Lake Magadi, flow towards Elementaita, 220 Nakuru and Bogoria is probable and is shown by others (Becht et al., 2006; Darling et al., 1996; Verschuren, 2001).

Vegetation cover is indicated in panel (b) utilizing the mean annual NDVI (LP DAAC, 2015). Vegetation density closely follows elevation, with higher areas and escarpments, e.g. Aberdares East of Naivasha, the Mau escarpment West of Nakuru or the mountain ranges around the Kerio

Valley East of Bogoria and Baringo, showing higher vegetation cover. Areas of lower vegetation cover are evident in the Rift floor (e.g. "Elementaita Badlands" (Onywere et al., 2013)) and generally towards the North and East of the study area. The vegetation cover has a very similar pattern compared to the rainfall distribution (see Figure 5), which makes sense. Vegetation and the hydro-meteorological system is water limited. 

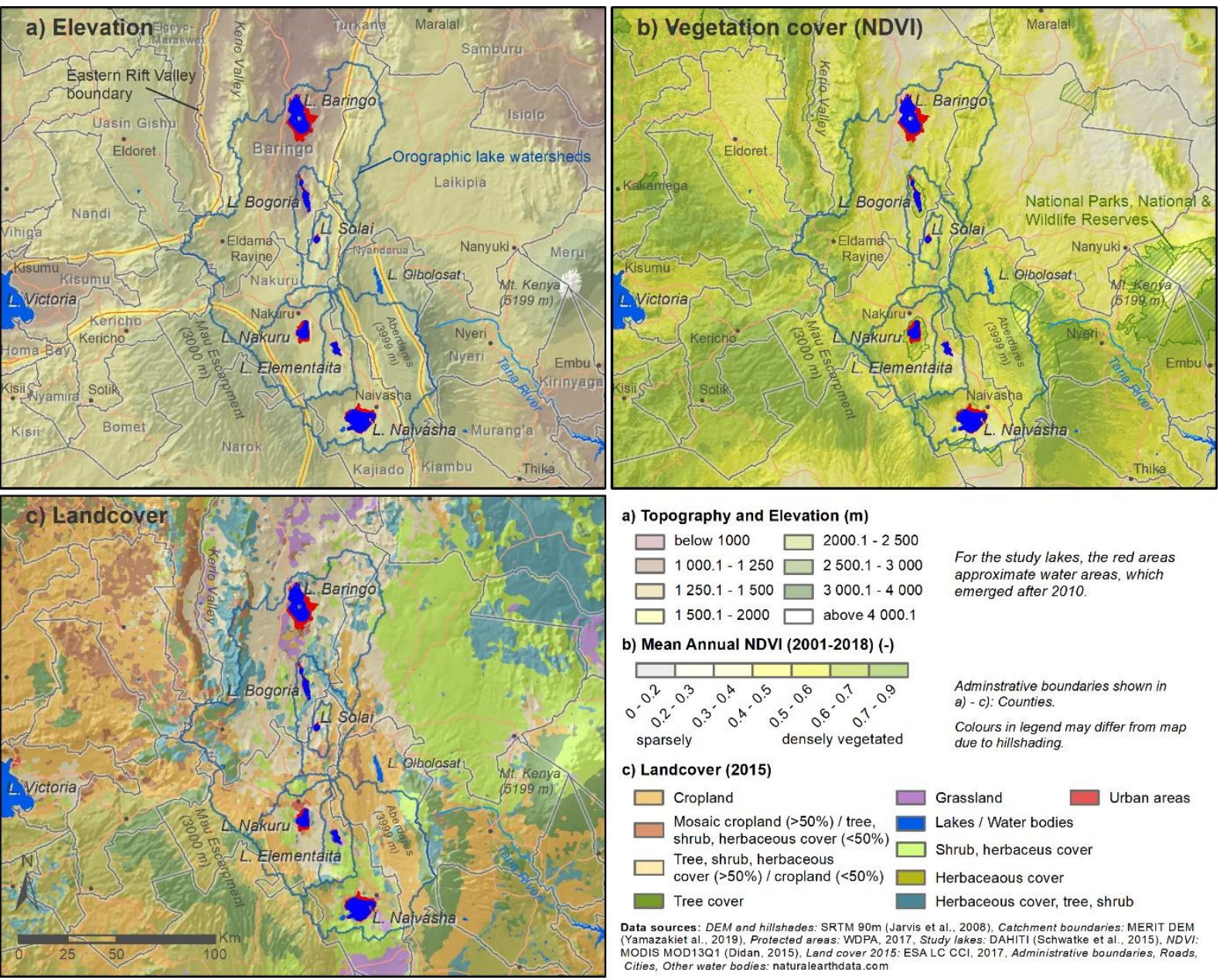

Figure 2: Study lakes and orographic catchment boundaries. Elevation and topography (a), the mean annual MODIS NDVI for the period 2001-2018 as a proxy for vegetation cover (b), and a slightly generalized land cover (c) are plotted to characterize spatial properties of the study region. For the study lakes, the red areas approximate water areas, which emerged after 2010.

235 Landcover, although already generalized for mapping, is heterogeneous (Figure 2, panel (c)).

Where climate allows, agriculture and cropland define the landcover. Systematic irrigation is limited to areas with water supply, e.g. around Lake Naivasha. A mix of shrub, trees and herbaceous cover are characteristic for the Rift floor, whereas the manifestation of the composition depends on (small scale) climatic aspects and mainly rainfall distribution. Higher

240 elevation areas show a landcover dominated by tree and herbaceous cover. East of the study area, the Laikipia plains are dominated by shrub and herbaceous cover.

Figure 3 shows the investigated lakes in more detail and thereby visualizing the water occurrence mask from 1984 to 2020. Especially for Lake Baringo, Nakuru and Naivasha, but also the smallest Lake - Solai - a large variability and expansion in lake area is visible. 

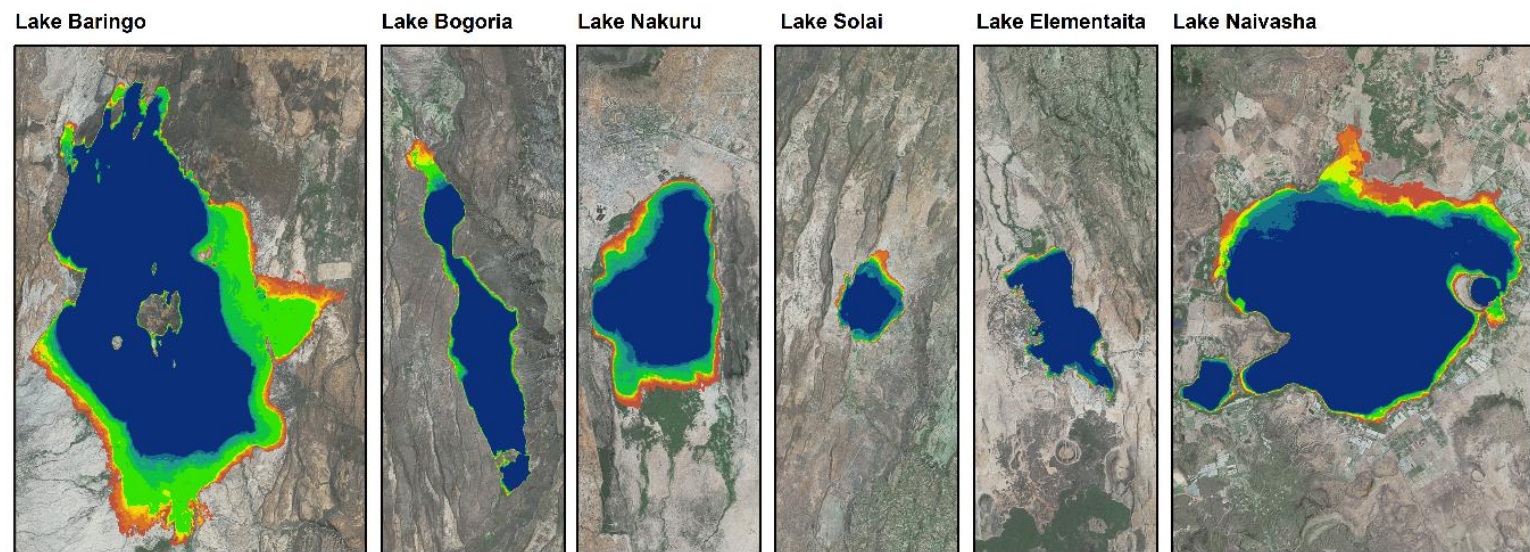

Water occurence [\%]
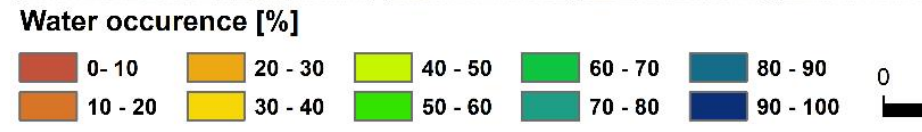

Figure 3: Water occurrence from 1984 to 2020 for the investigated lakes with data, emphasizing the variability of the surface area for the respective lakes in the given time period. Data based on Schwatke et al. (2015).

Lake Baringo (Kiage and Douglas, 2020; Obando et al., 2016; Odada et al., 2006; Onywere et al., 2013) is internationally recognized for its biodiversity, but is also important to the communities in its basin as a source of water for domestic and agricultural use and watering livestock. Other important uses are income generation through tourism, biodiversity conservation and fishing. Three indigenous human communities live in the basin namely the Ilchamus, Pokots and Tugens. Seasonal rivers that drain into the lake include Ol Arabel, Makutan, Tangulbei, Endao and Chemeron. Perkerra and Molo are perennial and significantly 255 lower discharges are characteristic during dry season. Lake Baringo experiences very high annual evaporation rates $(1650-2300 \mathrm{~mm})$, compared to an annual rainfall of 450-900 $\mathrm{mm}$ and therefore lake levels depend heavily on inflows from rivers originating from the humid parts of the drainage basin, where the annual rainfall varies between $1100 \mathrm{~mm}$ and $2700 \mathrm{~mm}$ (Onywere et al., 2013). Conductivity is reported to be around $1760 \mu \mathrm{S} / \mathrm{cm}$ (De Bock et al., 2009) or $894.4 \mu \mathrm{S} / \mathrm{cm}$ (Obando et al., 2016). The orographic catchment size is around $6610 \mathrm{~km}^{2}$. The region around Lake Baringo is presently inundated with several hotels and rural infrastructure, including homes, agricultural fields and grazing areas, dispensaries, health centres and schools being affected (Obando et al., 2016). About 5000 people living around the area have been displaced by the flood inundation (Avery, 2020). 
265 Lake Bogoria (Agembe et al., 2016; McCall, 2010; Renaut et al., 2017) is located in a deep depression with comparatively steeper slopes than Lakes Baringo or Nakuru. Although the lake level increases, when measured in absolute number, are high, the steeper topography of the surrounding area limits the spread of flood waters mostly to the North of the lake. The lake is located within a National Reserve, where important infrastructure related to tourism have been

270 affected and rendered unusable. Most geothermal springs associated with the lake region and a prominent touristic attraction have been submerged (Renaut et al., 2017). The lake is highly alkaline, with a conductivity of $31046 \mu \mathrm{S} / \mathrm{cm}$ (Obando et al., 2016) . The catchment area is around $1060 \mathrm{~km}^{2}$, receiving around mean annual rainfall of $1035 \mathrm{~mm}$ for the period 1981-2020. With increasing water levels of Lake Bogoria, there is renewed concern that the alkaline lake 275 will overflow and merge with the freshwater Lake Baringo located about $20 \mathrm{~km}$ to the North, thereby causing severe cross-contamination (Chepkoech, 2020).

Lake Nakuru (Kiage and Douglas, 2020; Kimaru et al., 2019; Obando et al., 2016; Onywere et al., 2013) is surrounded and protected by a National Park established in 1961 and which covers $188 \mathrm{~km}^{2}$. The lake is a Ramsar site of wetlands of international importance. Lake Nakuru 280 National Park is the only park within Kenya to be entirely fenced. Protective measures within the park have helped threatened species, including the famous Black Rhino, to repopulate. Lake Nakuru is also famous for its spectacular bird populations including both the Lesser and Greater Flamingo, who rely on the algae in the lake. The increases in the lake water levels have changed the water quality of the normally alkaline-saline lake (Oduor and Schagerl, 2007), leading to 285 loss of the algae abundance. In consequence, a vast number of Flamingos have left. Kiage and Douglas (2020) report on the hyper-salinity with conductivity values of up to $160,000 \mu \mathrm{S} / \mathrm{cm}$, however without reference date. Obando et al. (2016) report on a conductivity of 49,000 $\mu \mathrm{S} / \mathrm{cm}$. Lake Nakuru is fed by the Baharini spring on its eastern shoreline, four seasonal rivers and the permanent Ngosur River. The seasonal rivers are the Njoro, Nderit, Makalia and Lamudhiak, all of which originate in the Eastern Mau Forest. Mean annual catchment rainfall is $1013 \mathrm{~mm}$ 
for the period 1981-2020. The overall catchment size is around $1471 \mathrm{~km}^{2}$. Flood inundation around Lake Nakuru affect the existing national park and road infrastructure, thereby limiting accessibility, since about $60 \%$ of the park are inaccessible (Onywere et al., 2013). Other damages to the infrastructure, e.g. flooding of the main administrative block, also negatively affect tourism activities and the local economy that depends on this (Obando et al., 2016).

Lake Solai (De Bock et al., 2009; Goman et al., 2017; Nyaga et al., 2019), the smallest of the study lakes and until now not considered in an analysis of lake level and lake area variation, is located about $50 \mathrm{~km}$ north of Nakuru town and $20 \mathrm{~km}$ southeast of Lake Bogoria. It has a drainage basin of only $214 \mathrm{~km}^{2}$ and also does not have a surface outflow. Rainfall is comparable to Lake Bogoria, with a mean annual value of $1023 \mathrm{~mm} / \mathrm{a}$. Open water conductivity measured in 2003 and 2004 had a range of $776 \pm 111$ to $2398 \pm 166 \mu \mathrm{S} / \mathrm{cm}$ (De Bock et al., 2009). Maximum values of $2900 \mu \mathrm{S} / \mathrm{cm}$ are reported by Nyaga et al. (2019).

Lake Elementaita with a mean water surface area of $18.8 \mathrm{~km}^{2}$ lies $20 \mathrm{~km}$ south of Lake Nakuru and around $40 \mathrm{~km}$ north of Naivasha. The highly alkaline (sodium carbonate salts) and shallow lake is characterised by hypersaline waters with an electric conductivity between 12,000 and $40,000 \mu \mathrm{S} / \mathrm{cm}$ (Kiage and Douglas, 2020). The catchment area is the smallest after Solai and covers an area of $772 \mathrm{~km}^{2}$. Lake Elementaita receives the least rainfall of all investigated lakes (914 mm/a). Damage potential in riparian areas around Elementaita, but also Lake Solai, is low. The effects of the lake level rise are therefore, at least the ones directly aimed towards society, comparatively low.

Lake Naivasha (Becht et al., 2005; Maina et al., 2018) to the south has an orographic catchment area of $2355 \mathrm{~km}^{2}$ and receives around $13 \%$ more rainfall compared to Elementaita (1030 $\mathrm{mm} / \mathrm{a})$. The mean lake area is $128.8 \mathrm{~km}^{2}$ and, after Baringo, it is the second largest lake in the study. Agembe et al. (2016) report of conductivity values ranging from $250-400 \mu \mathrm{S} / \mathrm{cm}$. For 315 Lake Naivasha, impacts on the lake level increases can be said to be relatively lower. The long- 
term economic history and tradition around the lake (Becht et al., 2005; Ricciardi, 1981) also including a longer history of scientific research of the area, has also led to a stronger awareness of potential hazard from flooding, since the current fluctuations are not unprecedented (Richardson, 1966; Verschuren, 2001). Larger parts of the riparian zones surrounding Lake Naivasha are generally dominated by tourism infrastructure and more pronounced industrial agriculture and flower farms targeted mainly for export to other parts of the World. Lake Naivasha has a satellite lake to the west (Small Lake or Lake Oloiden), which is not covered in our analysis.

\subsection{Data Basis}

325 In this work (i) the "Database for Hydrological Time Series over Inland Waters" (DAHITI, Schwatke et al., 2020, 2019, 2015), (ii) Climate Hazards Group InfraRed Precipitation with Station data (CHIRPS, Funk et al., 2015)) dataset and (iii) ERA5-Land (Muñoz Sabater, 2019) dataset are the main data basis used for analyzing lake properties and hydro-meteorological conditions over time in the study area. The MERIT Hydro DEM (Yamazaki et al., 2019) is used

330 for delineating orographic catchment boundaries.

\subsubsection{Database for Hydrological Time Series over Inland Waters (DAHITI)}

Changes in lake volume can be derived by integrating ground measurements of lake levels and lake area estimates, e.g. from satellite imagery. For the study lakes, however, no complete measurements on lake levels exist. As an alternative, altimeter satellites with the capacity to measure water level have proven reliability over time from previous applications (Crétaux et al., 2011; Göttl et al., 2016; Santos da Silva et al., 2010; Villadsen et al., 2016). Information on the binary signal regarding water cover can be derived through systematic analysis of electromagnetic waves emitted due to specific surface properties, applying different combinations of spectral bands to derive a numerical number, which is subordinated to a 
products on water cover based on remote sensing data exist (e.g. Carroll et al., 2017; Hakimdavar et al., 2020; Klein et al., 2017; Pekel et al., 2016). One of the global products, "The Database for Hydrological Time Series of Inland Waters" (DAHITI; Busker et al., 2019; Schwatke et al., 2020, 2015), offers additional valuable information on properties of water 345 bodies, also including a description of uncertainty. DAHITI provides a variety of hydrological information on lakes, reservoirs, rivers, and wetlands derived from satellite data, i.e. from multimission satellite altimetry and optical remote sensing imagery. The comprehensive data set, spanning the period 1984 to near-present, contains consistent information on time series on lake areas, lake volumes, altimetry and bathymetry, which are very relevant for the current challenges in the Central Rift Valley lakes of Kenya.

In this study, DAHITI is utilized to describe the surface area, water level and volume variations. The lake surface area data is derived based on optical image analyses of Landsat and Sentinel2. The surface area time series of DAHITI is a continuous dataset ranging from 1984 to nearpresent (Schwatke et al., 2019). DAHITI also uses satellite altimetry to derive water level data

355 from wetlands, reservoirs, and other inland water bodies. The volume variations of DAHITI is calculated based on the combination of water surface area and water level time series. Based on the dependency of these two variables, a hypsometry model is computed based on the new modified Strahler approach. All hydrological products provided in the DAHITI dataset are developed and maintained by the Deutsches Geodätisches Forschungsinstitut der Technischen 360 Universität München (DGFI-TUM). They are free of charge and publicly available on the DAHITI website (https://dahiti.dgfi.tum.de/). DAHITI contains the data of the lakes Baringo (DAHITI-ID: 13608), Bogoria (13607), Nakuru (13220), Solai (13609), Elementaita (13611), Naivasha (13610) and Oloiden (17681). 


\subsubsection{Lake surface areas}

365 For the calculation of high-resolution time-variable water surfaces, optical images of Landsat and Sentinel-2 are used to identify surface water areas from 1984 to near-present. As a first step, a water-land mask is extracted by using five different water indexes accompanied by an automated threshold computation. The combination of five different water indexes is used because no optimal water index exists for all areas. The water indexes used to derive the landwater mask include the Modified Normalized Difference Water Index (MNDWI), New Water Index (NWI), Automated Water Extraction Index for Non-Shadow Areas (AWEInsh), Automated Water Extraction Index for Shadow Areas (AWEIsh), and the Tasseled Cap for Wetness (TCwet). By combining these five indexes, their unique advantages can be used. To finally achieve a daily land-water mask, all pixels classified as water by four or five indexes will be represented as water. Pixels that are classified as water by none or only one index are set to land. All other pixels, classified as water by two or three indexes, are set to data gaps and are filled in the following step. In the second step, data gaps occurring due to different causes (e.g. voids, cloud cover) are filled by using a long-term water probability mask. This mask is finally used iteratively to fill the data gaps, which leads to a gap-reduced surface area time series for lakes and reservoirs. The correlation of surface water and water levels from in situ and satellite altimetry has increased significantly from 0.61 to 0.86 after filling the data gaps of lake surfaces. This demonstrates the quality improvement by filling the data gaps as well as the enhanced reliability of the approach (Schwatke et al., 2019).

As reference and comparison data to the DAHITI lake area, lake area values published in Kiage and Douglas (2020), Obando et al. (2016) and Onywere et al. (2013) are additionally used.

\subsubsection{Lake water levels}

Initially, satellite altimetry was designed to monitor water levels over oceans. However, for almost two decades, satellite altimetry has been proven to have the potential to observe rivers 
and small lakes with reliable accuracies. The advantage of satellite altimetry is that even in remote areas without local infrastructure water levels can be estimated quite accurately. Since most satellite missions follow specific ground tracks, inland water bodies are only crossed by chance. Big water bodies have therefore a higher probability of being crossed compared to small ones. Additionally, the temporal resolution is also limited to 10 to 35 days due to the respective orbit repetition configuration of the specific satellite mission. Therefore, in DAHITI, multiple satellite altimeter systems are combined to increase the temporal and spatial resolution (Schwatke et al., 2015). Altimeter data provided by different missions, including Envisat, ERS2, Jason-1/-2/-3 TOPEX/Poseidon, SARAL/AltiKa, and Sentinel-3A/-3B are utilised for the DAHITI dataset.

The DAHITI method for estimation of water level time series incorporates three main steps of data processing, namely data pre-processing, Kalman filtering and postprocessing. The preprocessing step includes range corrections, computation of height errors, and outlier rejection. The last step is to merge all water levels derived from the previous steps to form a single time series (Schwatke et al., 2015).

DAHITI yields a very accurate water level time series estimation for inland water bodies. The

405 validation shows root mean square errors between 4 and $36 \mathrm{~cm}$ for lakes compared to in situ measurements. Generally, an increase in accuracy could be achieved compared to other available altimeter data bases (Schwatke et al., 2015).

In this study, the water level series of the lakes Baringo (2004-2020), Bogoria (2016-2020), Nakuru (2016-2020), Solai (2016-2020), Elementaita (2012-2020), Naivasha (2012-2020) and

410 Oloiden (not available) cover different periods because the lakes are crossed by different available altimeter mission. 


\subsubsection{Lake volume variation}

The DAHITI database also includes data of volume variations of inland water bodies. The volume variations are calculated based on the lake surface area and the water level time series

415 within the DAHITI database (Schwatke et al., 2020). The estimation of volume variations is based on three steps: (i) estimation of hypsometry, (ii) computation of bathymetry, and (iii) calculation of the volume variation.

The water area - water level relationship of each lake is described by the hypsometry. The hypsometry again depends on the lake's bathymetry. In the past, linear or polynomial functions have frequently been used to fit a hypsometric curve to every water body. Nevertheless, they do not capture the entire variations of the area-height relation. Therefore, Schwatke et al. (2020) utilize a modified Strahler model, developed in 1952. The Strahler model (Strahler, 1952) was originally developed to relate the horizontal cross-sectional area to the relative elevation above the basin outlet.

Water levels and surface areas are mostly not obtained on the same date. Therefore, only data pairs whose temporal difference is less than 10 days is used to establish the hypsometry. This maximizes the number of data pairs and minimizes possible errors.

As a pre-processing step to derive the bathymetry of inland water bodies, the water level of each surface area obtained has to be estimated. Therefore, the established hypsometric curve is also used to derive a water level time series. This method minimizes errors from altimetry, but other errors due to extrapolation or time-dependent changes might occur. The bathymetry is then calculated using the land water masks and the according water levels in a descending order. To calculate the height of the bathymetry, each pixel column is processed separately. Using a median filter of the size five for the land-water mask in the direction of decreasing water levels, uncertainties of corrupt land-water pixels are reduced (Schwatke et al., 2020). 
Finally, the volume variation time series of each lake can be computed. The volume variations are calculated based on the bathymetry and a combination of water levels obtained from satellite altimetry and the estimated water levels based on the hypsometric curve. To compute the volume below the respective water level, the water level is intersected pixel-wise with the bathymetry, which has a spatial resolution of $30 \mathrm{~m}$. These pixel volumes of the current water level are then accumulated to obtain a volume above the minimum observed surface area. It is important to note that the volume below the minimum observed value is unknown and that with this approach only volume variations can be computed, since not the complete bathymetry is known.

445 Due to the short periods of water level time series from satellite altimetry, the computed hypsometry is used to derived additional water levels from surface areas. This allows us to densify and to extend the water level time series until 1984.

\subsubsection{Rainfall data}

The Climate Hazards group Infrared Precipitation with Stations (CHIRPS) environmental record is a quasi-global $\left(50^{\circ} \mathrm{S}-50^{\circ} \mathrm{N}\right)$, high resolution $\left(0.05^{\circ}\right)$, daily, pentadal, and monthly precipitation dataset. The CHIRPS dataset builds on previous approaches to 'smart' interpolation techniques and high resolution, long period of record precipitation estimates based on infrared Cold Cloud Duration (CCD) observations. The algorithm i) is built around a $0.05^{\circ}$ climatology that incorporates satellite information to represent sparsely gauged locations, ii) incorporates daily, pentadal, and monthly 1981 -present $0.05^{\circ}$ CCD-based precipitation estimates, iii) blends station data to produce a preliminary information product with a latency of about 2 days and a final product with an average latency of about 3 weeks, and iv) uses a novel blending procedure incorporating the spatial correlation structure of CCD-estimates to assign interpolation weights (Funk et al., 2015).

Several global data sets of rainfall, some of which are referred to in the introduction, could have been used for this study. Our decision to use CHIRPS is based on several studies applying 
CHIRPS in East Africa, which showed comparatively better performances and agreements of CHIRPS with station data (e.g. Dinku et al., 2018, 2007; Kimani et al., 2017; Omonge et al., 2021). Also, recently Kimaru et al., (2019) modelled the inflows to Lake Nakuru using CHIRPS

rainfall as input.

Apart from CHIRPS, rainfall data from the ground stations Nakuru meteorological station and Snake Farm meteorological station on the shores of Lake Baringo, both time series digitalized from plots in Kiage and Douglas (2020) are used as reference for the remote sensing rainfall product CHIRPS.

\subsubsection{Evapotranspiration data and effective rainfall}

For the current study, data derived from the newest reanalysis product of ECMWF (European Centre for Medium-Range Weather Forecasts) is used. The ERA5-Land (ERA5L) dataset with global coverage thereby provides gap-free time series with monthly and hourly resolution for 15 meteorological variables for the period 1981 to near-present (Muñoz Sabater, 2019; Yang and Giusti, 2020). Here, we used monthly averages, which were processed via Google Earth Engine (Gorelick et al., 2017). ERA5-Land is a derivative of the ERA5 climate reanalysis (Hersbach et al., 2020), however only covering the terrestrial components with an improved spatio-temporal resolution. ERA5-Land has a spatial resolution of 0.1 arc degrees compared to the grid size of ERA5 with of 0.25 arc degrees. The temporal resolution of ERA5-Land is 1 hour, while ERA5 has a coarser 3-hour resolution. There is no data assimilation applied to ERA5-Land, but observations are indirectly implemented via the assimilated atmospheric fields of ERA5 (Yang and Giusti, 2020). For the current study, actual evapotranspiration and the ratio between actual evapotranspiration (AET) and rainfall (and thus indirectly the runoff coefficient) is derived from ERA5L. Potential evapotranspiration (PET) is also used for plotting to characterize the climate in the lake basins. The unitless runoff coefficient is defined as:

$$
r_{c}=\frac{Q}{R}=\frac{R-A E T}{R}
$$


with $r_{c}-$ runoff coefficient [-], Q - runoff [mm]; R - rainfall [mm] and AET - actual evapotranspiration $[\mathrm{mm}]$. The difference between AET and $\mathrm{R}$ is the effective rainfall.

\subsection{Integrated Catchment Response (ICR): Relating changes in lake volume to potential changes in the water balance and inflows to the lakes over time}

Understanding the underlying mechanisms leading to the lake level fluctuations necessitate an analysis of the temporal characteristics of the water balance and inflows to the lakes.

Bringing the storage term to the left, the following longer-term water balance equation for a lake watershed can be defined (all units in [mm]):

$$
\begin{aligned}
& S=R+Q_{g w}-\mathrm{A} E T-Q_{\text {out }}=r_{c} * R+Q_{g w}-Q_{\text {out }}= \\
& \frac{R-A E T}{R} * R+Q_{g w}-Q_{\text {out }}[\mathrm{mm}]
\end{aligned}
$$

where $\mathrm{S}$ refers to storage in the lake (i.e. increase/decrease in lake water volume from one year

to the next), $\mathrm{R}$ to catchment rainfall, $\mathrm{Q}_{\mathrm{gw}}$ to additional potential underground flow from neighbouring watersheds, AET to the actual catchment evapotranspiration (including evaporation from the lake surface), $r_{c}$ to the runoff coefficient (see Eq. 1) and Qout to runoff from the lake (i.e. outflow through a surface water body or the seepage into the underground).

The lake volume variation data from DAHITI allows to quantify the magnitude of changes to be expected on the right-hand side of the water balance equation, since $\mathrm{S}$ integrates potential changes occurring the catchment. The year-to-year lake volume variation data is, in combination with orographic catchment area, used to derive a magnitude for every year $\mathrm{t}$, which we refer to as "Integrated Catchment Response" (ICR, mm):

$$
I C R_{t}=\frac{\left(S_{t}\left[\mathrm{~km}^{3}\right]-S_{t-1}\left[\mathrm{~km}^{3}\right]\right) * 10^{12}}{\text { Area }\left[\mathrm{km}^{2}\right] * 10^{6}}[\mathrm{~mm}]
$$

In Eq. (3), the difference in lake volume variation $S$ from one year to the next is calculated and converted from $\left[\mathrm{km}^{3}\right]$ to $\left[\mathrm{dm}^{3}\right]$ and is then normalized by the orographic catchment area (Area), 
which is converted from $\left[\mathrm{km}^{2}\right]$ to $\left[\mathrm{m}^{2}\right]$. This results in the unit $[\mathrm{mm}]$ for the ICR, which is then used as a comparison to changes in water balance components, e.g. rainfall. ICR is based on the satellite derived lake volume variation data, normalized by catchment area and indicates, to which extent catchment water balance components changed from one year to the next to result in a change in lake volume. The analysis thereby focuses on deviations from long-term means of periods, when the lake was in an equilibrium and the surface areas and volumes did not change significantly over time.

\subsection{Time series analysis}

For analysing changes in the hydrometeorological characteristics, explorative statistics and

515 visual inspection of different time series is used. These analyses include time series in rainfall, AET and ratios between AET and rainfall, but also lake properties, such as lake areas. Potential trends in time series are evaluated by comparing averages of different periods. For evaluating breakpoints in time series the method described in Bai and Perron (2003) and Zeileis et al. (2003) are implemented in the current study.

\section{$520 \quad 3$ Results}

\subsection{Overview - relative changes in lake areas and observed trends in catchment rainfall}

Although interannual fluctuations were present regarding lake areas before 2010, a pronounced increase is evident from satellite-based observations congested into the DAHITI dataset after 2010 (Figure 4). The range of increase in relation to the mean values of 1984-2009 depends on the topographical setting of the lakes (see also Figure 3) and ranges from $21 \%$ for Lake Naivasha to an extraordinary $123 \%$ for Lake Solai in December 2020. Lake Bogoria $(+28 \%)$ is located in a deep depression, where increases in water level do not show a pronounced signal in water area. Lake Baringo (+59\% in December 2020) and Lake Nakuru (+70\%), just like Lake Solai, are located in flatter basins, where an increase in water level leads to a larger signal and 
530 increase in lake area. Similar to the adjacent Lake Naivasha, Lake Elementaita shows lower variation and a lower increase of around $25 \%$ since 2010.

Visual inspection of the relationship between rainfall and lake area fluctuations in Figure 4 clearly shows the reaction of deficits (brownish shaded bars) and surpluses (blueish shaded bars in Figure 4) of rainfall variability in signals in lake area. In Baringo, Bogoria and Solai, rainfall 535 surpluses of larger than 25\% compared to the long term mean of 1984-2009 lead to the exceptional increases in lake area. For Nakuru, Elementaita and Naivasha, at least around 2010, rainfall surpluses lie around $25 \%$, but three wet subsequent years lead to the observed increases in lake areas. Before 2010, wetter years and partially wetter periods are visible, where the magnitudes of surpluses in rainfall are however lower. These periods are characterized by

540 steady or slightly increasing lake areas. For all lakes and after 2018, rainfall anomalies in the catchment rainfall exceed $50 \%$ leading to further increases in lake levels. 

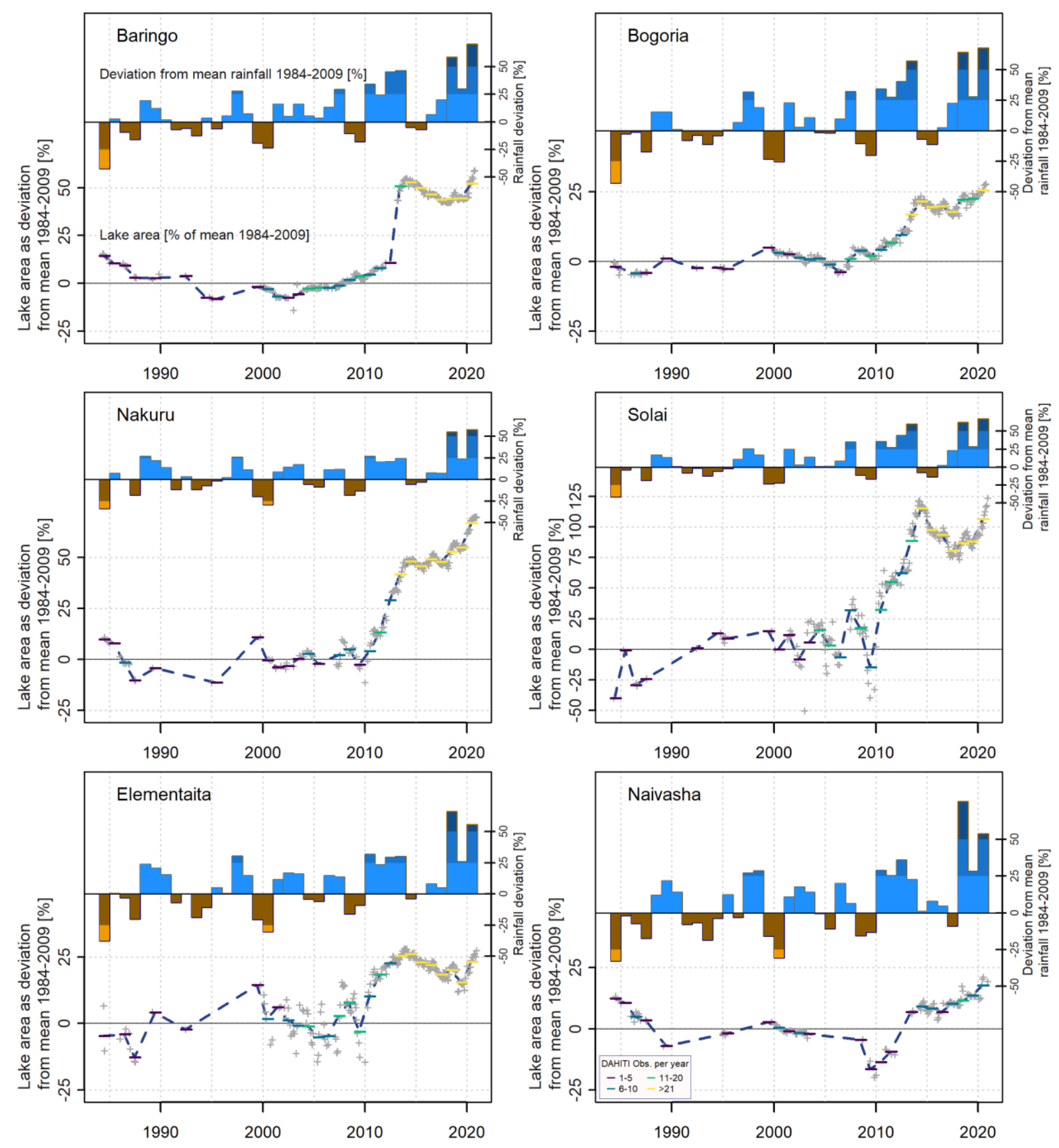

Figure 4: Deviation of lake surface areas and annual rainfall from the long term mean of the years 1984-2009 [\%]. Colored horizontal lines on the bars indicate the number of observations per year of the DAHIT lake area data. Grey crosses depict mean monthly values of lake areas.

An important component and driver of the water balance of the lakes is therefore rainfall. Figure 5 shows a more detailed temporal development of the mean annual rainfall sums for the orographic lake catchments for the period 1981-2020. As orange dashed line, meteorological station data from Snake Farm / Lake Baringo and Nakuru Meteorological Station (data extracted from Kiage and Douglas (2020) using tools provided by Rohatgi (2020)) are shown as comparison for the remote sensing derived areal means for the basins. The two rainfall curves 
(CHIRPS / station data) match quite well for Nakuru regarding interannual variability and generally mean values for longer time periods. In contrast, the Snake Farm rainfall time series shows a more pronounced interannual variability compared to CHIRPS. Also, before the year 2000, the longer-term means are lower compared to the remotely sensed data. The differences in variability may be explained by spatio-temporal variability of the rainfall process. The mean basin value represents the rainfall for an area of over $6600 \mathrm{~km}^{2}$ with an elevation range of around 963 - $3014 \mathrm{~m}$ (Table 1). This value will be smoother compared to a point observation. Deviations from the mean are smaller as shown in Figure A1 and Figure A2, resulting in the conclusion, that although the mean is different, the temporal variability shows a better agreement. Tabulated data on annual rainfall is documented in Table A1.

Why did we relate annual rainfall to the mean of 1984-2009 in Figure 4? The rainfall in all lake basins shows a changepoint in year 2009 (vertical dashed line in Figure 5) due to a structural change in the time series. The breakpoints were thereby objectively calculated following the method described in Bai and Perron (2003) and Zeileis et al. (2003) and which are implemented in the R-Package "strucchange" (Team R Development Core, 2018; Zeileis et al., 2002). This means that the longer term means substantially differ between 1981-2009 and 2010-2020, as can be seen by the different dashed lines, labeled with the respective means.

As can be seen from Figure 5, the long-term mean rainfall for the period 1981-2020 is similar for nearly all lake basins and lies around 1010 to 1040 mm/a. Lake Elementaita basin however is around $10 \%$ drier, with a mean basin value of around $900 \mathrm{~mm} / \mathrm{a}$. Parts of the basin, especially in the Rift Valley floor, receives less than $700 \mathrm{~mm}$ annual rainfall, with Elementaita "Badlands", Gilgil and Marigat areas receiving the least $(<500 \mathrm{~mm})$ (Onywere et al., 2013). For the 11 years following 2009, the annual rainfall mean increases by around $28 \% /+265 \mathrm{~mm}$ (Baringo), 27\%/+264mm (Bogoria), 20\%/193mm (Nakuru), 27\%/+260mm (Solai), and 23\%/201mm 
24\%/231mm and for Elementaita and Naivasha (also see Figure A1 and Figure A2 for plots on deviations in $\%$ and $\mathrm{mm}$ ).
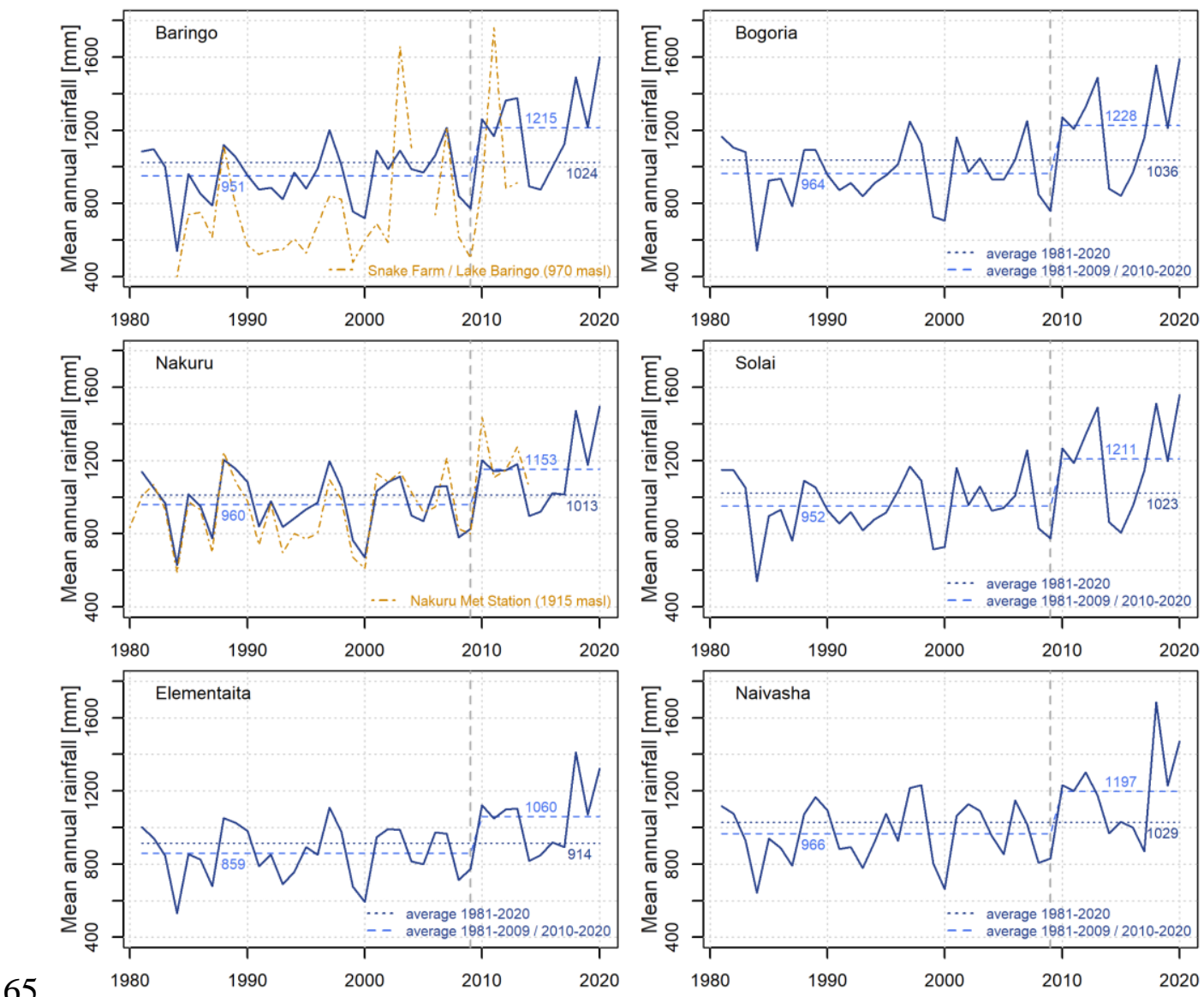

Figure 5: Mean annual rainfall for the orographic catchments of the single lakes (Baringo $6609 \mathrm{~km}^{2}$, Bogoria $1060 \mathrm{~km}^{2}$, Nakuru $1471 \mathrm{~km}^{2}$, Solai $214 \mathrm{~km}^{2}$, Elementaita $772 \mathrm{~km}^{2}$, Naivasha $3229 \mathrm{~km}^{2}$ ). Also shown as dashed horizontal lines are averages for the overall period 1981-2020 and the periods 1981-2009 and 2010-2020. The last two periods are separated by a breakpoint year in 2009 (dashed vertical line), where a change in structure of rainfall time series occurs, also regarding the means. To compare the CHIRPS-rainfall used, station data from Snake Farm on the shores of Lake Baringo and the Nakuru Meteorological Station are plotted in the panel for Baringo and Nakuru. Data was extracted from Kiage and Douglas (2020) using tools provided by Rohatgi (2020).

It is interesting to observe that, although a change point in rainfall is already found for the year 2009, the signal in the changes/rises in lake areas is lagged and occurs approximately one year later. This is confirmed when calculating the correlation between lagged rainfall and lake area (Figure 6). With the exception of Lake Solai, the largest correlation values are found with a

rainfall lag of one year. Lake Solai has the smallest orographic catchment area of $214 \mathrm{~km}^{2}$ and the reaction of rainfall on the lake area is therefore more immediate and the highest correlation is also found for a lag of 0 years. The same is the case for Elementaita, which also has a comparatively small catchment area of $772 \mathrm{~km}^{2}$. Although the highest correlation for Baringo 
is found with a lag of one year, the correlation of lag with the year two is not very much smaller.

595 This means that the "memory" of rainfall regarding lake area is longer and that it takes longer that a reaction of rainfall is visible in a signal in the lake area. This corresponds well with the fact that the Lake Baringo basin with $6609 \mathrm{~km}^{2}$ is the largest among the investigated lakes and that size does matter in this case. Correlation values for monthly data is documented in the Appendix in Figure A4.
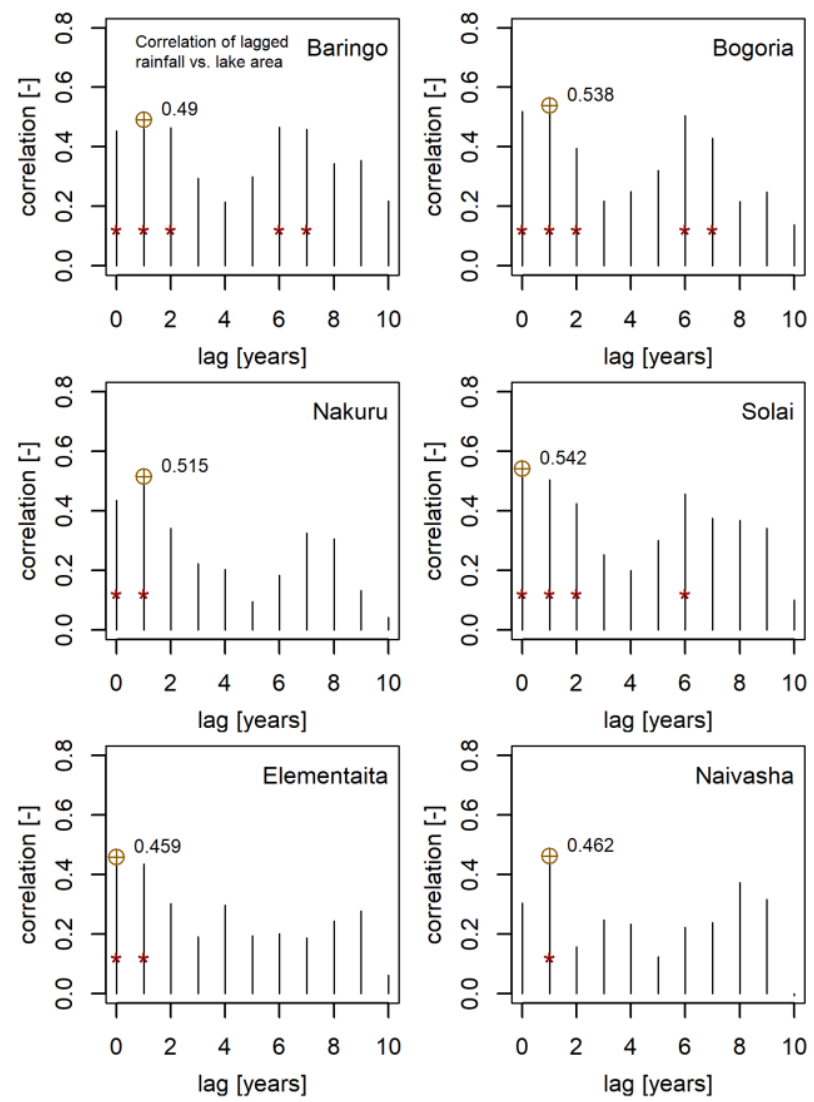

Figure 6: Correlation between lagged annual rainfall and lake area, evaluated with annual data covering the years 1984-2020. The lag indicates the number of years a signal in rainfall is observed in lake area. The circles in the plots indicate the maximum correlation value found. The red stars indicate statistically significant correlation values $(p \leq 0.05)$. 


\subsection{Spatial trends in rainfall}

The drier Rift Valley floors, e.g. between Lake Naivasha and Lake Elementaita or south of Lake Baringo, are also visible in Figure 7 (a), which depicts the spatial distribution of the long-term mean annual rainfall for the overall period with data (1981-2020). From Figure 7 (a) it is also

610 visible that the highest rainfall sums and thus most significant water contributions to the lakes are to be expected in higher elevation zones, like the Aberdares Range East of Lake Naivasha, the Mau Escarpment to the West of Lake Nakuru or the mountain range south-east of Lake Baringo. Whilst in the lower valley floors annual rainfall of 500 to $1000 \mathrm{~mm} / \mathrm{a}$ can be expected, the upper elevation zones receive up to $2000 \mathrm{~mm} / \mathrm{a}$ on the long-term average. Generally, a mean

615 increase in rainfall as a function of altitude of around $24 \mathrm{~mm} / 100 \mathrm{~m}$ is found for the study area and on an annual scale.

As was already shown for the time series of basin average rainfall values, changes in rainfall over time have occurred. The spatial distribution of the temporal rainfall trend for the period 1981-2020 in mm/a for the study region is shown in Figure 7 (b). The lowest, at least in absolute

620 number, increases are found in the Rift Valley floor with an increase of $0-10 \mathrm{~mm} / \mathrm{a}$. In contrast, highest increases are found for higher elevated areas at the top of the escarpments with increases of slightly above $15 \mathrm{~mm} / \mathrm{a}$. Generally, an upward, increasing trend in rainfall is found for all lake basins. A comparison of the four decades between 1981 and 2020 (Figure 7 (c)-(f)) shows that until 2000 rainfall was mostly around or below the long term mean of 1981-2020.

625 Especially after 2010, however, noteworthy positive deviations in rainfall are visible, this decade being much wetter compared to the long term mean for the entire study region. This agrees with recently published data by Wainwright et al. (2020). 

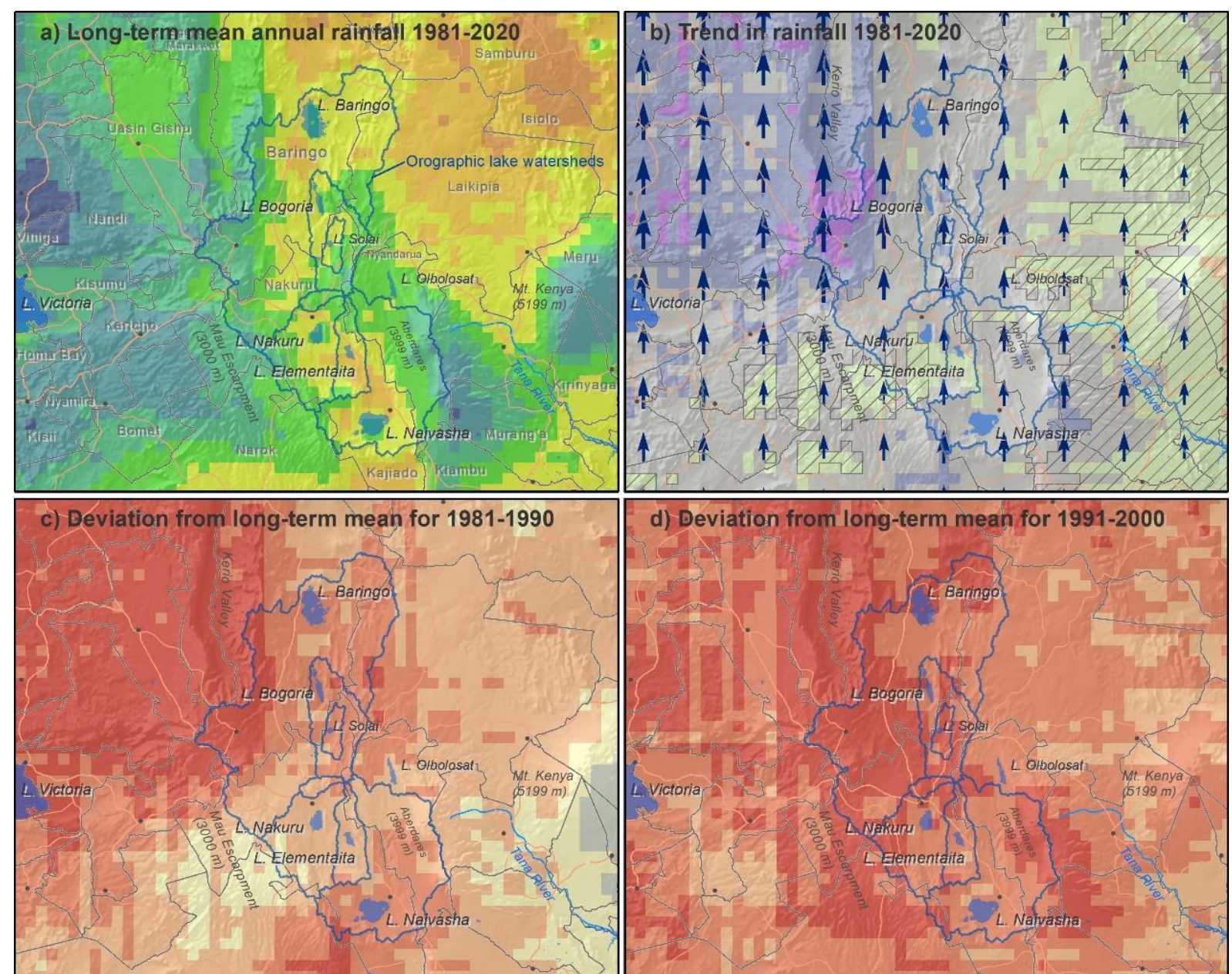

d) Deviation from long-term mean for 1991-2000

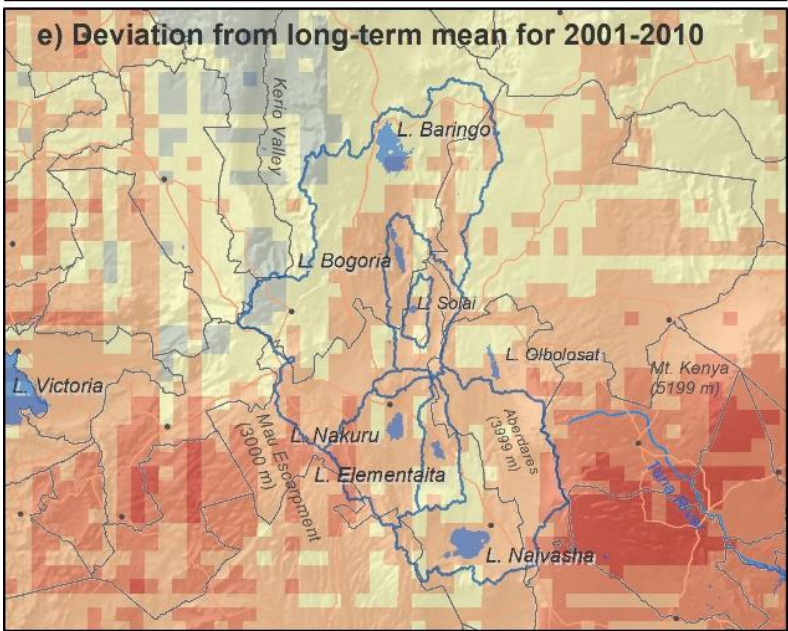

f) Deviation from long-term mean for 2011-2020

a) Long-term mean annual rainfall 1981-2020 (mm)

b) Trend in annual rainfall 1981-2020 (mm/year)

c) - f) Deviation from long-term mean rainfall ( $\mathrm{mm}$ )

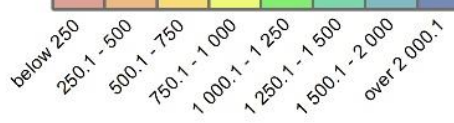

Adminstrative boundaries shown in a) - c): Counties

Data sources: Rainfall: CHIRPS V2.0 (Funk et al., 2015), DEM and hillshades: SRTM $90 \mathrm{~m}$ (Jarvis et al., 2008), Catchment boundaries: MERIT DEM

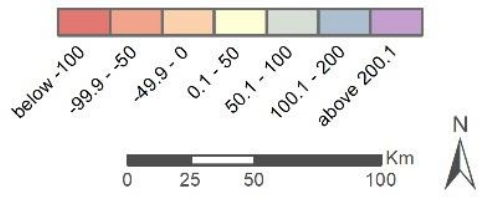

Colours in legend may differ from map due to hillshading.

Figure 7: Spatial and temporal trends in rainfall for the study region. Long-term mean annual rainfall for the period 1981-2020 (a), trends in rainfall as change in mm/year (b) and deviation from long-term mean rainfall (panel (a)) for the four decades in 1981-2020 (c)-(f) illustrate changes over time. The orographic lake catchments shown are the basis for meteorological time series shown in other sections. In panel (b), shaded cells indicate areas without statistically significant trend. 
Figure A3 shows mean annual rainfall and temporal trends in rainfall for Kenya for the same

635 periods. For the majority of the country, for the overall period 1981-2010, a positive trend is visible (Figure A3 (b)). The highest increases are found West of the study region, between Mt. Elgon and Lake Victoria. Although an overall positive trend is found for most areas in the country, the maps show a regionally more heterogenous picture in the single decades (Figure A3 (c)-(f)), with regions being drier and wetter, compared to the long-term mean. This is

640 especially the case for the periods before 2011. After 2011, however, wetter conditions are found for all nearly all regions, with the exception of an area East of Garissa and around the coast towards Somalia (Figure A3 (f)).

\subsection{Changes in lake areas and lake levels over time}

The time series analysis of rainfall showed that 2009 was a breakpoint, after which catchment

645 rainfall characteristics changed and a noteworthy increase in the average of rainfall occurred after this year. This also matches well with the succeeding rising signals in lake level displayed in Figure 8 and Figure 9, which document - in absolute numbers $\left[\mathrm{km}^{2}\right]$ and $[\mathrm{m}]$ - the temporal developments of lake areas and lake levels. The green bars depict mean annual values, which are connected by a dashed line. In case of missing annual data, the points are linearly connected.

650 Additionally, the mean monthly data available is displayed as grey crosses. The coloring of horizontal lines on top of the bars shows the number of observations per year. Uncertainties in the estimates are shown as light blue error bars. The completeness of the time series varies depending on the lake, whereas after 1999 complete time series are available for most lakes, with the exception of Lake Nakuru with one missing year and Lake Naivasha with several years 655 missing. Before 1999, fewer data points are available and even if annual values are displayed, the number of underlying data points of single years is rather low. This is due to scanty satellite imagery available before this time. Nevertheless, general trends can also be depicted for most lakes in the 1980s and 1990s. It is important to note that the data of Lake Baringo for the year 
2012 is probably biased, since only two observations in January are available, so that potential lake level rises during this year are not appropriately captured. The tabulated annual values can be found in the Appendix (Table A2). To our knowledge, lake area and water level data in this consistent form has previously not been available for the study lakes. When comparing the absolute values of lake levels to previous data, it must be considered that the reference elevation may be different. DAHITI provides orthometric height which are related to a geoid model. The relative changes however are consistent.

The temporal patterns of lake areas and levels correlate between the lakes and, with the exception of Lake Naivasha, show correlations values of above 0.8 to 0.9 (Figure A5). Due to intensive water use, e.g. for irrigation purposes, the lake area and level of Naivasha is anthropogenically influenced (Onywere et al., 2013), what may also explain the lower 670 correlation values. Lowest lake levels in Naivasha are found in 2009.

The figures again show that lake areas and levels closely follow rainfall fluctuations, reacting to wetter and drier periods. The reaction of the lakes with the smallest catchment and surface areas, Lake Solai and Elementaita, show the fastest and most pronounced reaction to rainfall fluctuations. This also corresponds to the correlation between lagged rainfall and lake area 675 shown in Figure 6 and Figure A4. Lake Baringo and Nakuru exhibited the smallest areas and lowest levels in 1995, with 118.3 and $33.1 \mathrm{~km}^{2}$ and lake levels of 971.4 and $1759.8 \mathrm{~m}$. Bogoria showed the second lowest levels in $1995\left(31.9 \mathrm{~km}^{2}\right)$, which is slightly higher compared to the absolute minimum of $31.5 \mathrm{~km}^{2}$ in 2006. Data for Solai and Elementaita show that the lowest lake area extents occurred in the 1984 and 1987 with $3.3 \mathrm{~km}^{2}(1005.9 \mathrm{~m})$ and $15.1 \mathrm{~km}^{2}(1775.9$ m), respectively. Different characteristics regarding the occurrence of the minimum lake area is found for Naivasha. Here, a value of $104.9 \mathrm{~km}^{2}(1880 \mathrm{~m})$ is found in the year 2009 .

Lake Baringo's largest extent, at least measured as a mean annual value, occurred in 2014 with $197.1 \mathrm{~km}^{2}$. This is also the case for Solai $\left(11.7 \mathrm{~km}^{2}\right)$ and Elementaita $\left(21.9 \mathrm{~km}^{2}\right)$. From Figure 
8 and Figure 9 it is however evident, that the trends in the monthly data (grey crosses) show a 685 steep increase in 2020, where the latest observations in December 2020 exceed all previous measurements. This is the case for all lakes. Accordingly, largest mean annual lake areas (lake levels) of $41.2 \mathrm{~km}^{2}(998.1 \mathrm{~m}), 62.3 \mathrm{~km}^{2}(1766.2 \mathrm{~m})$ and $147.7 \mathrm{~km}^{2}(1887.5 \mathrm{~m})$ are found for Bogoria, Nakuru and Naivasha in 2020.

Largest difference or largest fluctuation between minimum and maximum water level is found

690 for Lake Solai with $8.53 \mathrm{~m}$, followed by Baringo $(8.23 \mathrm{~m})$, Naivasha $(7.48 \mathrm{~m})$, Nakuru $(6.40$ $\mathrm{m})$, Bogoria $(4.99 \mathrm{~m})$ and finally Elementaita with $2.38 \mathrm{~m}$. For most lakes, the highest levels are found around 2013/2014, which are however surpassed in the year 2020, in which new records are evident (Figure 9). 

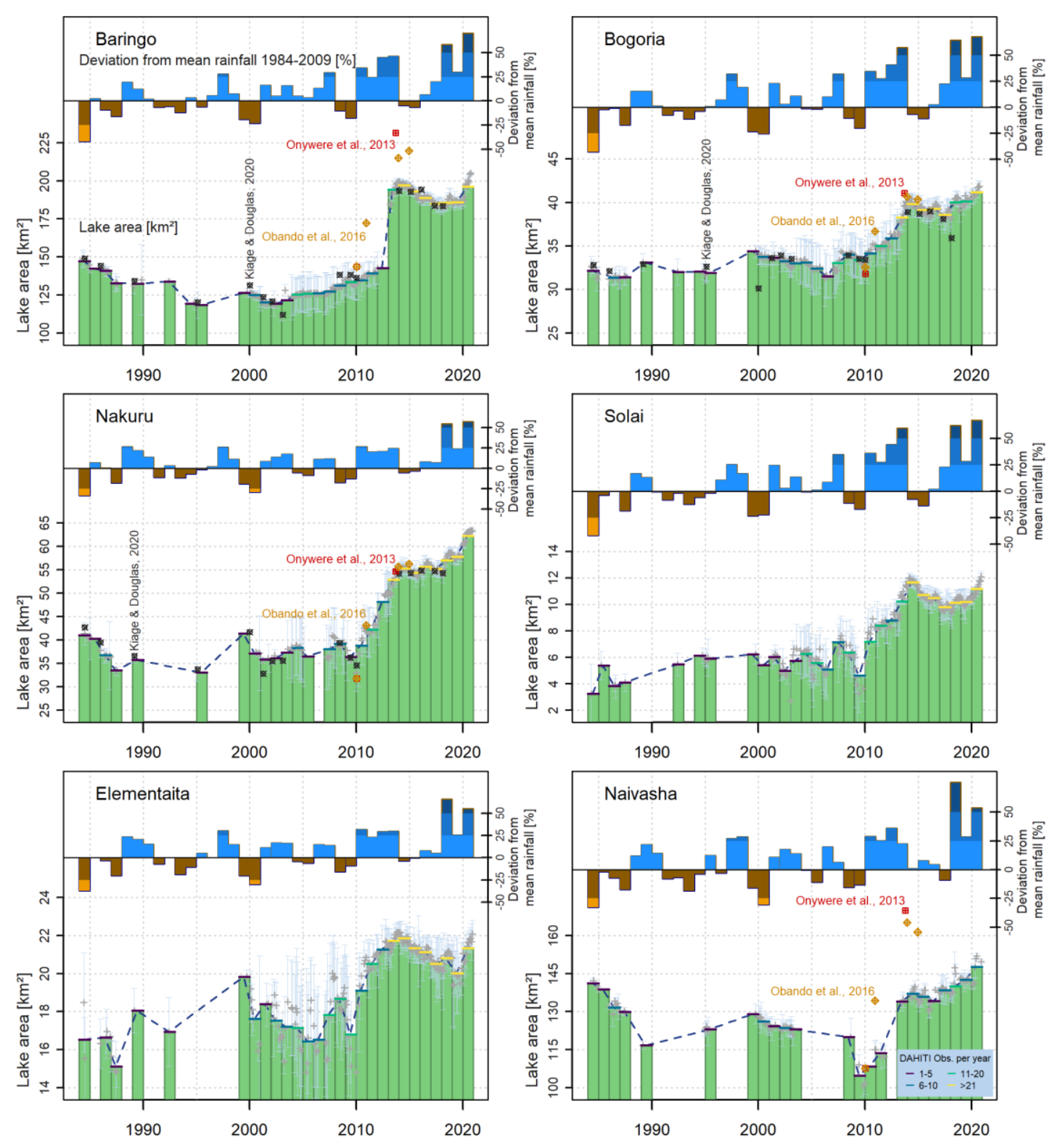

Figure 8: Development of study lake areas $\left[\mathrm{km}^{2}\right]$ and deviation of annual rainfall from the mean [\%] since 1984. Colored horizontal lines on the bars indicate the number of observations per year and error bars in light blue indicate potential uncertainties in the DAHIT lake area data. Available evidence from literature are plotted as black (Kiage and Douglas, 2020), orange (Obando et al., 2016) and red (Onywere et al., 2013) points. 

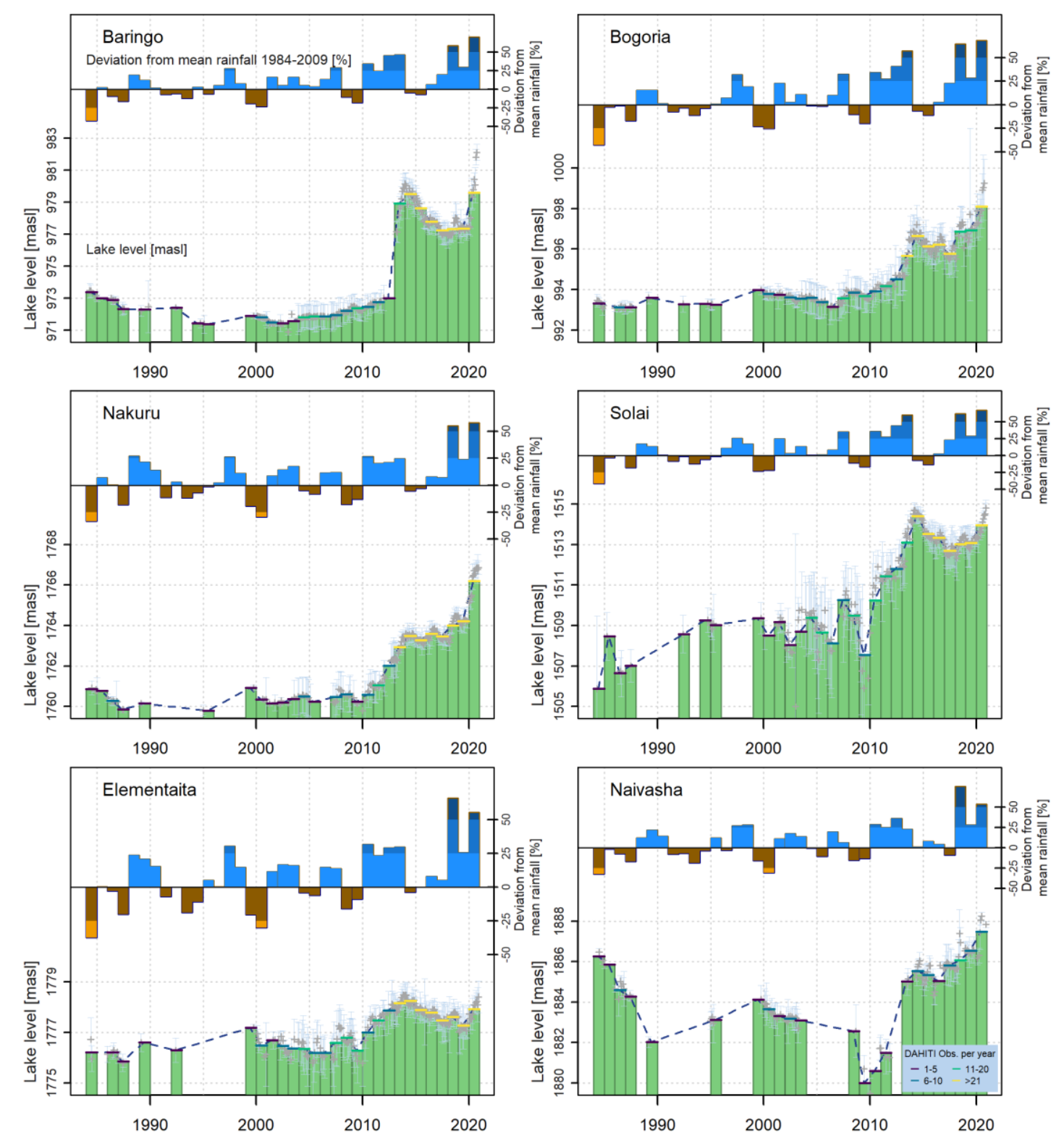

Figure 9: Lake levels [m] and deviation of annual rainfall from the mean 1984-2009 [\%]. Horizontal lines on the bars indicate the number of observations per year and error bars in light blue indicate potential uncertainties in the DAHIT lake area data. No data for ground-based verification was available.

In Figure 8 published lake area data - available for Baringo, Bogoria, Nakuru and Naivasha - is additionally plotted as reference. For Bogoria and Nakuru, the independent area estimations mostly match quite well. This is also the case for the data from Kiage and Douglas (2020), which also matches well in Baringo. This is not necessarily surprising and can be explained with the fact that Kiage and Douglas (2020) also used the Modified Normalized Difference Water Index (MNDWI) to delineate the lake surfaces and MNDWI is one of the indexes used in DAHITI. 
For Baringo and Naivasha, larger deviations are evident when comparing our results with Obando et al. (2016) and Onywere et al. (2013), who both manually delineated water areas for satellite imagery for the respective lakes. Maximum water surface areas in Onywere et al. (2013) are documented for September 2013 (Baringo; $231.6 \mathrm{~km}^{2}$ ) and October 2013 (Naivasha; $169.9 \mathrm{~km}^{2}$ ). Obando et al. (2016) find December 2014 (Baringo; $219.8 \mathrm{~km}^{2}$ ) and December 2013 (Naivasha; 165,2 km²). Evaluating our data for the years 2013 and 2014, maximum lake extent in DAHITI is found in January 2014 for Baringo $\left(199.5 \mathrm{~km}^{2}\right)$ and September 2014 for Naivasha $\left(139.9 \mathrm{~km}^{2}\right)$. For Baringo, the difference to Onywere et al. (2013) is thus $32.1 \mathrm{~km}^{2}$ or $16.1 \%$ and $20.1 \mathrm{~km}^{2}(10.1 \%)$ in comparison to Obando et al. (2016). For Naivasha, the deviation compared to Onywere et al. (2013) is $30.1 \mathrm{~km}^{2}(21.5 \%)$ and $25.3 \mathrm{~km}^{2}(18.1 \%)$ in comparison to Obando et al. (2016).

Both lakes have fringing swamps and (submerged) vegetation. This vegetation is dynamic and follows water level fluctuations (Garcia Benedito, 2019). A possible explanation for the differences could therefore be that these riparian areas where not identified as water surfaces in the automatic classification scheme of DAHITI, since the water signal was too weak and vegetation dominated the signal. In contrast, during manual classification, the expert can decide to classify these areas as water, maybe due to additional knowledge from a field visit. A comparison and visual inspection of Figure 2 in Onywere et al. (2013) and the land-water mask from DAHITI for October 2013 (Figure A6) seem to indicate this, where larger differences in water classification are evident in the northern part of Lake Naivasha. From Figure A6 these areas look like fringing swamps and water coverage is not evident. In contrast, the expansion of water in these areas is visible in Figure A7, which shows the situation in July 2020. Additionally, for Naivasha, Obando et al. (2016) and Onywere et al. (2013) both included Lake Oloiden, a small satellite lake west of Lake Naivasha, in their estimations of water surface area for Naivasha. Figure 10 shows the surface area of Oloiden based on DAHITI data. 


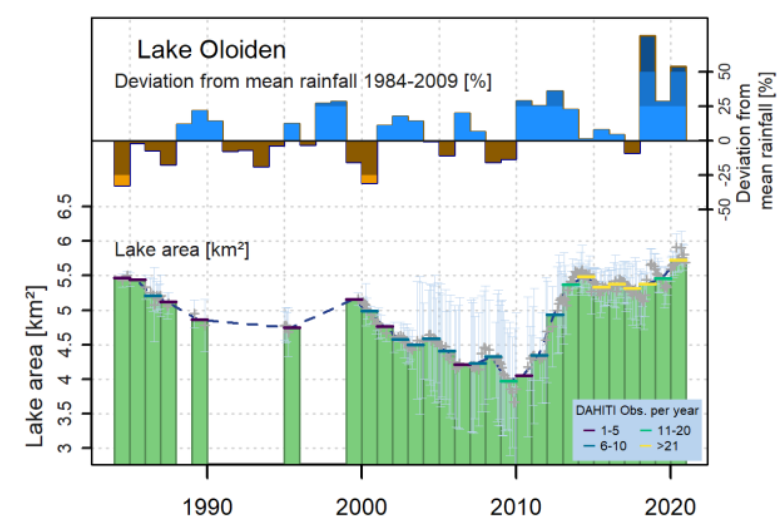

Figure 10: Surface area $\left[\mathrm{km}^{2}\right]$ of Lake Oloiden adjacent to Lake Naivasha and deviation of annual rainfall from the mean [\%] as observed for the Naivasha watershed. Colored horizontal lines on the bars indicate the number of observations per year and error bars in light blue indicate potential uncertainties in the DAHIT lake area data.

740 At the low water level in 2010, Lake Oloiden had developed alkalinity that allowed a large population of flamingos to inhabit it (Onywere et al., 2013). When adding the maximum extent of Lake Oloiden in 2013 and $2014\left(5.6 \mathrm{~km}^{2}\right)$ to our estimates, a sum of $145.43 \mathrm{~km}^{2}$ is found, which is however still substantially smaller. The deviation compared to Onywere et al. (2013) is still $24.5 \mathrm{~km}^{2}(16.8 \%)$ and $19.7 \mathrm{~km}^{2}(13.6 \%)$ in comparison to Obando et al. (2016). Lake

745 Oloiden was not included in the systematic analysis of the study lakes, since no altimetry and in consequence volume data is available.

\subsection{Trends in lake volume and water balance components}

Figure 11 depicts the temporal development of the lake volume variation $\left[\mathrm{km}^{3}\right]$ for the study lakes. The lake volume variation thereby shows the water volume in the lakes above a threshold value, which corresponds to the observed surface area within the period 1984-2020. 

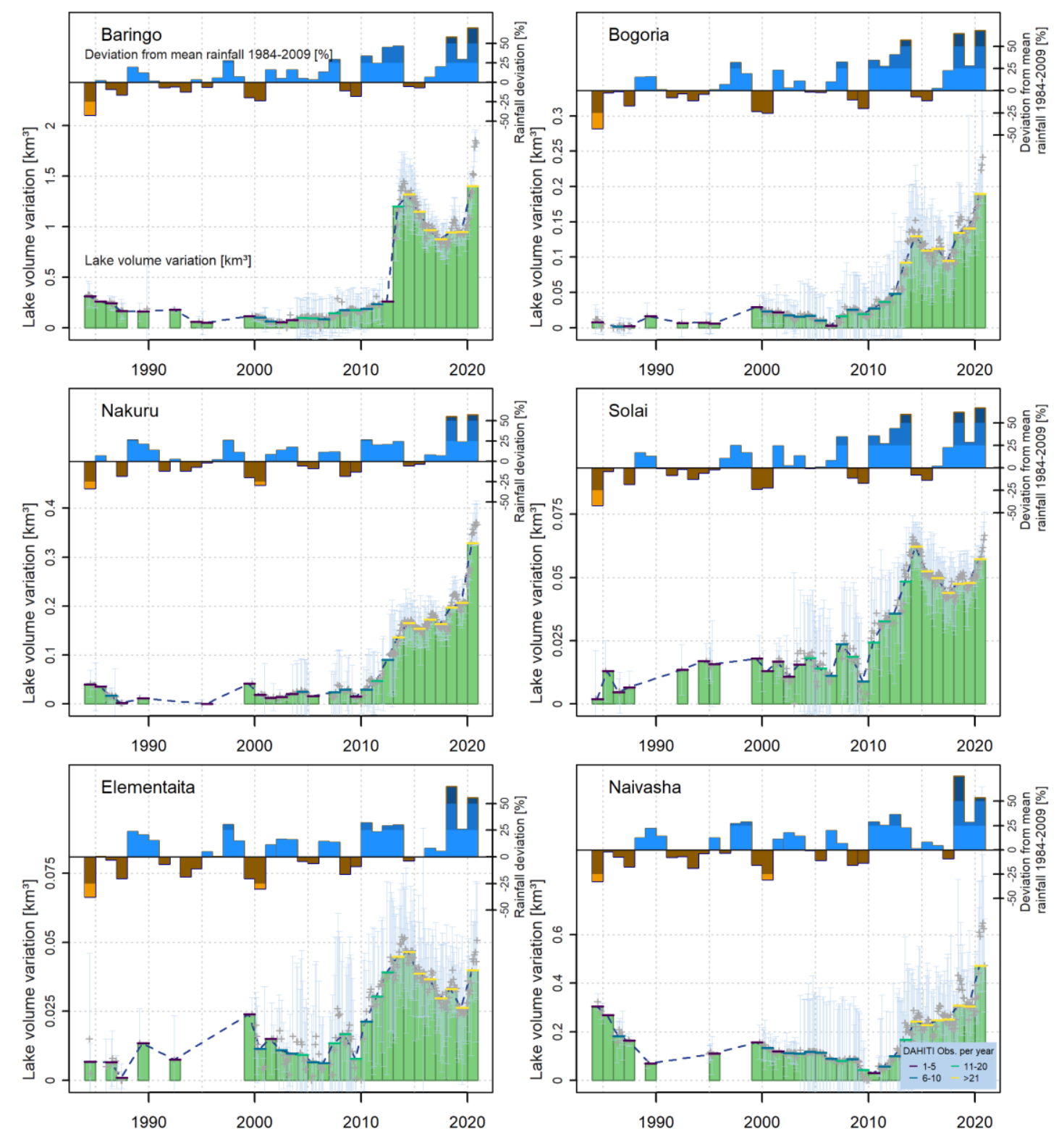

Figure 11: Lake volume variation $\left[\mathrm{km}^{3}\right]$ of the study lakes. The deviation of annual rainfall from the mean19842009 [\%] is shown in the upper part of the plots. Blue and orange color tones indicate wetter and drier conditions compared to the mean. Error bars in light blue, including the grey data points, show potential uncertainties in the data.

The data therefore does not show the total lake volume since the bathymetric conditions below the lowest observed water level are unknown. For this information bathymetric surveys would be necessary, as has, e.g., been done by Maina et al. (2018) for Lake Naivasha and Lake Oloiden. Maina et al. (2018) report a total volume of $0.72 \mathrm{~km}^{3}$ for Lake Naivasha in the year 2016. Our lake volume variation data shows a value of around $0.25 \mathrm{~km}^{3}$ for 2016 , leading to the conclusion that the difference of $0.47 \mathrm{~km}^{3}$ of water was stored in Lake Naivasha during the lowest period of available observation in DAHITI. Since we are interested in the year-to-year 
changes in water volume, the data is nevertheless sufficient. For brevity, we will use the term lake volume in the following.

765 With the exception of Lake Naivasha, which experienced a decline in water volume until around 1990, the other lakes show little interannual variability and fairly stable conditions until around 2010. Only after this period, after which rainfall characteristics changed (see vertical lines in Figure 5 in the year 2009), lake volumes substantially increased. Compared to 1984-2009, annual rainfall increased by around $25 \%$ in 2010 and after 2018 by even more than $50 \%$. Noticeable is also that single months in the year 2020 are substantially larger compared to the mean annual value. This can be explained with the very wet second half year of 2020, which led to a strong increase in lake volume (Figure 11, Figure A7).

For Figure 12, the difference in year-to-year lake volume variation data is, in combination with orographic catchment area, used to derive a magnitude for every year, which we refer to as

775 "Integrated Catchment Response" (ICR, mm). Interannual changes in lake volume follow rainfall anomalies shown in the upper section of the plots. Similar patterns can be detected, especially after 2000, when the lake data situation becomes more consistent. Before 2000, single values are present, but unfortunately do not allow to judge on reaction of wet rainfall anomalies on ICR. Striking, since suspicious, is the ICR of 2013, with a value of over $140 \mathrm{~mm}$ 780 for Lake Baringo. The reason is probably unrepresentative data for the year 2012. In this whole year only two data point are observed in the dry season month of January, biasing the picture. In nature, mean lake volume variation of 2012 was probably higher, since lake level already increased during the whole year 2012. Since ICR is calculated as the difference between lake volume of 2013 and 2012, a bias is present. Already in the previous figures of lake area, level 785 and volume variation, the clear discontinuity at Baringo of 2012 was unrealistic. The structure of the lake volume variation and the ICR probably followed a pattern observed at Lake 
Naivasha or Lake Nakuru, the larger lakes. It is however important to note that averaging over several years eliminates this bias.
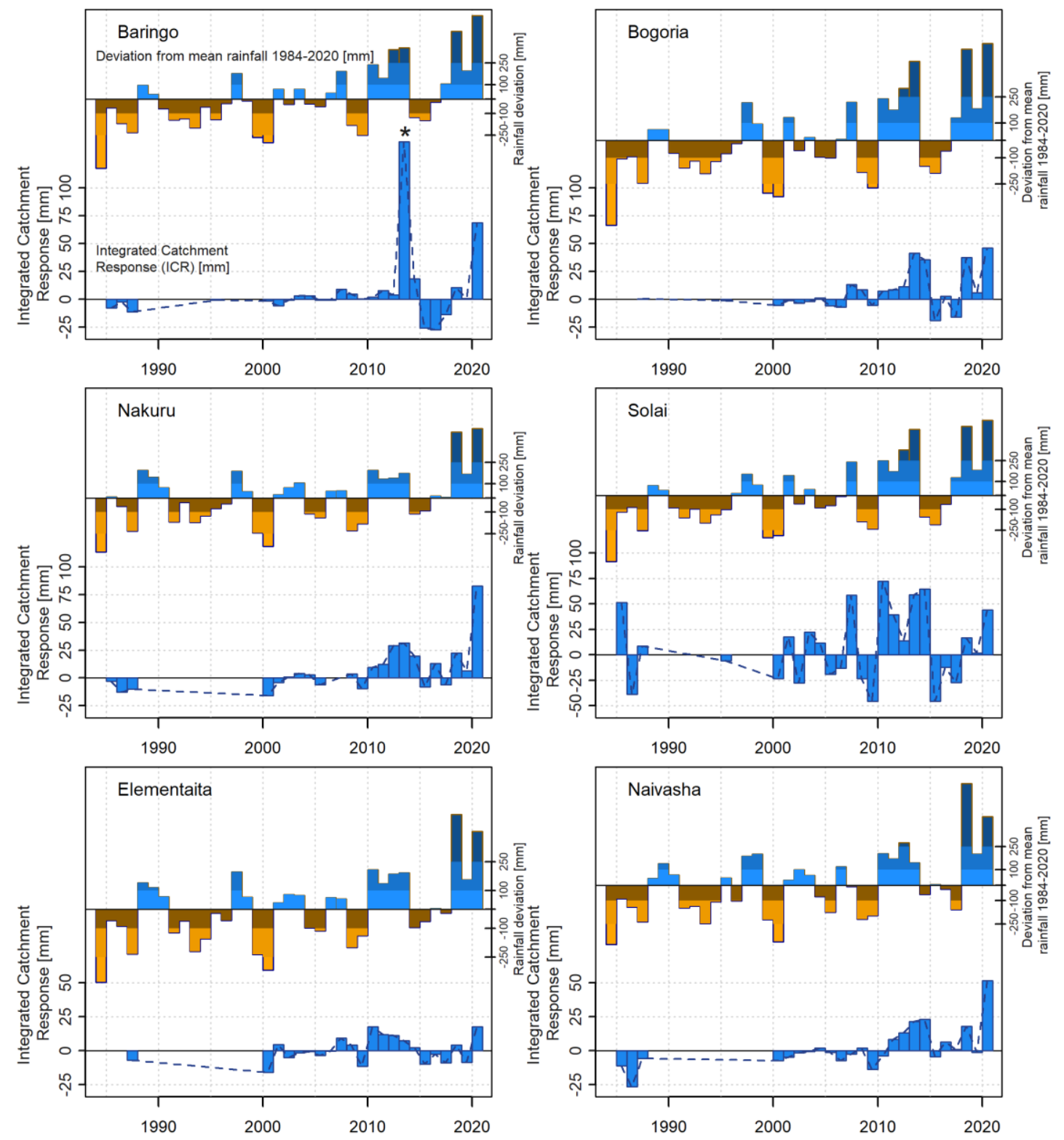

790 Figure 12: Integrated Catchment Response [ICR, $\mathrm{mm}$ ] based on year to year changes in lake volume. The deviation of annual rainfall from the mean [mm] since 1984 is shown in the upper part of the plots. Blue and orange color tones indicate wetter and drier conditions compared to the mean. The large change in Baringo in 2013 marked with a star is to be taken with caution, since 2012 data is probably too low with only two measurements in the dry season month of January.

795 ICR indicates, to which extent catchment water balance components changed from one year to the next to result in a change in lake volume. A comparison of water balance components is reasonable for the averages of over 2 to 5 years, also considering the temporal correlation structure between lagged rainfall and lake signal shown in Figure 6. The number of years also depends on lake catchment area, since smaller lakes like Solai will probably have a smaller 
storage. A small torrent shows immediate reaction to rainfall, the effects on runoff and flood will however vanish comparatively fast. Accordingly, Lake Solai with a catchment of only $214 \mathrm{~km}^{2}$, which is only $3 \%$ of the Baringo basin, shows particular immediate responses to rainfall anomalies, resulting in the somewhat choppy picture of the ICR in Figure 12.

Considering means of several years and thereby neglecting interannual storage in the catchment, several scenarios are feasible. They depend on potential trends in the boundary conditions (e.g. underground seepage, intercatchment leakages) and meteorological drivers (i.e. rainfall, actual evapotranspiration) and include:

(i) No change from one year to the next in lake levels could mean that rainfall, evapotranspiration, boundary conditions, (subterranean) inflow or seepage are stable and stationary, so that the lake stays in an equilibrium.

(ii) An increase in lake volume from one year to the next could mean that rainfall has increased or evapotranspiration has decreased, again that assuming stable seepage.

(iii) Again, assuming otherwise constant boundary conditions, a decrease in the lake level could mean that rainfall has decreased or evapotranspiration has increased.

815 Scenarios (i) to (iii) can clearly become more complex, when potential changes or interactions between rainfall and evapotranspiration are considered, namely when they change in such a way that they enhance or compensate each other. Lake levels can remain constant, when rainfall increases, but also actual evapotranspiration increases with the same magnitude at the same time. Lake levels can also stay constant if rainfall decreases and actual evapotranspiration

820 decreases. Apart from this interplay of rainfall and actual evapotranspiration, changes in boundary conditions can have similar effects. At this point we ignore these and assume that they are stable over time. Subsurface outflow, intercatchment leakages to other lake basins are present but are also stable over time. We are simplifying the domain of analysis. 
In Figure 12 we only showed rainfall anomalies, which however were, at least regarding

825 temporal trends, closely followed by the ICR. Apart from rainfall, actual evapotranspiration is especially important in the water limited systems the lakes are located. Here, potentially a much larger amount of water could be lost to the atmosphere, than is available (with the exception of the lake surface). Potential evapotranspiration (PET) from ERA5L ranges from around 3020 $\mathrm{mm} / \mathrm{a}$ in Baringo to $2225 \mathrm{~mm} / \mathrm{a}$ in the Solai catchment (Figure A8). In relation to ERA5L-

830 rainfall, PET is 2.65 (Baringo) to 1.2 (Solai) times higher compared to rainfall (Figure A9). With the exception of single years in Solai, the catchments are always water limited.

Actual evapotranspiration based on ERA5L (AET, Figure A10) is, as expected, much lower compared to PET. Interannual variability in AET is high and follows rainfall anomalies. Very low outliers in AET in single years occur during dry years or periods. The direction of longer835 term trends in AET also follows rainfall, with lower values before 2009. However, no breakpoint year is found for 2009 for ERA5L-AET.

AET values shown in Figure A10 are partially higher compared to CHIRPS rainfall (see Figure 5 and Table 2). The reason is that ERA5L rainfall is substantially higher compared to CHIRPS, so that, at least within ERA5L, the water balance is closed and consistent. Differences in rainfall

840 between CHIRPS and ERA5L range from around 20\% in Baringo (1021 mm/a vs. 1240 mm/a for 1984-2020) to nearly $100 \%$ in Solai (1015 vs. $2021 \mathrm{~mm} / \mathrm{a}$ ) (Table 2). Since CHIRPS has proven to provide reliable rainfall estimates in the study region (see references in section "Data Basis"), the high ERA5L rainfall and in consequence ERA5L AET values seem unrealistic and are therefore not used directly. To account for this probable overestimation, we use the ratio 845 between ERA5L AET to rainfall (Figure 13) to derive an Adjusted AET values based on CHIRPS rainfall (see "Adj. AET" in Table 2). We thereby assume that the partitioning of rainfall and AET in ERA5L is in a correct magnitude and can be used to derive AET based on CHIRPS rainfall. 
In contrast to AET, which is quite stationary over time, the ratio between AET and rainfall from

ERA5L (Figure 13) shows a much more pronounced change signal when comparing the periods before and after 2009. Here, the year 2009 is also calculated as a breakpoint year, similar to rainfall. For all lake catchments, the ratio substantially decreased after 2009, meaning that in relation less rainfall is evapotranspirated. Generally, the ratio between AET and rainfall shows a high interannual variability. Values of larger than one can be explained with storage effects from one year to the next and also evaporation from the lake surfaces. The highest ratios of around 0.85 for the period 1984-2020 are found for Lake Nakuru and Baringo. Around 80-85\% of rainfall is lost to the atmosphere and around $15-20 \%$ are available for runoff. The lowest values are found for Lake Solai with a long-term mean of 0.62 for the overall period and 0.51 for 2010-2020.

860 Even if the ERA5L rainfall and AET values are too high, we assume that the ratio between AET and rainfall is in the correct magnitude. The unitless runoff coefficient (ratio between runoff and precipitation, $r_{c}$ ) can be calculated as the difference between 1 and the ratio between AET and rainfall. A comparison with published data for the study region shows that the numbers given in Figure 13 and Table 2 are somewhat in the range of previously published runoff 865 coefficients. For Lake Naivasha, where a long-term mean ratio of AET to rainfall of 0.72 results in a runoff coefficient $r_{c}$ of 0.28 for the ERA5L-data, Ayenew et al., (2007) used a value of 0.13 for $r_{c}$. For the same lake, Odongo (2016) published mean $r_{c}$ values of $0.2-0.25$. Muthuwatta (2014) evaluated runoff and precipitation data for a single year (1971) for Lake Naivasha tributaries and found very low $r_{c}$ values of $8.5 \%$ at Gilgil and $3.5 \%$ for the Malewa subbasin.

870 Evaluating runoff coefficients for only a single year must however be taken with care, since high interannual variability and storage effects are ignored. For the Njemps Flats in Baringo, Wairagu et al. (1993) published $r_{c}$ values of 0.2, which are in the range of our values. For single events from a $0.3 \mathrm{~km}^{2}$ highly erodible semiarid catchment in the Baringo District, Sutherland and Bryan (1990) publish a runoff coefficient of 46\%. Critchley and The World Bank (1986) 

$19 \%$ for larger catchments in Turkana, which is further North and drier compared to our study lakes. In a more recent study, data in Kimaru et al. (2019) can be used to derive a ratio between AET and rainfall of 0.74 , which is around 0.07 lower, compared to our values. The comparison with published data in summary highlights uncertainties regarding runoff coefficients. Some studies agree with our numbers, others do not. Additionally, for Bogoria, Solai and Elementaita, no studies were found for comparison and especially for Lake Solai and Lake Bogoria, the ERA5L-derived ratio of AET to rainfall seem too low, considering the dry climate. This is especially the case to the years after 2009.
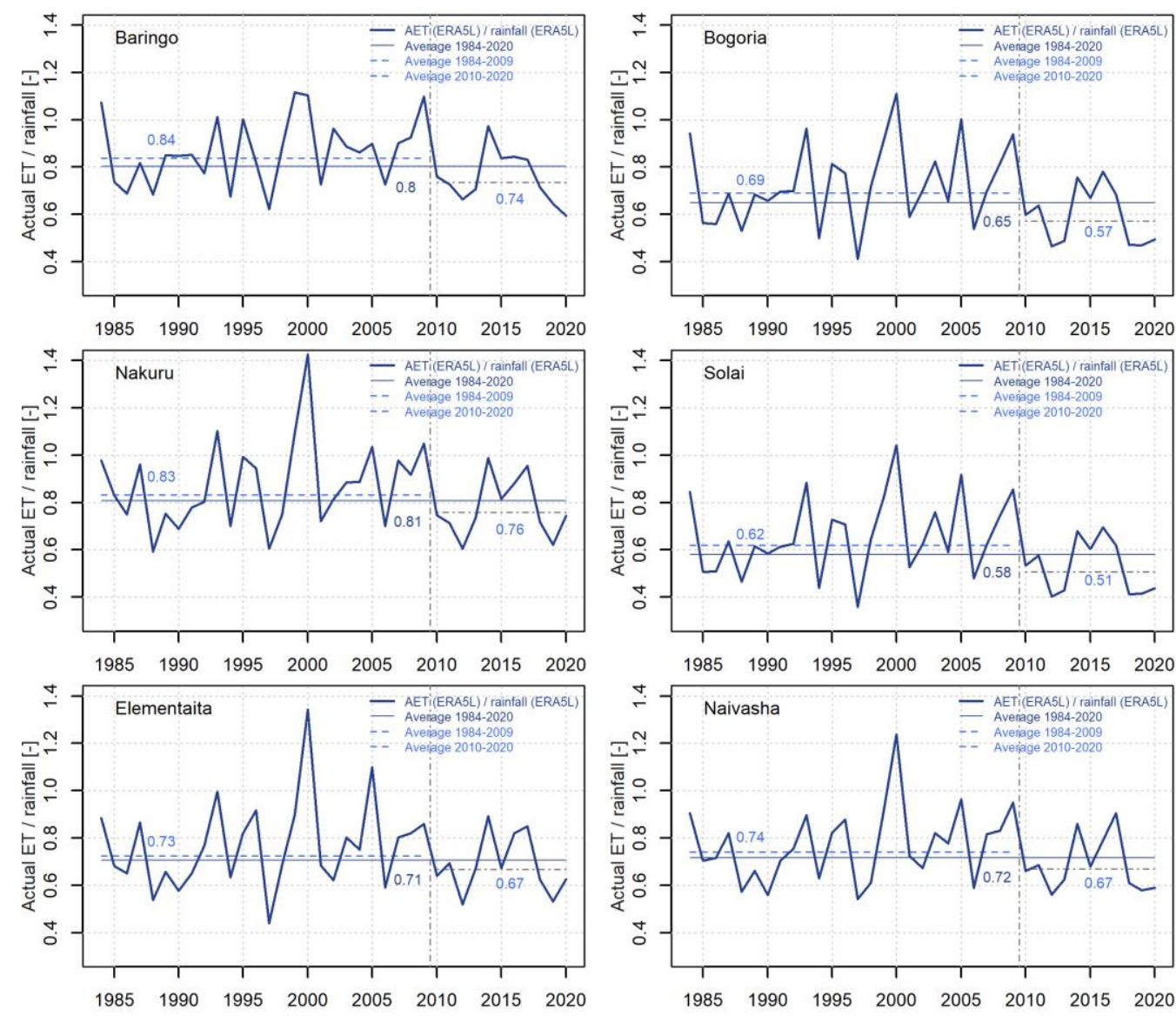

885 Figure 13: Annual ratio between actual evapotranspiration (AET) and rainfall, both based on ERA5L, for the orographic catchments of the single lakes. Also shown as dashed horizontal lines are averages for the period 1984-2020, 1984-2009 and 2010-2020. The last two periods are separated by a breakpoint year in 2009 (dashed vertical line), where a change in structure of rainfall time series and ratio AET to rainfall occurred.

Table 2 summarizes the mean catchment water balance components and the Integrated

Catchment Response (ICR) for 1984-2020 (black font), 1984-2009 (orange font) and 2010- 
2020 (blue font). Apart from averages and deviations from the long-term mean of 1984-2009 of AET and rainfall, the deviation of effective rainfall is shown, which was calculated using CHIRPS rainfall and the ERA5L ratio between AET and rainfall. For the calculation of deviations in Table 2, 1984-2009 is used as a reference, since in this period the lakes were more or less in an equilibrium and the following deviations from the mean of this period after 2010 led to the observed lake level rises. This is confirmed by the ICR for 1984-2009, which lies around zero in most lakes. One exception is Lake Naivasha, where water levels were however anthropogenically influenced in this period (Onywere et al., 2013). In the period 2010-2020, rainfall increased by around 30\% for the Baringo, Bogoria and Solai catchments. In Nakuru,

900 Elementaita and Naivasha, the rainfall increases were lower, amount to $21 \%, 25 \%$ and $25 \%$ respectively. In contrast, the increases in AET are lower compared to changes in rainfall and lie around 14\% for Baringo and Elementaita, 13\% for Naivasha, 11\% for Nakuru and 7\% for Bogoria and Solai.

For 2010-2020, the ICR is positive, corresponding to positive deviations in rainfall. Although the absolute differences between ICR and deviation of effective CHIRPS rainfall are high, the signals show in the expected directions. Positive, wet, rainfall anomalies lead to an increase in the ICR and vice versa. Generally, effective rainfall deviation is larger, compared to the ICR and although these numbers do not match, the positive deviations in (effective) rainfall are very sufficient to explain the lake level rises. 
915 Table 2: Mean catchment water balance components and Integrated Catchment Response (ICR) for 1984-2020, 1984-2009 and 2010-2020. Adj. AET is based on the ratio between ERA5L AET and rainfall and CHIRPS rainfall.

Water balance components and Integrated Catchment Response (ICR)

\begin{tabular}{|c|c|c|c|c|c|c|c|c|c|c|}
\hline Lake & Period & $\begin{array}{l}\text { ERA5L } \\
\text { rainfall } \\
{[\mathrm{mm} / \mathrm{a}]}\end{array}$ & $\begin{array}{c}\text { ERA5L } \\
\text { AET } \\
{[\mathrm{mm} / \mathrm{a}]}\end{array}$ & $\begin{array}{c}\text { ERA5L } \\
\text { AET to } \\
\text { rainfall [-] }\end{array}$ & $\begin{array}{c}\text { CHIRPS } \\
\text { rainfall } \\
{[\mathrm{mm} / \mathrm{a}]}\end{array}$ & $\begin{array}{c}\text { Adj. AET } \\
{[\mathrm{mm} / \mathrm{a}]}\end{array}$ & $\begin{array}{c}\text { Deviation } \\
\text { of Adj. } \\
\text { AET from } \\
\text { 1984-2009 } \\
\text { [mm/a] }\end{array}$ & $\begin{array}{c}\text { Deviation } \\
\text { CHIRPS } \\
\text { rainfall } \\
\text { from 1984- } \\
2009 \\
{[\mathrm{~mm} / \mathrm{a}]}\end{array}$ & $\begin{array}{c}\text { Dev. } \\
\text { effective } \\
\text { CHIRPS } \\
\text { rainfall } \\
\text { from 1984- } \\
2009 \\
{[\mathrm{~mm} / \mathrm{a}]}\end{array}$ & $\begin{array}{c}\text { Integrated } \\
\text { Catchment } \\
\text { Response } \\
{\left[\begin{array}{c}\text { mm/a }] \\
\end{array}\right.}\end{array}$ \\
\hline Baringo & $1984-2020$ & 1239.6 & 994.4 & 0.80 & 1020.7 & 816.6 & 28.4 & 82.4 & 54.0 & 6.9 \\
\hline Baringo & 1984-2009 & 1158.7 & 969.5 & 0.84 & 938.3 & 788.2 & 0.0 & 0.0 & 0.0 & -1.0 \\
\hline Baringo & 2010-2020 & 1430.8 & 1053.0 & 0.74 & 1215.5 & 899.5 & 111.3 & 277.2 & 165.9 & 16.9 \\
\hline Bogoria & $1984-2020$ & 1840.1 & 1194.2 & 0.65 & 1029.5 & 669.2 & 16.6 & 83.7 & 67.1 & 6.6 \\
\hline Bogoria & 1984-2009 & 1722.5 & 1187.6 & 0.69 & 945.8 & 652.6 & 0.0 & 0.0 & 0.0 & -0.8 \\
\hline Bogoria & $2010-2020$ & 2118.1 & 1210.0 & 0.57 & 1227.5 & 699.7 & 47.1 & 281.7 & 234.6 & 14.6 \\
\hline Nakuru & $1984-2020$ & 1257.7 & 1016.5 & 0.81 & 1009.4 & 817.6 & 30.0 & 60.5 & 30.5 & 7.4 \\
\hline Nakuru & 1984-2009 & 1203.7 & 1001.9 & 0.83 & 948.9 & 787.6 & 0.0 & 0.0 & 0.0 & -4.5 \\
\hline Nakuru & $2010-2020$ & 1385.1 & 1051.0 & 0.76 & 1152.5 & 875.9 & 88.3 & 203.6 & 115.3 & 19.4 \\
\hline Solai & $1984-2020$ & 2020.5 & 1174.9 & 0.58 & 1015.4 & 588.9 & 10.7 & 82.8 & 72.1 & 8.0 \\
\hline Solai & 1984-2009 & 1890.8 & 1172.3 & 0.62 & 932.6 & 578.2 & 0.0 & 0.0 & 0.0 & -2.0 \\
\hline Solai & $2010-2020$ & 2327.0 & 1181.0 & 0.51 & 1211.3 & 617.8 & 39.6 & 278.7 & 239.1 & 20.6 \\
\hline Elementaita & 1984-2020 & 1354.9 & 957.6 & 0.71 & 912.6 & 647.9 & 27.2 & 62.3 & 35.1 & 0.6 \\
\hline Elementaita & 1984-2009 & 1311.1 & 950.7 & 0.73 & 850.3 & 620.7 & 0.0 & 0.0 & 0.0 & -2.6 \\
\hline Elementaita & a 2010-2020 & 1458.4 & 973.8 & 0.67 & 1059.8 & 710.1 & 89.4 & 209.5 & 120.1 & 3.8 \\
\hline Naivasha & $1984-2020$ & 1415.1 & 1014.7 & 0.72 & 1028.3 & 740.4 & 32.3 & 71.4 & 39.1 & 2.2 \\
\hline Naivasha & 1984-2009 & 1366.2 & 1010.7 & 0.74 & 956.9 & 708.1 & 0.0 & 0.0 & 0.0 & -6.1 \\
\hline Naivasha & $2010-2020$ & 1530.8 & 1024.3 & 0.67 & 1197.0 & 802.0 & 93.9 & 240.1 & 146.2 & 12.1 \\
\hline
\end{tabular}




\section{Discussion}

In a perfect world, the deviations of effective rainfall would equal the Integrated Catchment

Response ICR in Table 2, given that all other boundary conditions (e.g. underground seepage, intercatchment leakages) are constant. When focusing on the ICR and effective rainfall, possible explanations for the differences include:

(i) The effective rainfall is based on CHIRPS and on the ratio between ERA5L AET and rainfall. These ratios are connected with uncertainties and it is feasible, that in effect the runoff coefficients are smaller, which would mean that effective rainfall is also smaller and lead to a better matching with the ICR. This is especially the case for Solai and Bogoria, where runoff coefficients seem too high for a dry climate. Especially in the period after 2009, higher runoff coefficients could be expected, since potential evapotranspiration was not reduced and higher rainfall was available for AET. In summary, uncertainties in AET are large and there are indications that our calculations based on ERA5L data show too low AET values.

(ii) Although CHIRPS has proven to be reliable for hydrological applications in the study region in the past, it is clear that the estimates are also afflicted with uncertainties, especially when considering that catchment means are used. Nevertheless, the deviations between effective rainfall and ICR for 2010-2020 are large in absolute numbers, but comparatively low in relative terms. For Baringo, for example, the difference amounts to $149 \mathrm{~mm}$, which is only $12 \%$ of the mean rainfall. For Bogoria and Solai, the difference is around $18 \%$ of rainfall and for the other lakes it is lower compared to Baringo. When put into perspective, considering all the numerous uncertainties in (i) point rainfall measurements and (ii) areal or basin averages estimates (Herrnegger et al., 2018, 2015), the relative errors are low.

(iii) The ICR dependents on lake volume variation data and thus on multiple satellite data and complex pre-processing steps. Comparisons with published data (Figure 8) suggest 
that the lake areas used are possibly too small, since inundated swamps and riparian vegetation is not identified as water. Assuming that larger water areas were present would mean that the lake volume would be larger, compared to our data. In this case, the lake volumes and ICR would be larger and would better fit to the effective rainfall values.

950 Whatever the reasons are, the results however clearly show the connection between (effective) rainfall and changes in lake areas. Although other mechanisms cannot be ruled out and may play a role, the ICR values show that only very small changes in the overall water balance are necessary to explain the lake level rises. For Baringo, for example, a change of only $16.9 \mathrm{~mm} / \mathrm{a}$, which is less than $2 \%$ of the annual rainfall before 2010 of $938.3 \mathrm{~mm} / \mathrm{a}$, is sufficient.

955 The analysis of the hydrometeorological conditions show that changes in boundary conditions (e.g. changes in catchment properties due to anthropogenic influences, intercatchment leakages, changes in underground permeability) are not necessary to explain lake level rises. Apart from inflow and direct evaporation and rainfall, the lake levels clearly depend on the degree of underground seepage for Baringo, Solai and Naivasha, since they are the only fresh-water lakes

960 and therefore must have an underground outflow, hindering the accumulation of salt leading to alkalinity. For Bogoria, Nakuru and Elementaita, since they are alkaline and, if existent, underground seepage is of lower relevance (Becht et al., 2006, 2005; Onywere et al., 2013; Verschuren, 2001b; Verschuren et al., 2000; Yihdego and Becht, 2013). The faults, especially for Lakes Baringo, Solai and Naivasha, are not necessarily reduced and our analysis shows that 965 changes in permeability are not necessary to explain increases in lake levels.

Compared to rainfall, the changes in ERA5L based AET are significantly lower. This is surprising, especially considering the energy oversupply for the evapotranspiration process shown in the data of potential evapotranspiration. Regarding AET however, even larger 
uncertainties exist, since no direct measurements exist and the magnitude of AET directly

970 defines the effective rainfall. Larger AET values compared to our results are very probable.

It remains important to benchmark remote sensing or numerical modelling-based rainfall products like CHIRPS or meteorological parameters from ERA5L. Although many issues exist regarding comparability of products covering very different spatial domains (Omonge et al., 2021), a comparison simply helps to gain credibility and assurance. The estimates of AET are

975 purely model driven and could not be validated. In contrast, the CHIRPS rainfall estimates per se include ground station data. Accordingly, and as could be shown with the comparison with published station data, a high agreement could be found for rainfall data from Nakuru Meteorological station and CHIRPS. For data of Snake Farm near the shores of Lake Baringo larger deviations were found regarding absolute values, where however differences in the

980 spatial domains of the time series are problematic in this case. It must be considered that Lake Baringo lies in the drier North and in the Rift floor, where it is generally drier. The main sources of water for the catchment lies in the upstream areas, which show higher elevation areas. The areal rainfall will therefore be different (higher) from a ground station located in the driest part of the catchment.

985 This analysis heavily depends and was only possible due to the availability of relevant remotely sensed data. At the same time, information from a hydrometeorological observation network on the ground would significantly reduce speculative aspects and increase credibility of this analysis. The upkeeping and maintenance of the ground observation network for the measurement of meteorological and hydrological parameters is of uttermost importance. 990 Remotely sensed data cannot (completely) substitute these measurements of e.g. rainfall, temperature, discharge, or lake levels. It is clear that financial and administrative challenges exist. It must however be clear that only these measurements allow to analyse and plan water 
resources in a sustainable manor. To plan for the future, but also understand the past, we need historical observations.

Averages in the ICR for several years indicate changes in water balance components in comparison to the mean. Using the mean ICR for the period 2010-2020, changes of inflow into the lakes in comparison to mean discharge can be evaluated. For Lake Baringo, a difference to the mean of around $3.5 \mathrm{~m}^{3} / \mathrm{s}$ is found. This means that the average inflow to the lake must have increased by this size, simply to explain the observed surge in lake volume. For the other lakes, also due to their smaller catchments, smaller values are found and range from $0.5 \mathrm{~m}^{3} / \mathrm{s}$ for Bogoria, $0.9 \mathrm{~m}^{3} / \mathrm{s}$ for Nakuru, $0.14 \mathrm{~m}^{3} / \mathrm{s}$ for Solai, $0.1 \mathrm{~m}^{3} / \mathrm{s}$ for Elementaita and $1.2 \mathrm{~m}^{3} / \mathrm{s}$ for Naivasha. Measurements of discharge, if provided to stakeholders and science in a timely manner, could allow for validation of these values. Additionally, with discharge data, runoff coefficients could be estimated with higher certainties, which in our case had to be estimated purely based on numerical model outputs and are afflicted with large uncertainties.

The climate in Eastern Africa has shown substantial variability in the distant but also near past, where distinct wet and dry periods occur. We are currently again in such a wet period. Also in the context of the ability in differentiating between climate variability and human induced climate change, it is very important to sustain and provide ground measurements of relevant hydrometeorological variables. The long-term observations within the Nile basin (see examples in the Introduction) highlight the benefit of these kind of measurements.

\section{Summary and Conclusions}

The lakes in the Central Rift Valley of Kenya have experienced extraordinary rises in their water levels since 2010. The increases in lake level areas and consequent inundations of the

1015 riparian areas have had significant negative impacts on the local communities, since homes, schools, hospitals, roads, but also the basis for the local economy such as agricultural areas or tourism infrastructure like hotels have been submerged and rendered unusable. Intense country- 
wide media coverage due to increases in the water levels have provoked public debates on the potential causes, with expert opinions divided along geological, anthropogenic and hydro1020 climatic influences. This study assessed potential hydro-climatic influences, covering the six most affected lakes.

The aim of this work was the systematic analysis and documentation of the trends and changes in lake areas, lake levels and lake volumes for the period 1984-2020 and covering 37 years. Additionally, a hydrometeorological analysis is performed to understand the underlying mechanisms behind the lake level rises. Apart from (effective) rainfall and actual evapotranspiration (AET) trends, we also analyze changes in the Integrated Catchment Response (ICR), a magnitude derived from year to year lake volume changes and which reflects changes in the lake catchment water balance. As data sources, we use DAHITI for information on lake properties over time, CHIRPS for rainfall and ERA5-Land (ERA5L) for deriving actual evapotranspiration. When possible and available, data from ground observations are used for comparison and validation. The work focuses on the main affected lakes, which are Baringo, with a catchment area of $6609 \mathrm{~km}^{2}$, Bogoria $\left(1060 \mathrm{~km}^{2}\right)$, Nakuru $\left(1471 \mathrm{~km}^{2}\right)$, Solai $\left(214 \mathrm{~km}^{2}\right)$, Elementaita $\left(772 \mathrm{~km}^{2}\right)$ and Naivasha $\left(3229 \mathrm{~km}^{2}\right)$.

In relation to the mean of 1984-2009, the increases in lake areas ranges from $21 \%$ for Lake

1035 Naivasha to an extraordinary $123 \%$ for Lake Solai in December 2020. Lake Bogoria (+28\%) is located in a deep depression, where increases in water level do not show such a pronounced signal in water area. Lake Baringo (+59\% in December 2020) and Lake Nakuru (+70\%), just like Lake Solai, are located in flatter basins. Similar to the adjacent Lake Naivasha, Lake Elementaita shows lower variation and a lower increase of around $25 \%$ compared to values 1040 before 2010.

Largest fluctuation between minimum and maximum water level is found for Lake Solai with $8.53 \mathrm{~m}$, followed by Baringo (8.23 m), Naivasha (7.48 m), Nakuru (6.40 m), Bogoria (4.99 m) 
and finally Elementaita with $2.38 \mathrm{~m}$. For most lakes, the highest levels are found around 2013/2014, which are however surpassed in the year 2020, in which new records are observed.

1045 The analysis of lake catchment rainfall time series shows that 2009 is a breakpoint year. The time series 1981-2009 and 2010-2020 show different properties with noteworthy differences in the average rainfall values. This matches well with observations in lake levels, which were more or less constant in the period before 2009. In the period 2010-2020, rainfall increased by around $30 \%$ for the Baringo, Bogoria and Solai catchments. In Nakuru, Elementaita and Naivasha, the rainfall increases were lower and amount to $21 \%, 25 \%$ and $25 \%$ respectively. After 2018, annual rainfall partially increased by even more than $50 \%$. In contrast, the increases in ERA5L based AET are lower compared to changes in rainfall and lie around 14\% for Baringo and Elementaita, $13 \%$ for Naivasha, $11 \%$ for Nakuru and $7 \%$ for Bogoria and Solai. These increases are probably too low.

1055 For 2010-2020, the Integrated Catchment Response (ICR) is positive, corresponding to positive deviations in (effective) rainfall. Although the absolute differences between ICR and deviation of effective CHIRPS rainfall are high, the signals show in the expected directions. Positive, wet, rainfall anomalies lead to an increase in the ICR and vice versa. The ICR indicates that only small changes in water balance components explain the lake level rises, i.e. $16.9 \mathrm{~mm} / \mathrm{a}$ 1060 (Baringo), $14.6 \mathrm{~mm} / \mathrm{a}$ (Bogoria), $19.4 \mathrm{~mm} / \mathrm{a}$ (Nakuru), $20.6 \mathrm{~mm} / \mathrm{a} \quad$ (Solai), $3.8 \quad \mathrm{~mm} / \mathrm{a}$ (Elementaita) and $12.1 \mathrm{~mm} / \mathrm{a}$ for Naivasha. These values correspond to only around 0.4 to $2 \%$ of annual rainfall before the lake levels increased and are magnitudes, which are difficult to observe, especially when considering catchment-wide rainfall.

From the ICR, changes in mean inflows compared to the mean, when the lake is in an 1065 equilibrium, can be evaluated. For Lake Baringo, the average inflow to the lake must have increased by at least $3.5 \mathrm{~m} / \mathrm{s}$, simply to explain the observed surge in lake volume. For the other lakes, also due to their smaller catchments, smaller values are found and range from 0.5 
$\mathrm{m}^{3} / \mathrm{s}$ for Bogoria, $0.9 \mathrm{~m}^{3} / \mathrm{s}$ for Nakuru, $0.14 \mathrm{~m}^{3} / \mathrm{s}$ for Solai, $0.1 \mathrm{~m}^{3} / \mathrm{s}$ for Elementaita and $1.2 \mathrm{~m} / \mathrm{s}$ for Naivasha.

The results clearly show the connection between (effective) rainfall and changes in lake areas. And, although other mechanisms cannot be ruled out and may play a role, the analysis of the hydrometeorological trends shows that changes in boundary conditions (e.g. changes in catchment properties due to anthropogenic influences, intercatchment leakages, changes in underground permeability) are not necessary to explain the lake level rises. Generally, the increases in (effective) rainfall are sufficient to explain the lake level rises.

We closely describe potential uncertainties in the analysis. Here we conclude that information from the ground observation network would significantly reduce speculative aspects and increase credibility of this analysis. Remotely sensed data cannot (completely) substitute the measurements of e.g. rainfall, temperature, discharge, or lake levels. These time series should be made available to the public and science for further analysis and understanding. In this respect, further analysis should include additional measurements from the ground, e.g. for the analysis of changes in runoff coefficients, since especially the ratios between ETA and rainfall from ERA5L seem to be biased.

This work purely focused on the statistical analysis of time series of lake properties and hydro1085 meteorological time series, with the aim to describe and understand the underlying mechanisms leading to the observed changes. Analysis on seasonal level, also including in-situ data and other meteorological parameters such as air temperature, should be part of future work. Important future work must also include the analysis of flood hazard, flood exposition and flood risk stemming from the lake level rises. It is clear that the current fluctuations in lake levels 1090 have been there in past - probably with higher intensity. At the same time, the negative effects on the local population are not comparable. Higher population densities, especially in the riparian areas and generally higher damage potentials are very different now. In this context, 
the analysis of the potential flood risk and generation of anticipatory flood risk maps, considering continued lake levels rises, constitute an important work for the future, since it can 1095 allow to mitigate potential losses.

\section{Author contributions}

MH and LO designed the study. MH, GS and CS performed all analyses. MH, CS and GS prepared the figures. MH and GS established the methodological framework. MH drafted and compiled the manuscript with contributions by GS, CS, and LO.

\section{Data availability}

The study was performed using openly available primary input data. All these input data can be acquired from the rights holders of these data sets. All intermediate and final data that were generated in this study are available upon request to the corresponding authors.

\section{Competing interests}

1105 The authors declare that they have no conflict of interest.

\section{Acknowledgments}

We thank Christoph Klingler for helping in extracting ERA5L data used in this study. Comments and suggestions from two anonymous reviewers helped to improve this work. This is highly acknowledged.

111010 Financial support

N/A.

\section{References}

Agembe, S., Ojwang, W., Olilo, C., Omondi, R., Ongore, C., 2016. Soda Lakes of the Rift Valley (Kenya), in: The Wetland Book. Springer Netherlands, Dordrecht, pp. 1-11. https://doi.org/10.1007/978-94-007-6173-5_150-1

Andréassian, V., 2004. Waters and forests: From historical controversy to scientific debate. J. Hydrol. https://doi.org/10.1016/j.jhydrol.2003.12.015

Ashouri, H., Hsu, K.L., Sorooshian, S., Braithwaite, D.K., Knapp, K.R., Cecil, L.D., Nelson, B.R., Prat, O.P., 2015. PERSIANN-CDR: Daily precipitation climate data record from multisatellite observations for hydrological and climate studies. Bull. Am. Meteorol. Soc. 
96, 69-83. https://doi.org/10.1175/BAMS-D-13-00068.1

Aura, C.M., Nyamweya, C.S., Owili, M., Gichuru, N., Kundu, R., Njiru, J.M., Ntiba, M.J., 2020. Checking the pulse of the major commercial fisheries of lake Victoria Kenya, for sustainable management. Fish. Manag. Ecol. 27, 314-324. https://doi.org/10.1111/fme.12414

Avery, S., 2020. Kenya's Rift Valley lakes have been this high before. But there's cause for concern [WWW Document]. Conversat. URL https://theconversation.com/kenyas-riftvalley-lakes-have-been-this-high-before-but-theres-cause-for-concern-147476 (accessed 1.29.21).

1130 Avery, S.T., Tebbs, E.J., 2018. Lake Turkana, major Omo River developments, associated hydrological cycle change and consequent lake physical and ecological change. J. Great Lakes Res. 44, 1164-1182. https://doi.org/10.1016/j.jglr.2018.08.014

Ayenew, T., Becht, R., van Lieshour, A., Gebreegziabher, Y., Legesse, D., Onyando, J., 2007. Hydrodynamics of topographically closed lakes in the Ethio-Kenyan Rift: The case of lakes Awassa and Naivasha, Journal of Spatial Hydrology.

Bai, J., Perron, P., 2003. Computation and analysis of multiple structural change models. J. Appl. Econom. 18, 1-22. https://doi.org/10.1002/jae.659

Baldocchi, D., Falge, E., Gu, L., Olson, R., Hollinger, D., Running, S., Anthoni, P., Bernhofer, C., Davis, K., Evans, R., Fuentes, J., Goldstein, A., Katul, G., Law, B., Lee, X., Malhi, Y.,

1140 Meyers, T., Munger, W., Oechel, W., Paw, U.K.T., Pilegaard, K., Schmid, H.P., Valentini, R., Verma, S., Vesala, T., Wilson, K., Wofsy, S., 2001. FLUXNET: A New Tool to Study the Temporal and Spatial Variability of Ecosystem-Scale Carbon Dioxide, Water Vapor, and Energy Flux Densities. Bull. Am. Meteorol. Soc. 82, 2415-2434. https://doi.org/10.1175/1520-0477(2001)082<2415:FANTTS >2.3.CO;2

1145 Becht, R., Mwango, F., Muno, F., 2006. Groundwater links between Kenyan Rift Valley lakes, in: Odada, E.O., Olago, D.O., Ochola, W., Ntiba, M., Wandiga, S., Gichuki, N., Oyieke, H. (Eds.), Journal of Chemical Information and Modeling. p. 12.

Becht, R., Odada, E.O., Higgins, S., 2005. Lake Naivasha: experience and lessons learned brief. Lake basin Manag. Initiat. Exp. lessons Learn. briefs. Incl. Final Rep. Manag. lakes basins 1150 Sustain. use, a Rep. lake basin Manag. stakeholders. Kusatsu Int. Lake Environ. Committe Founda.

Beck, H.E., Wood, E.F., Pan, M., Fisher, C.K., Miralles, D.G., Van Dijk, A.I.J.M., McVicar, T.R., Adler, R.F., 2019. MSWep v2 Global 3-hourly $0.1^{\circ}$ precipitation: Methodology and quantitative assessment. Bull. Am. Meteorol. Soc. 100, 473-500. https://doi.org/10.1175/BAMS-D-17-0138.1

Boitt, M.K., 2016. Impacts of Mau Forest Catchment on the Great Rift Valley Lakes in Kenya. J. Geosci. Environ. Prot. 04, 137-145. https://doi.org/10.4236/gep.2016.45014

Busker, T., De Roo, A., Gelati, E., Schwatke, C., Adamovic, M., Bisselink, B., Pekel, J.F., Cottam, A., 2019. A global lake and reservoir volume analysis using a surface water 1160 dataset and satellite altimetry. Hydrol. Earth Syst. Sci. 23, 669-690. https://doi.org/10.5194/hess-23-669-2019

Carroll, M.L., DiMiceli, C.M., Wooten, M.R., Hubbard, A.B., Sohlberg, R.A., Townshend, J.R.., 2017. MOD44W MODIS/Terra Land Water Mask Derived from MODIS and SRTM L3 Global 250m SIN Grid V006. NASA EOSDIS L. Process. DAAC. 1165 https://doi.org/10.5067/MODIS/MOD44W.006

Chebet, C., 2018. Alarm raised as water levels in Kenya's Rift Valley lakes rise, submerging 
tourism

facilities

[WWW

Document].

URL

https://www.independent.co.uk/voices/campaigns/giantsclub/kenya/alarm-raised-waterlevels-kenya-s-rift-valley-lakes-rise-submerging-tourism-facilities-a8689141.html (accessed 1.29.21).

Chepkoech, A., 2020. Kenya: Rift Valley Lakes Water Levels Rise Dangerously [WWW Document]. URL https://allafrica.com/stories/202008310228.html (accessed 1.29.21).

Cherono, S., 2021. Kenya: Experts - Why the Water Levels of Rift Valley Lakes Are Rising [WWW Document]. URL https://allafrica.com/stories/202101110248.html (accessed $1175 \quad 1.29 .21)$.

Chiu, Y.T., Schechter, J., 1966. Weak-Interaction Universality and Octet Dominance. Phys. Rev. Lett. 16, 1022-1025. https://doi.org/10.1103/PhysRevLett.16.1022

Conway, D., 2002. Extreme Rainfall Events and Lake Level Changes in East Africa: Recent Events and Historical Precedents. pp. 63-92. https://doi.org/10.1007/0-306-48201-0_2

1180 Cowx, I.G., Ogutu-Owhayo, R., 2019. Towards sustainable fisheries and aquaculture management in the African Great Lakes. Fish. Manag. Ecol. 26, 397-405. https://doi.org/10.1111/fme.12391

Crétaux, J.-F., Arsen, A., Calmant, S., Kouraev, A., Vuglinski, V., Bergé-Nguyen, M., Gennero, M.-C., Nino, F., Abarca Del Rio, R., Cazenave, A., Maisongrande, P., 2011.

1185 SOLS: A lake database to monitor in the Near Real Time water level and storage variations from remote sensing data. Adv. Sp. Res. 47, 1497-1507. https://doi.org/10.1016/j.asr.2011.01.004

Critchley, W., The World Bank, 1986. Some lessons from water harvesting in sub-Saharan Africa, Report from a workshop held in Baringo, Kenya, 13-17 October 198658.

1190 Darling, W.G., Allen, D.J., Armannsson, H., 1990. Indirect detection of subsurface outflow from a rift valley lake. J. Hydrol. 113, 297-306. https://doi.org/10.1016/00221694(90)90180-6

Darling, W.G., Gizaw, B., Arusei, M.K., 1996. Lake-groundwater relationships and fluid-rock interaction in the East African Rift Valley: Isotopic evidence. J. African Earth Sci. 22, 423-431. https://doi.org/10.1016/0899-5362(96)00026-7

De Bock, T., Kervyn De Meerendré, B., Hess, T., Gouder De Beauregard, A.C., 2009. Ecohydrology of a seasonal wetland in the Rift Valley: Ecological characterization of Lake Solai. Afr. J. Ecol. 47, 289-298. https://doi.org/10.1111/j.1365-2028.2008.00949.x

deMenocal, P.B., Rind, D., 2019. Sensitivity of Subtropical African and Asian Climate to Prescribed Boundary Condition Changes: Model Implications for the Plio-Pleistocene Evolution of Low-Latitude Climate, in: The Limnology, Climatology and Paleoclimatology of the East African Lakes. Routledge, pp. 57-77. https://doi.org/10.1201/9780203748978-3

Derakhshan, S., 2017. Ground and Surface Water Flow Modeling in the Lake Naivasha Basin. 1205 University of Twente.

Dinku, T., Ceccato, P., Grover-Kopec, E., Lemma, M., Connor, S.J., Ropelewski, C.F., 2007. Validation of satellite rainfall products over East Africa's complex topography. Int. J. Remote Sens. 28, 1503-1526. https://doi.org/10.1080/01431160600954688

Dinku, T., Funk, C., Peterson, P., Maidment, R., Tadesse, T., Gadain, H., Ceccato, P., 2018. Validation of the CHIRPS satellite rainfall estimates over eastern Africa. Q. J. R. Meteorol. Soc. 144, 292-312. https://doi.org/10.1002/qj.3244 
du Preez, C.C., van Huyssteen, C.W., 2020. Threats to soil and water resources in South Africa. Environ. Res. 183, 109015. https://doi.org/10.1016/j.envres.2019.109015

Finney, B.P., Scholz, C.A., Johnson, T.C., Trumbore, S., 2019. Late Quaternary Lake-Level Changes of Lake Malawi, in: The Limnology, Climatology and Paleoclimatology of the East African Lakes. Routledge, pp. 495-508. https://doi.org/10.1201/9780203748978-27

Fishman, R., 2018. Groundwater depletion limits the scope for adaptation to increased rainfall variability in India. Clim. Change 147, 195-209. https://doi.org/10.1007/s10584-0182146-x

1220 Flörke, M., Schneider, C., McDonald, R.I., 2018. Water competition between cities and agriculture driven by climate change and urban growth. Nat. Sustain. 1, 51-58. https://doi.org/10.1038/s41893-017-0006-8

Fouchy, K., McClain, M.E., Conallin, J., O’Brien, G., 2018. Multiple stressors in african freshwater systems, in: Multiple Stressors in River Ecosystems: Status, Impacts and Prospects for the Future. Elsevier, pp. 179-191. https://doi.org/10.1016/B978-0-12811713-2.00010-8

Funk, C., Peterson, P., Landsfeld, M., Pedreros, D., Verdin, J., Shukla, S., Husak, G., Rowland, J., Harrison, L., Hoell, A., Michaelsen, J., 2015. The climate hazards infrared precipitation with stations - A new environmental record for monitoring extremes. Sci. Data 2, 1-21. https://doi.org/10.1038/sdata.2015.66

Garcia Benedito, E., 2019. Hydrological \& vegetation dynamics in Lake Ngami, Okavango Delta. Institute for Hydrology and Water Management, University of Natural Resources and Life Sciences, Vienna, Austria.

Gichuru, G., Waithaka, H., 2015. Analysis of Lake Nakuru Surface Water Area Variations Using Geospatial Technologies, in: The 2015 JKUAT Scientific Conference - Water, Energy, Environment and Climate. pp. 308-322.

Goman, M., Ashley, G.M., Owen, R.B., Hover, V.C., Maharjan, D.K., 2017. Late Holocene Environmental Reconstructions from Lake Solai, Kenya. Prof. Geogr. 69, 438-454. https://doi.org/10.1080/00330124.2016.1266948

1240 Gorelick, N., Hancher, M., Dixon, M., Ilyushchenko, S., Thau, D., Moore, R., 2017. Google Earth Engine: Planetary-scale geospatial analysis for everyone. Remote Sens. Environ. 202, 18-27. https://doi.org/10.1016/j.rse.2017.06.031

Göttl, F., Dettmering, D., Müller, F.L., Schwatke, C., 2016. Lake level estimation based on CryoSat-2 SAR altimetry and multi-looked waveform classification. Remote Sens. 8. $1245 \quad$ https://doi.org/10.3390/rs8110885

Gownaris, N.J., Rountos, K.J., Kaufman, L., Kolding, J., Lwiza, K.M.M., Pikitch, E.K., 2018. Water level fluctuations and the ecosystem functioning of lakes. J. Great Lakes Res. 44, 1154-1163. https://doi.org/10.1016/j.jglr.2018.08.005

Gregory, J.W., 1896. The Great Rift Valley : being the narrative of a journey to Mount Kenya and Lake Baringo : with some account of the geology, natural history, anthropology and future prospects of British East Africa / J.W. Gregory., The Great Rift Valley: being the narrative of a journey to Mount Kenya and Lake Baringo: with some account of the geology, natural history, anthropology and future prospects of British East Africa / J.W. Gregory. J. Murray, London : https://doi.org/10.5962/bhl.title.12499

1255 Grove, A.T., 2019. African River Discharges and Lake Levels in the Twentieth Century, in: The Limnology, Climatology and Paleoclimatology of the East African Lakes. Routledge, pp. 95-100. https://doi.org/10.1201/9780203748978-5 
Guzha, A.C., Rufino, M.C., Okoth, S., Jacobs, S., Nóbrega, R.L.B., 2018. Impacts of land use and land cover change on surface runoff, discharge and low flows: Evidence from East Africa. J. Hydrol. Reg. Stud. https://doi.org/10.1016/j.ejrh.2017.11.005

Hakimdavar, R., Hubbard, A., Policelli, F., Pickens, A., Hansen, M., Fatoyinbo, T., Lagomasino, D., Pahlevan, N., Unninayar, S., Kavvada, A., Carroll, M., Smith, B., Hurwitz, M., Wood, D., Uz, S.S., 2020. Monitoring water-related ecosystems with earth observation data in support of Sustainable Development Goal (SDG) 6 reporting. Remote Sens. 12, 1634. https://doi.org/10.3390/rs12101634

Herndon, K., Muench, R., Cherrington, E., Griffin, R., 2020. An assessment of surface water detection methods for water resource management in the Nigerien Sahel. Sensors (Switzerland) 20, 1-14. https://doi.org/10.3390/s20020431

Herrnegger, M., Nachtnebel, H.P., Schulz, K., 2015. From runoff to rainfall: Inverse rainfallrunoff modelling in a high temporal resolution. Hydrol. Earth Syst. Sci. 19, 4619-4639. https://doi.org/10.5194/hess-19-4619-2015

Herrnegger, M., Senoner, T., Nachtnebel, H., 2018. Adjustment of spatio-temporal precipitation patterns in a high Alpine environment. J. Hydrol. 556, 913-921. https://doi.org/10.1016/j.jhydrol.2016.04.068

1275 Hersbach, H., Bell, B., Berrisford, P., Hirahara, S., Horányi, A., Muñoz-Sabater, J., Nicolas, J., Peubey, C., Radu, R., Schepers, D., Simmons, A., Soci, C., Abdalla, S., Abellan, X., Balsamo, G., Bechtold, P., Biavati, G., Bidlot, J., Bonavita, M., De Chiara, G., Dahlgren, P., Dee, D., Diamantakis, M., Dragani, R., Flemming, J., Forbes, R., Fuentes, M., Geer, A., Haimberger, L., Healy, S., Hogan, R.J., Hólm, E., Janisková, M., Keeley, S., Laloyaux, 1280 P., Lopez, P., Lupu, C., Radnoti, G., de Rosnay, P., Rozum, I., Vamborg, F., Villaume, S., Thépaut, J.N., 2020. The ERA5 global reanalysis. Q. J. R. Meteorol. Soc. 146, 1999-2049. https://doi.org/10.1002/qj.3803

Huffman, G.J., Bolvin, D.T., Nelkin, E.J., Wolff, D.B., Adler, R.F., Gu, G., Hong, Y., Bowman, K.P., Stocker, E.F., 2007. The TRMM Multisatellite Precipitation Analysis (TMPA):

1285 Quasi-Global, Multiyear, Combined-Sensor Precipitation Estimates at Fine Scales. J. Hydrometeorol. 8, 38-55. https://doi.org/10.1175/JHM560.1

Jenny, J.-P., Anneville, O., Arnaud, F., Baulaz, Y., Bouffard, D., Domaizon, I., Bocaniov, S.A., Chèvre, N., Dittrich, M., Dorioz, J.-M., Dunlop, E.S., Dur, G., Guillard, J., Guinaldo, T., Jacquet, S., Jamoneau, A., Jawed, Z., Jeppesen, E., Krantzberg, G., Lenters, J., Leoni, B.,

1290 Meybeck, M., Nava, V., Nõges, T., Nõges, P., Patelli, M., Pebbles, V., Perga, M.-E., Rasconi, S., Ruetz, C.R., Rudstam, L., Salmaso, N., Sapna, S., Straile, D., Tammeorg, O., Twiss, M.R., Uzarski, D.G., Ventelä, A.-M., Vincent, W.F., Wilhelm, S.W., Wängberg, S.-Å., Weyhenmeyer, G.A., 2020. Scientists' Warning to Humanity: Rapid degradation of the world's large lakes. J. Great Lakes Res. 46, 686-702. https://doi.org/10.1016/j.jglr.2020.05.006

Joyce, R.J., Janowiak, J.E., Arkin, P.A., Xie, P., 2004. CMORPH: A method that produces global precipitation estimates from passive microwave and infrared data at high spatial and temporal resolution. J. Hydrometeorol. 5, 487-503. https://doi.org/10.1175/15257541(2004)005<0487:CAMTPG>2.0.CO;2

1300 Kiage, L.M., Douglas, P., 2020. Linkages between land cover change, lake shrinkage, and sublacustrine influence determined from remote sensing of select Rift Valley Lakes in Kenya. Sci. Total Environ. 709, 136022. https://doi.org/10.1016/j.scitotenv.2019.136022

Kimani, M.W., Hoedjes, J.C.B., Su, Z., 2017. An assessment of satellite-derived rainfall products relative to ground observations over East Africa. Remote Sens. 9, 430. 
Kimaru, A.N., Gathenya, J.M., Cheruiyot, C.K., 2019. The Temporal Variability of Rainfall and Streamflow into Lake Nakuru, Kenya, Assessed Using SWAT and $\begin{array}{lllll}\text { Hydrometeorological Hydrology } & \text { Indices. } & 68\end{array}$ https://doi.org/10.3390/hydrology6040088

1310 Klein, I., Gessner, U., Dietz, A.J., Kuenzer, C., 2017. Global WaterPack - A 250 m resolution dataset revealing the daily dynamics of global inland water bodies. Remote Sens. Environ. 198, 345-362. https://doi.org/10.1016/j.rse.2017.06.045

LP DAAC, 2015. Global $250 \mathrm{~m}$ SIN Grid V006. NASA L. Data Prod. Serv. https://doi.org/10.5067/MODIS/MOD13Q1.006

1315 Maidment, R.I., Grimes, D., Allan, R.P., Tarnavsky, E., Marcstringer, M., Hewison, T., Roebeling, R., Black, E., 2014. The 30 year TAMSAT african rainfall climatology and time series (TARCAT) data set. J. Geophys. Res. 119, 10,619-10,644. https://doi.org/10.1002/2014JD021927

Maina, C.W., Sang, J.K., Mutua, B.M., Raude, J.M., 2018. Bathymetric survey of Lake Naivasha and its satellite Lake Oloiden in Kenya; using acoustic profiling system. Lakes Reserv. Res. Manag. 23, 324-332. https://doi.org/10.1111//re.12247

McCall, J., 2010. Lake Bogoria, Kenya: Hot and warm springs, geysers and Holocene stromatolites. Earth-Science Rev. https://doi.org/10.1016/j.earscirev.2010.08.001

Minale, A.S., 2020. Water level fluctuations of Lake Tana and its implication on local communities livelihood, northwestern Ethiopia. Int. J. River Basin Manag. 18, 503-510. https://doi.org/10.1080/15715124.2019.1700512

Moturi, N.F., 2015. A hydrological study of the rising water level at Lake Nakuru. University of Nairobi.

Muñoz Sabater, J., 2019. ERA5-Land monthly averaged data from 1981 to present. Clim. Data $1330 \quad$ Store. https://doi.org/10.24381/cds.68d2bb3

Muthuwatta, L., 2014. Long term Rainfall-Runoff-Lake Level Modelling of the Lake Naivasha Basin, Kenya. University of Twente.

Nicholson, S.E., 2019. A Review of Climate Dynamics and Climate Variability in Eastern Africa, in: The Limnology, Climatology and Paleoclimatology of the East African Lakes. Routledge, pp. 25-56. https://doi.org/10.1201/9780203748978-2

Nyaga, J., Koskei, E., Kotut, K., Oduor, S.O., 2019. Temporal variation in physico-chemical characteristics, phytoplankton composition and biomass in Lake Solai, Kenya. Int. J. Aquat. Sci. 10, 101-111.

Obando, J.A., Onywere, S., Shisanya, C., Ndubi, A., Masiga, D., Irura, Z., Mariita, N., Maragia,

1340 H., 2016. Impact of Short-Term Flooding on Livelihoods in the Kenya Rift Valley Lakes, in: Geomorphology and Society. Springer, pp. 193-215. https://doi.org/10.1007/978-4431-56000-5_12

Odada, E.O., Onyando, J., Obudho, P.A., 2006. Lake Baringo: Experience and Lessons Learned Brief, World Lake Basin Management Initiative: experience and lessons learned briefs.

1345 Odongo, V.O., 2016. How climate and land use determine the hydrology of lake Naivasha basin. University of Twente. https://doi.org/10.3990/1.9789036542333

Odongo, V.O., van der Tol, C., van Oel, P.R., Meins, F.M., Becht, R., Onyando, J., Su, Z., 2015. Characterisation of hydroclimatological trends and variability in the Lake Naivasha 
basin, Kenya. Hydrol. Process. 29, 3276-3293. https://doi.org/10.1002/hyp.10443

1350 Oduor, S.O., Schagerl, M., 2007. Temporal trends of ion contents and nutrients in three Kenyan Rift Valley saline-alkaline lakes and their influence on phytoplankton biomass, in: Gulati, R.D., Lammens, E., De Pauw, N., Van Donk, E. (Eds.), Hydrobiologia. Springer Netherlands, Dordrecht, pp. 59-68. https://doi.org/10.1007/s10750-007-0605-X

Ojwang, W.O., Obiero, K.O., Donde, O.O., Gownaris, N., Pikitch, E.K., Omondi, R., Agembe, S., Malala, J., Avery, S.T., 2016. Lake Turkana: World's Largest Permanent Desert Lake (Kenya), in: The Wetland Book. Springer Netherlands, pp. 1-20. https://doi.org/10.1007/978-94-007-6173-5_254-1

Olago, D.O., Mavuti, K., 2017. The Diversity \& Ecology of the East African Lakes, with a case study of lakes Baringo, Nakuru and Victoria-Nyanza, in: Least Developed Countries Expert Group Regional Training Workshop on National Adaptation Plans for Anglophone Africa. Lilongew, Malawi, pp. 1-24.

Olson, D.M., Dinerstein, E., 2002. The global 200: Priority ecoregions for global conservation, in: Annals of the Missouri Botanical Garden. Missouri Botanical Garden, pp. 199-224. https://doi.org/10.2307/3298564

1365 Omondi, F., 2020a. The rising lakes of the Rift Valley [WWW Document]. URL https://africasacountry.com/2020/09/the-rising-lakes-of-the-rift-valley (accessed 1.29.21).

Omondi, F., 2020b. Rising water levels in Kenya's Great Rift Valley threaten jobs and wildlife [WWW Document]. BBC. URL https://www.bbc.com/news/av/world-africa-53776774 $1370 \quad$ (accessed 1.29.21).

Omonge, P., Schulz, K., Olang, L., Herrnegger, M., 2021. Evaluation of satellite precipitation products for water allocation studies in the Sio-Malaba-Malakisi River Basin of East Africa. https://doi.org/https://doi.org/10.31223/X51C8J

Onywere, S., Shisanya, C., Obando, J., Ndubi, A., Masiga, D., Irura, Z., Mariita, N., Maragia, 1375 H., 2013. Geospatial extent of 2011-2013 flooding from the Eastern African Rift Valley Lakes in Kenya and its implication on the ecosystems, in: Papers, Kenya Soda Lakes Workshop. Kenya Wildlife Service Training Institute, Naivasha. p. 22.

Pekel, J.F., Cottam, A., Gorelick, N., Belward, A.S., 2016. High-resolution mapping of global surface water and its long-term changes. Nature 540, 418-422.

RCMRD, n.d. The Rising Water Level and Expansion of the Rift Valley Lakes from Space [WWW Document]. URL https://rcmrd.org/the-rising-water-level-and-expansion-of-therift-valley-lakes-from-space (accessed 6.18.21).

Renaut, R.W., Owen, R.B., Ego, J.K., 2017. Geothermal activity and hydrothermal mineral deposits at southern Lake Bogoria, Kenya Rift Valley: Impact of lake level changes. J. African Earth Sci. 129, 623-646. https://doi.org/10.1016/j.jafrearsci.2017.01.012

Ricciardi, M., 1981. African Saga. Collins, London.

Richardson, J.L., 1966. Changes in level of Lake Naivasha, Kenya, during postglacial times [7]. Nature 209, 290-291. https://doi.org/10.1038/209290a0

1390 Ricketts, R.D., Johnson, T.C., 2019. Early Holocene Changes in Lake Level and Productivity in Lake Malawi as Interpreted from Oxygen and Carbon Isotopic Measurements of Authigenic Carbonates, in: The Limnology, Climatology and Paleoclimatology of the East African Lakes. Routledge, pp. 475-493. https://doi.org/10.1201/9780203748978-26 
Rienecker, M.M., Suarez, M.J., Gelaro, R., Todling, R., Bacmeister, J., Liu, E., Bosilovich, M.G., Schubert, S.D., Takacs, L., Kim, G.K., Bloom, S., Chen, J., Collins, D., Conaty, A., Da Silva, A., Gu, W., Joiner, J., Koster, R.D., Lucchesi, R., Molod, A., Owens, T., Pawson, S., Pegion, P., Redder, C.R., Reichle, R., Robertson, F.R., Ruddick, A.G., Sienkiewicz, M., Woollen, J., 2011. MERRA: NASA's modern-era retrospective analysis for research and applications. J. Clim. 24, 3624-3648. https://doi.org/10.1175/JCLI-D-11-00015.1

1400 Rodell, M., Houser, P.R., Jambor, U., Gottschalck, J., Mitchell, K., Meng, C.J., Arsenault, K., Cosgrove, B., Radakovich, J., Bosilovich, M., Entin, J.K., Walker, J.P., Lohmann, D., Toll, D., 2004a. The Global Land Data Assimilation System. Bull. Am. Meteorol. Soc. 85, 381394. https://doi.org/10.1175/BAMS-85-3-381

Rodell, M., Houser, P.R., Jambor, U., Gottschalck, J., Mitchell, K., Meng, C.J., Arsenault, K., Cosgrove, B., Radakovich, J., Bosilovich, M., Entin, J.K., Walker, J.P., Lohmann, D., Toll, D., 2004b. The Global Land Data Assimilation System. Bull. Am. Meteorol. Soc. 85, 381394. https://doi.org/10.1175/BAMS-85-3-381

Rohatgi, A., 2020. Webplotdigitizer: Version 4.4.

Saha, S., Moorthi, S., Wu, X., Wang, J., Nadiga, S., Tripp, P., Behringer, D., Hou, Y.T., Chuang, H.Y., Iredell, M., Ek, M., Meng, J., Yang, R., Mendez, M.P., Van Den Dool, H., Zhang, Q., Wang, W., Chen, M., Becker, E., 2014. The NCEP climate forecast system version 2. J. Clim. 27, 2185-2208. https://doi.org/10.1175/JCLI-D-12-00823.1

Salmaso, N., Buzzi, F., Capelli, C., Cerasino, L., Leoni, B., Lepori, F., Rogora, M., 2020. Responses to local and global stressors in the large southern perialpine lakes: Present status and challenges for research and management. J. Great Lakes Res. 46, 752-766. https://doi.org/10.1016/j.jglr.2020.01.017

Santos da Silva, J., Calmant, S., Seyler, F., Rotunno Filho, O.C., Cochonneau, G., Mansur, W.J., 2010. Water levels in the Amazon basin derived from the ERS 2 and ENVISAT radar altimetry missions. Remote Sens. Environ. 114, 2160-2181. https://doi.org/10.1016/j.rse.2010.04.020

Schwatke, C., Dettmering, D., Bosch, W., Seitz, F., 2015. DAHITI - An innovative approach for estimating water level time series over inland waters using multi-mission satellite altimetry. Hydrol. Earth Syst. Sci. 19, 4345-4364. https://doi.org/10.5194/hess-19-43452015

1425 Schwatke, C., Dettmering, D., Seitz, F., 2020. Volume variations of small inland water bodies from a combination of satellite altimetry and optical imagery. Remote Sens. 12. https://doi.org/10.3390/rs12101606

Schwatke, C., Scherer, D., Dettmering, D., 2019. Automated extraction of consistent timevariable water surfaces of lakes and reservoirs based on Landsat and Sentinel-2. Remote Sens. 11. https://doi.org/10.3390/rs11091010

Smith, A., 1989. The Great Rift : Africa's Changing valley. BBC Books, London.

Strahler, A.N., 1952. Hypsometric (area-altitude) analysis of erosional topography. Bull. Geol. Soc. Am. 63, 1117-1142. https://doi.org/10.1130/00167606(1952)63[1117:HAAOET]2.0.CO;2

1435 Sutcliffe, J.V., Parks, Y.P., 1999. The Hydrology of the Nile. IAHS Spec. Publ. 5, 192.

Sutherland, R.A., Bryan, K.B., 1990. Runoff and erosion from a small semiarid catchment, Baringo district, Kenya. Appl. Geogr. 10, 91-109. https://doi.org/10.1016/01436228(90)90046-R 
Tarnavsky, E., Grimes, D., Maidment, R., Black, E., Allan, R.P., Stringer, M., Chadwick, R., Kayitakire, F., 2014. Extension of the TAMSAT satellite-based rainfall monitoring over Africa and from 1983 to present. J. Appl. Meteorol. Climatol. 53, 2805-2822. https://doi.org/10.1175/JAMC-D-14-0016.1

Team R Development Core, 2018. A Language and Environment for Statistical Computing. R Found. Stat. Comput.

1445 Tole, M.P., 1996. Geothermal energy research in Kenya: A review. J. African Earth Sci. 23, 565-575. https://doi.org/10.1016/S0899-5362(97)00019-5

Verschuren, D., 2019. Comparative Paleolimnology in a System of Four Shallow Tropical Lake Basins, in: The Limnology, Climatology and Paleoclimatology of the East African Lakes. Routledge, pp. 559-572. https://doi.org/10.1201/9780203748978-32

1450 Verschuren, D., 2001. Reconstructing fluctuations of a shallow East African lake during the past 1800 yrs from sediment stratigraphy in a submerged crater basin. J. Paleolimnol. 25, 297-311. https://doi.org/10.1023/A:1011150300252

Verschuren, D., Tibby, J., Sabbe, K., Roberts, N., 2000. Effects of depth, salinity, and substrate on the invertebrate community of a fluctuating tropical lake. Ecology 81, 164-182. https://doi.org/10.1890/0012-9658(2000)081[0164:EODSAS]2.0.CO;2

Villadsen, H., Deng, X., Andersen, O.B., Stenseng, L., Nielsen, K., Knudsen, P., 2016. Improved inland water levels from SAR altimetry using novel empirical and physical retrackers. J. Hydrol. 537, 234-247. https://doi.org/10.1016/j.jhydrol.2016.03.051

Wainwright, C.M., Finney, D.L., Kilavi, M., Black, E., Marsham, J.H., 2020. Extreme rainfall in East Africa, October 2019-January 2020 and context under future climate change. Weather. https://doi.org/10.1002/wea.3824

Wambua-Soi, C., 2020. Why Kenya's Rift Valley lakes are going through a crisis [WWW Document]. URL https://www.aljazeera.com/news/2020/8/30/why-kenyas-rift-valleylakes-are-going-through-a-crisis

1465 Whittaker, K.T., 2019. The Limnology, Climatology and Paleoclimatology of the East African Lakes, The Limnology, Climatology and Paleoclimatology of the East African Lakes. Routledge. https://doi.org/10.1201/9780203748978

Yamazaki, D., Ikeshima, D., Sosa, J., Bates, P.D., Allen, G.H., Pavelsky, T.M., 2019. MERIT Hydro: A High-Resolution Global Hydrography Map Based on Latest Topography Dataset. Water Resour. Res. 55, 5053-5073. https://doi.org/10.1029/2019WR024873

Yang, X., Giusti, M., 2020. ERA5-Land: data documentation, CDS dataset documentation, European Centre for Medium-Range Weather Forecasts (ECMWF).

Yihdego, Y., Becht, R., 2013. Simulation of lake-aquifer interaction at Lake Naivasha, Kenya using a three-dimensional flow model with the high conductivity technique and a DEM with bathymetry. J. Hydrol. 503, 111-122. https://doi.org/10.1016/j.jhydrol.2013.08.034

Zeileis, A., Kleiber, C., Walter, K., Hornik, K., 2003. Testing and dating of structural changes in practice. Comput. Stat. Data Anal. 44, 109-123. https://doi.org/10.1016/S01679473(03)00030-6

Zeileis, A., Leisch, F., Hornik, K., Kleiber, C., 2002. Strucchange: An R package for testing for 1480 structural change in linear regression models. J. Stat. Softw. 7, 1-38. https://doi.org/10.18637/jss.v007.i02 


\section{Appendix}
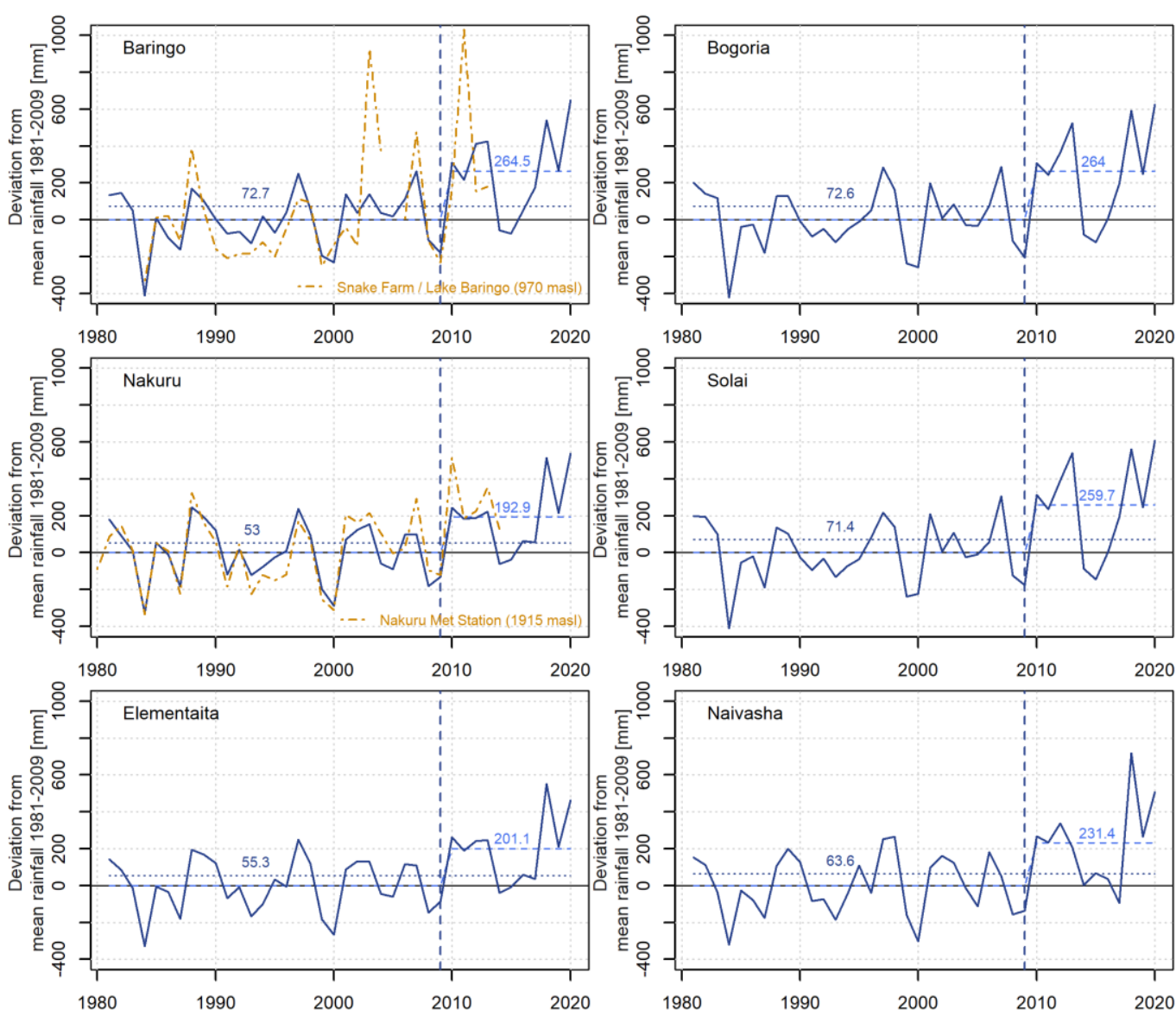

Figure A1: Deviation of mean annual rainfall from the long term mean 1981-2009 [mm]. CHIRPS data is shown for the orographic catchments of the single lakes (Baringo $6609 \mathrm{~km}^{2}$; Bogoria $1060 \mathrm{~km}^{2}$, Nakuru $1471 \mathrm{~km}^{2}$, Solai $214 \mathrm{~km}$; Elementaita $772 \mathrm{~km}^{2}$; ${ }^{2}$; Naivasha $3229 \mathrm{~km}^{2}$ ). Also shown as dashed horizontal lines are the deviations for the long term means 1981-2020 and 2010-2020 from the reference period 1981-2009. The periods 1981-2009 and 2010-2020 are separated by breakpoint year in 2009 (dashed vertical line), where a change in structure of rainfall times series occurs, also regarding the means. Station data from Snake Farm on the shores of Lake Baringo and the Nakuru Meteorological Station are plotted in the panel for Baringo and Nakuru. Data was extracted from Kiage and Douglas (2020) using tools provided by Rohatgi (2020). 

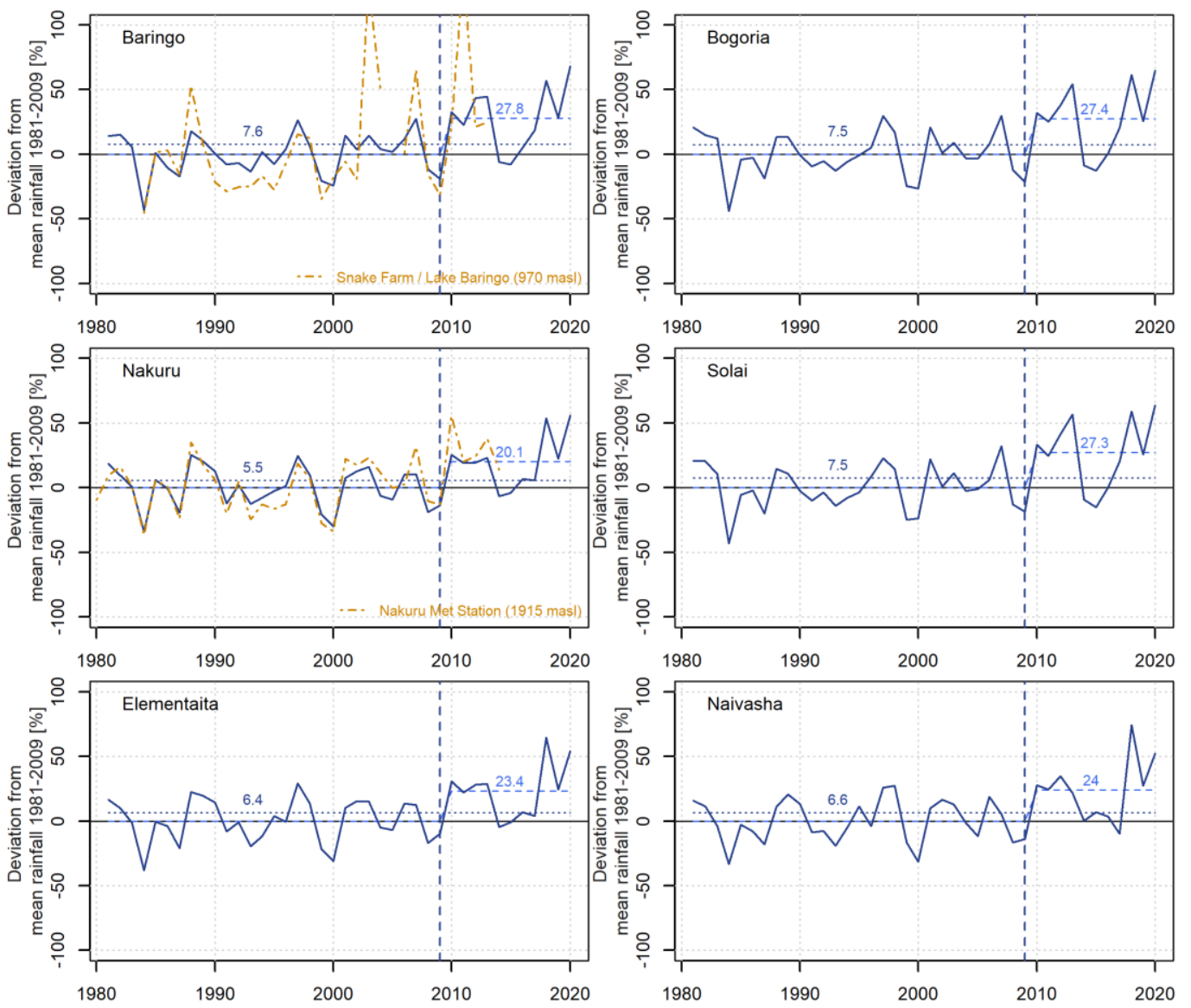

1495 Figure A2: Deviation of mean annual rainfall from the long term mean 1981-2009 [\%]. CHIRPS data is shown for the orographic catchments of the single lakes (Baringo $6609 \mathrm{~km}^{2}$; Bogoria $1060 \mathrm{~km}^{2}$, Nakuru $1471 \mathrm{~km}^{2}$, Solai $214 \mathrm{~km}$; Elementaita $772 \mathrm{~km}^{2}$; ${ }^{2}$; Naivasha $3229 \mathrm{~km}^{2}$ ). Also shown as dashed horizontal lines are the deviations from long-term means. The periods 1981-2009 and 2010-2020 are separated by breakpoint year in 2009 (dashed vertical line), where a change in structure of rainfall times series occurs, also regarding the means. As a reference station data is shown for Baringo and Nakuru. Station data from Snake Farm on the shores of Lake Baringo and the Nakuru Meteorological Station are plotted in the panel for Baringo and Nakuru. Data was extracted from Kiage and Douglas (2020) using tools provided by Rohatgi (2020). 

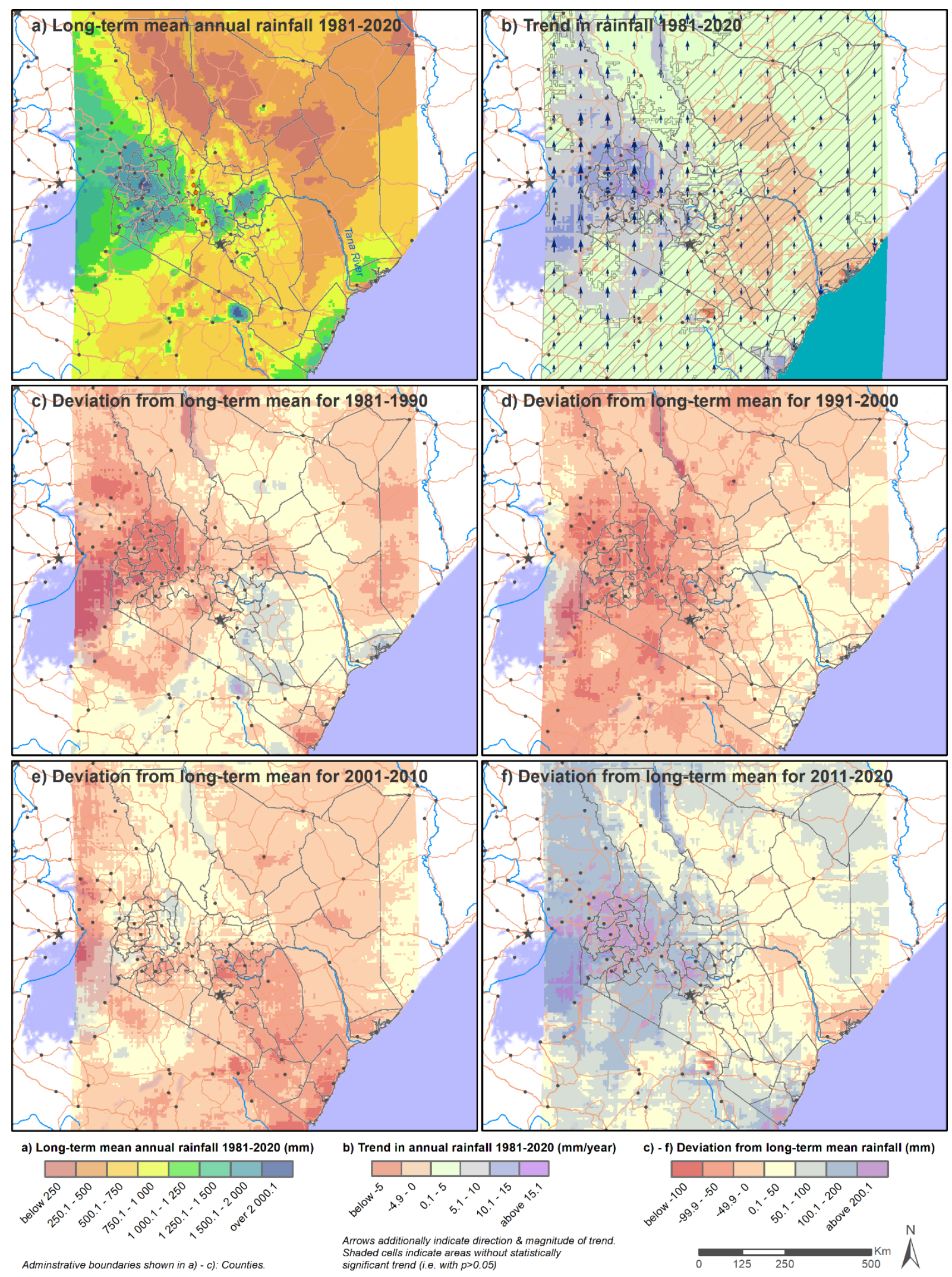

Data sources: Rainfall: CHIRPS v2.0 (Funk et al., 2015), Administrative boundaries, Roads, Cities, Water bodies: naturalearthdata.com, GSWv1.2 (Pekel et al., 2016)

1505 Figure A3: Spatial and temporal trends in rainfall for Kenya. Long-term mean annual rainfall for the period 1981 2020 (a), trends in rainfall as change in mm/year (b) and deviation from long-term mean rainfall (panel (a)) for the four decades in 1981-2020 (c)-(f) 

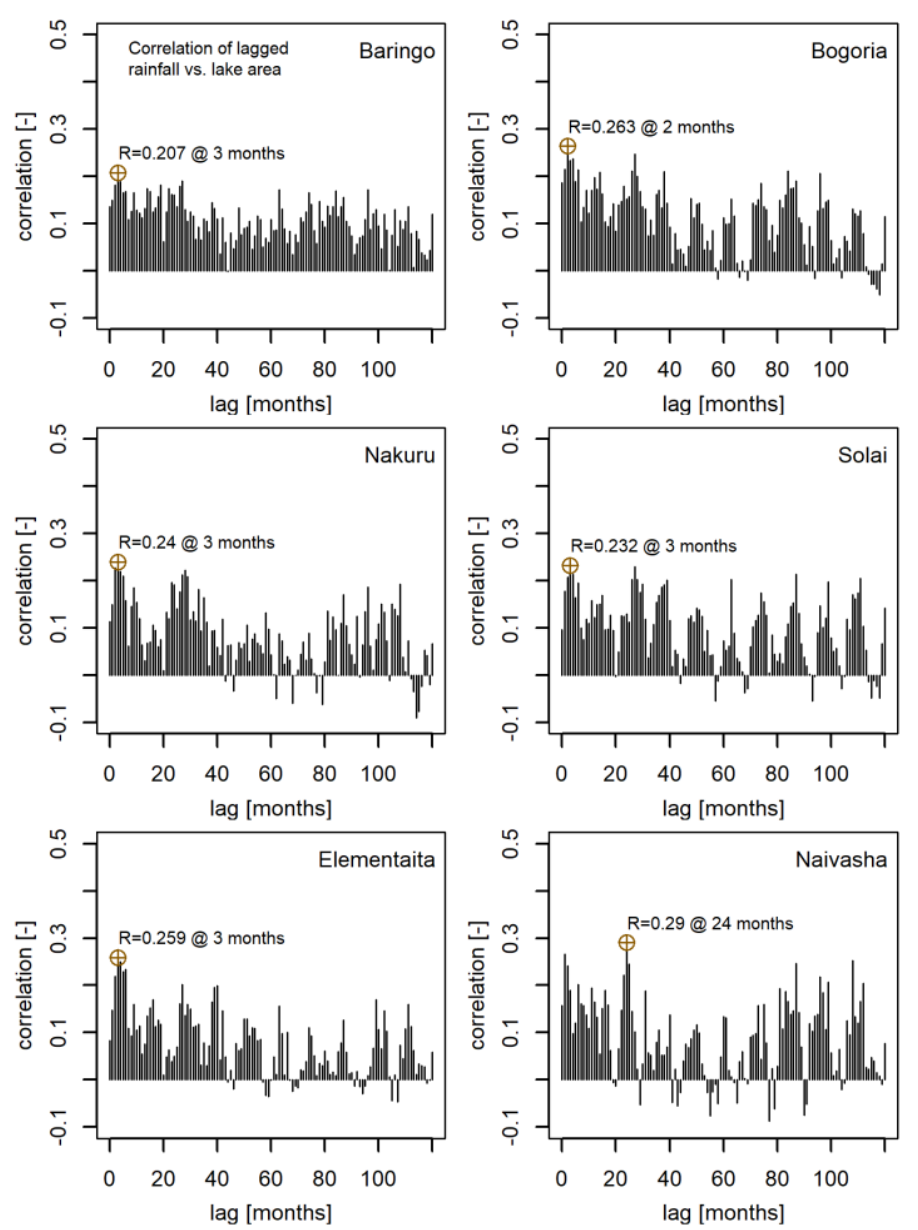

1510 Figure A4: Correlation between lagged monthly rainfall and lake area. The shift indicates the number of months a signal in rainfall is observed in lake area. The circles and labels indicate the maximum correlation, including the number of months of occurrence and corresponding correlation value.

\section{Mean monthly lake area}

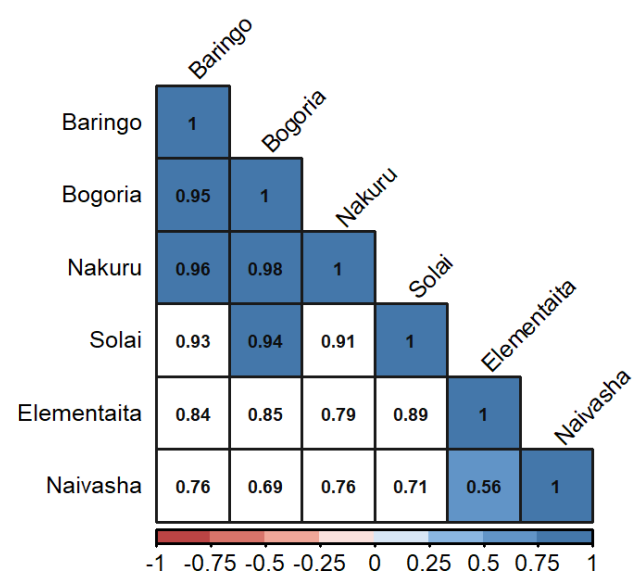

Mean monthly lake level

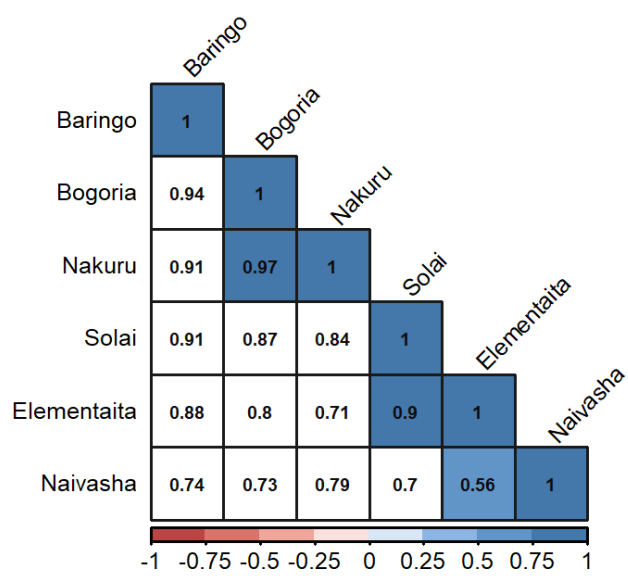

1515 Figure A5: Correlation matrix of monthly lake areas (left) and level (right). White colored boxes indicate correlation values, which are statistically not significant $(p \leq 0.05)$ 


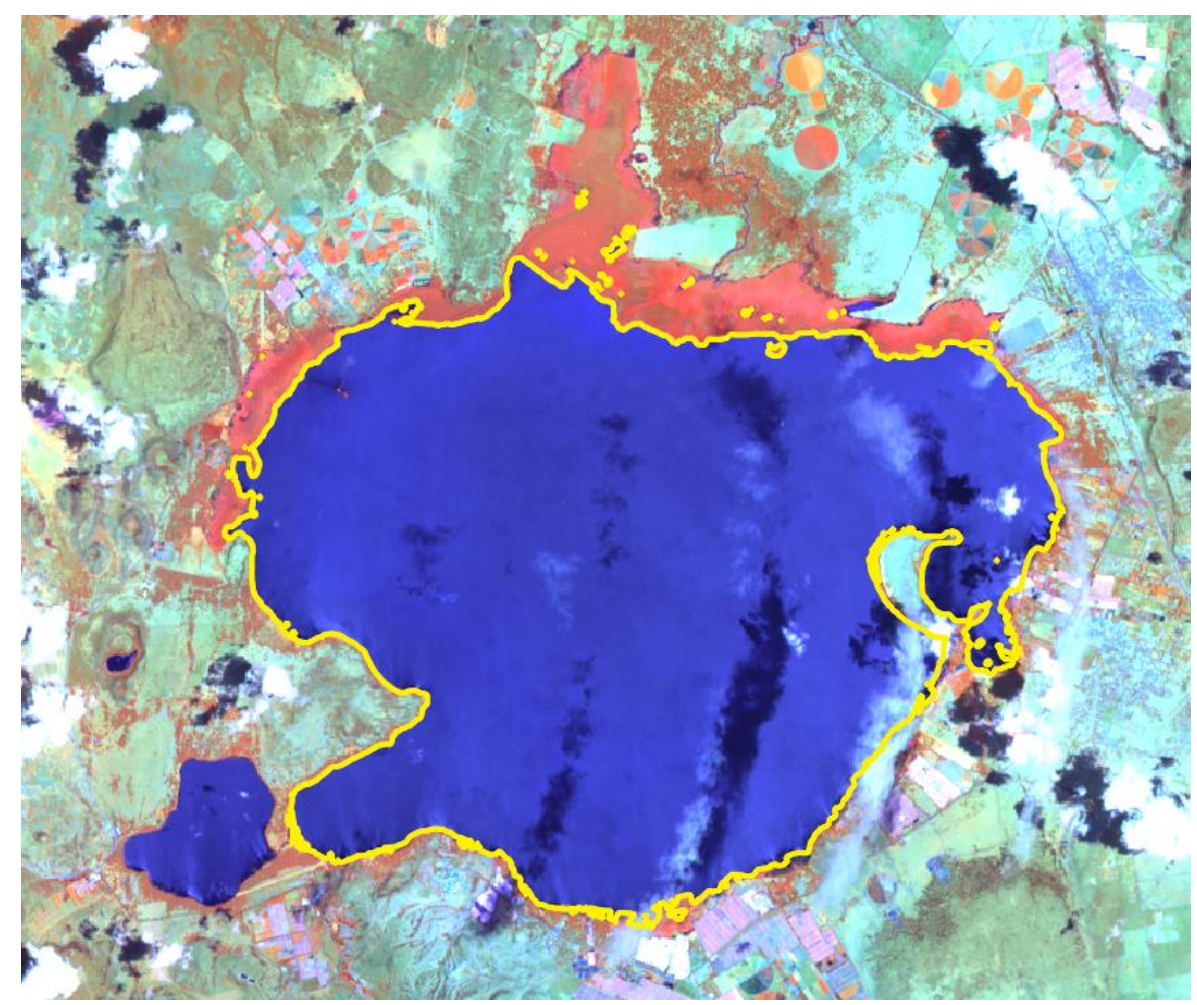

Figure A6: Land-water mask indicated by yellow polygons for Lake Naivasha for 05.10.2013

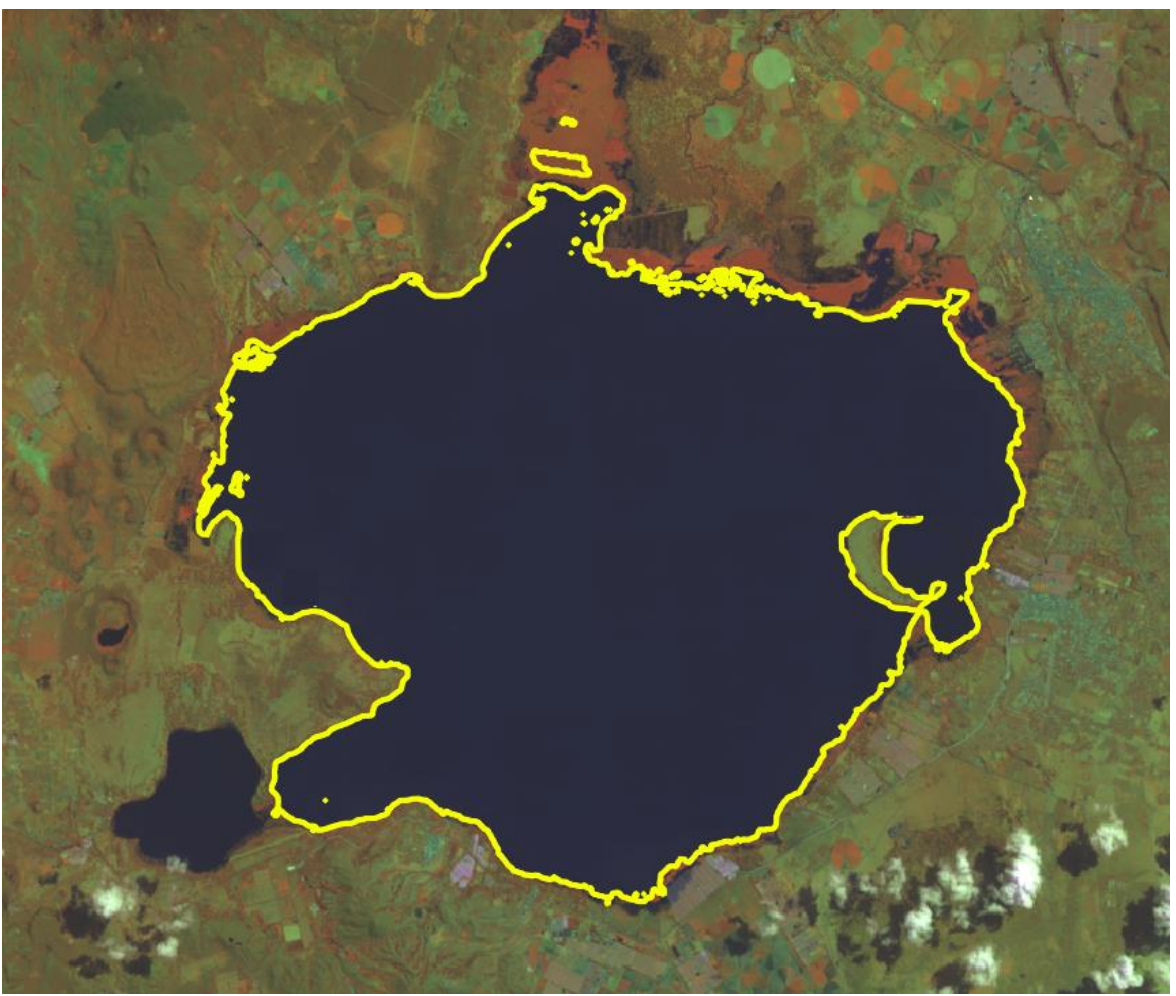

Figure A7: Land-water mask indicated by yellow polygons for Lake Naivasha for 20.07.2020 

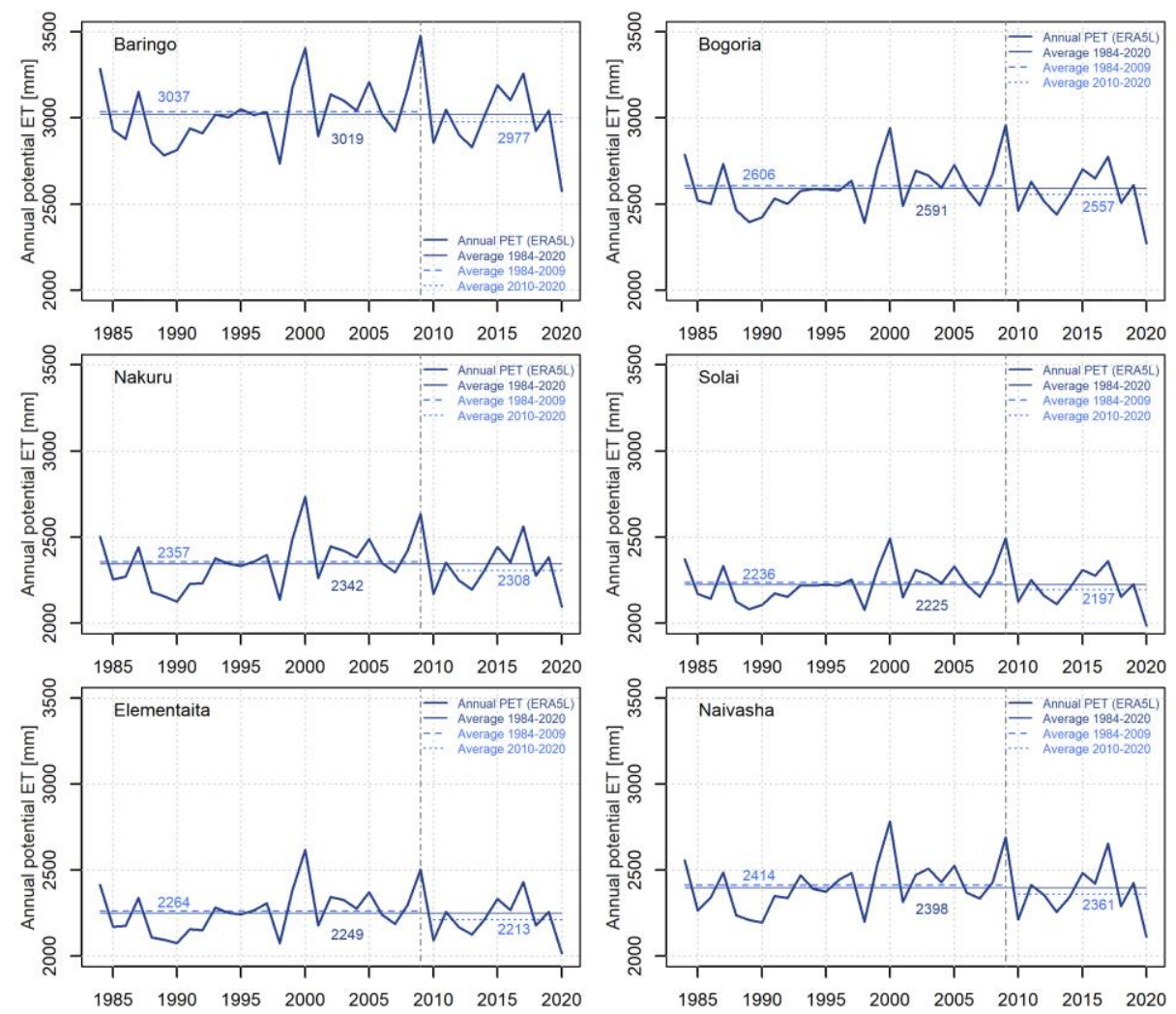

Figure A8: Annual potential evapotranspiration sums for the study lake catchments, incl. averages for 1984-2020, 1984-2009 and 2010-2020.
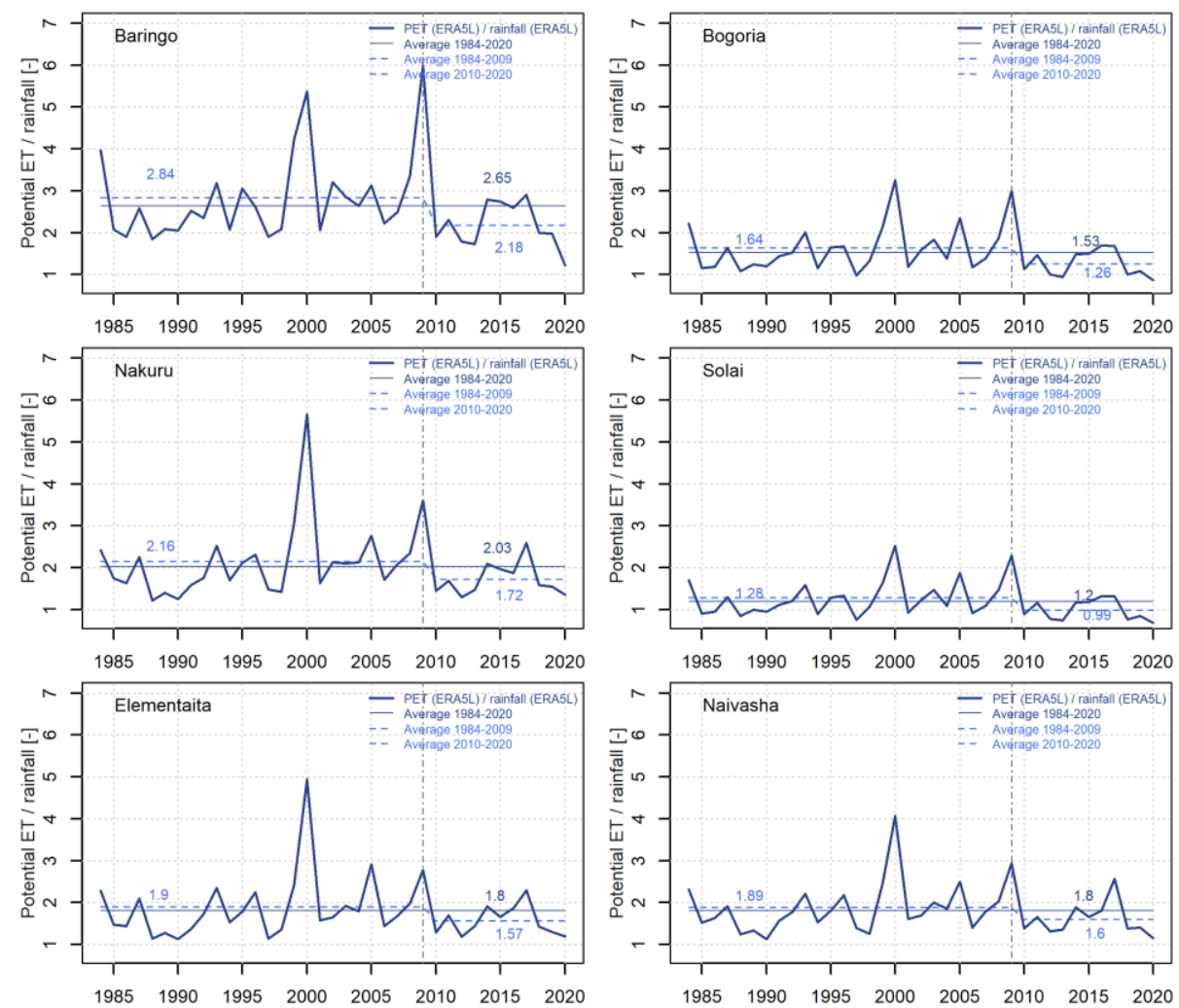

Figure A9:Ratio between potential evapotranspiration and rainfall (Climatic Water Balance) for the study lake catchments, incl. averages for 1984-2020, 1984-2009 and 2010-2020. 2009 is a breakpoint in all catchments. 

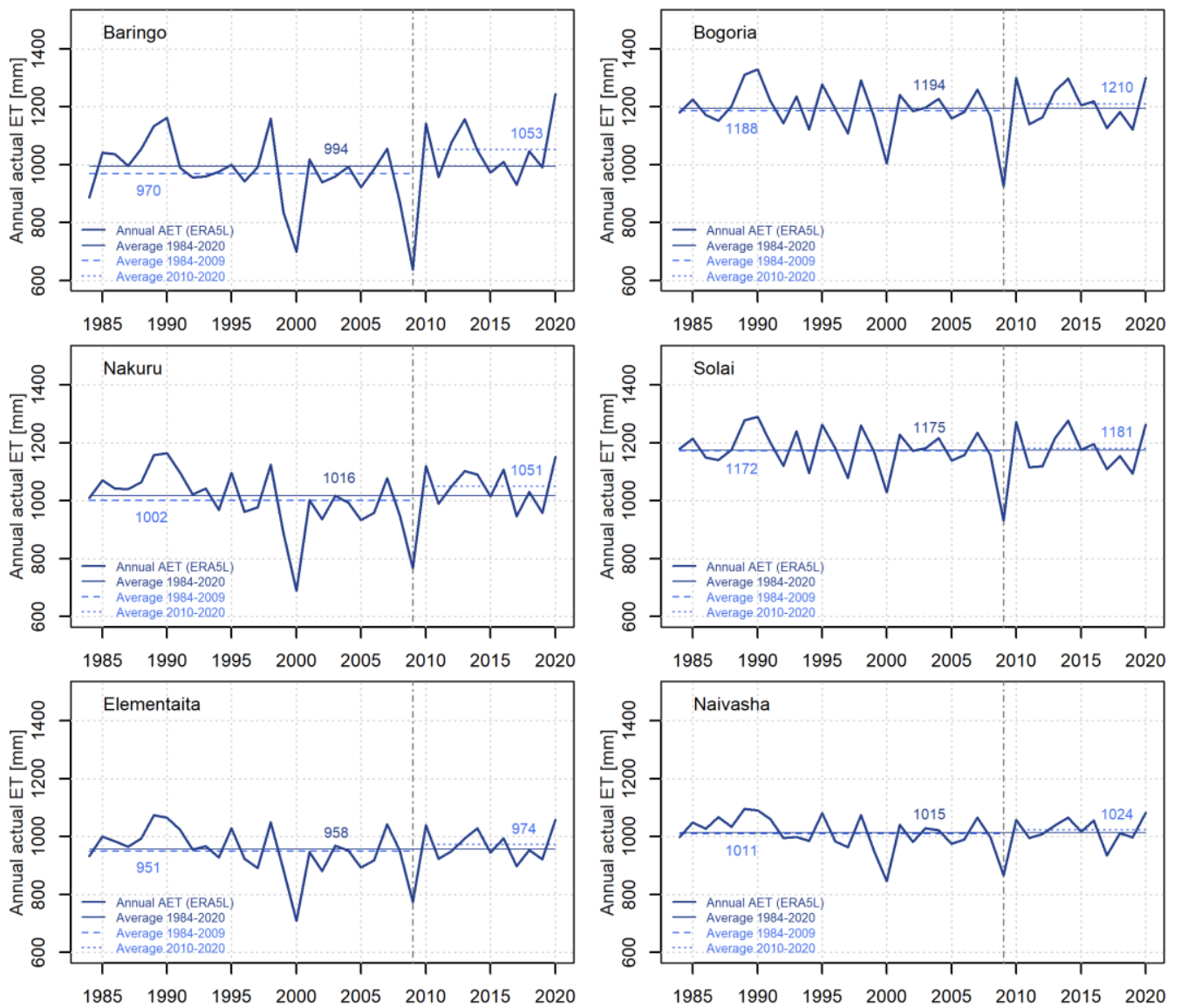

Figure A10: Mean annual actual Evapotranspiration (AET) for the orographic catchments of the single lakes. Also shown as dashed horizontal lines are averages for the period 1984-2020 and the periods 1981-2009 and 2010-2020. The last two periods are separated by a breakpoint year in 2009 (dashed vertical line), where a change in structure of rainfall time series occurred.

Table A1: Annual rainfall [mm] for orographic catchments of the study lakes.

Annual rainfall $[\mathrm{mm}]$ for orographic catchments (CHIRPS)

\begin{tabular}{ccccccc}
\hline Year & Baringo & Bogoria & Nakuru & Solai & Elementaita & Naivasha \\
\hline 1981 & 1083.97 & 1164.67 & 1140.04 & 1151.31 & 1001.40 & 1117.45 \\
1982 & 1097.21 & 1105.70 & 1050.85 & 1146.26 & 943.14 & 1076.23 \\
1983 & 1002.00 & 1081.54 & 967.91 & 1052.16 & 846.31 & 929.04 \\
1984 & 541.12 & 541.84 & 630.46 & 542.13 & 530.43 & 644.18 \\
1985 & 961.50 & 925.05 & 1016.71 & 897.90 & 853.15 & 939.97 \\
1986 & 852.84 & 936.86 & 951.71 & 931.53 & 824.70 & 886.96 \\
1987 & 788.96 & 785.34 & 776.51 & 761.75 & 678.79 & 791.68 \\
1988 & 1119.40 & 1091.84 & 1204.37 & 1089.15 & 1052.12 & 1073.04 \\
1989 & 1053.31 & 1092.59 & 1154.19 & 1053.81 & 1026.82 & 1166.85 \\
1990 & 955.16 & 957.05 & 1081.50 & 927.64 & 980.52 & 1093.32
\end{tabular}


Annual rainfall [mm] for orographic catchments (CHIRPS)

\begin{tabular}{|c|c|c|c|c|c|c|}
\hline Year & Baringo & Bogoria & Nakuru & Solai & Elementaita & Naivasha \\
\hline 1991 & 875.83 & 873.85 & 841.27 & 855.33 & 790.29 & 882.43 \\
\hline 1992 & 886.85 & 913.65 & 977.55 & 918.45 & 851.23 & 892.68 \\
\hline 1993 & 823.82 & 840.67 & 838.75 & 819.23 & 690.85 & 779.22 \\
\hline 1994 & 968.60 & 911.10 & 883.94 & 878.93 & 758.58 & 920.72 \\
\hline 1995 & 880.90 & 954.50 & 934.45 & 915.81 & 892.79 & 1075.53 \\
\hline 1996 & 990.01 & 1012.63 & 969.58 & 1033.01 & 852.91 & 927.40 \\
\hline 1997 & 1200.23 & 1248.22 & 1196.78 & 1168.44 & 1109.36 & 1216.51 \\
\hline 1998 & 1009.17 & 1126.48 & 1055.08 & 1090.69 & 976.78 & 1230.51 \\
\hline 1999 & 757.37 & 727.11 & 764.10 & 714.44 & 676.61 & 805.46 \\
\hline 2000 & 719.07 & 707.05 & 670.94 & 727.74 & 593.68 & 662.97 \\
\hline 2001 & 1090.04 & 1162.66 & 1032.28 & 1160.63 & 947.52 & 1062.09 \\
\hline 2002 & 986.69 & 972.88 & 1082.44 & 957.82 & 991.87 & 1127.23 \\
\hline 2003 & 1089.38 & 1047.84 & 1114.51 & 1058.64 & 987.05 & 1090.93 \\
\hline 2004 & 987.85 & 934.15 & 900.08 & 927.39 & 814.76 & 953.42 \\
\hline 2005 & 969.60 & 931.02 & 869.94 & 942.71 & 799.51 & 853.29 \\
\hline 2006 & 1062.51 & 1038.86 & 1056.27 & 1010.82 & 975.12 & 1147.47 \\
\hline 2007 & 1213.57 & 1250.36 & 1060.75 & 1257.06 & 967.11 & 1018.37 \\
\hline 2008 & 841.14 & 848.61 & 779.33 & 828.96 & 712.90 & 807.76 \\
\hline 2009 & 770.79 & 757.64 & 827.55 & 776.33 & 773.52 & 829.93 \\
\hline 2010 & 1260.21 & 1270.91 & 1202.82 & 1266.44 & 1121.41 & 1232.82 \\
\hline 2011 & 1167.24 & 1206.44 & 1143.16 & 1186.57 & 1048.92 & 1199.63 \\
\hline 2012 & 1363.66 & 1329.42 & 1147.48 & 1343.63 & 1099.59 & 1303.19 \\
\hline 2013 & 1376.22 & 1486.47 & 1181.89 & 1491.12 & 1104.80 & 1174.56 \\
\hline 2014 & 893.75 & 882.37 & 897.18 & 863.34 & 818.50 & 968.19 \\
\hline 2015 & 874.82 & 842.67 & 920.84 & 807.41 & 849.41 & 1031.77 \\
\hline 2016 & 999.64 & 970.23 & 1023.18 & 952.88 & 918.76 & 1000.68 \\
\hline 2017 & 1126.89 & 1159.54 & 1015.65 & 1144.57 & 893.51 & 870.85 \\
\hline 2018 & 1490.56 & 1554.91 & 1472.92 & 1513.08 & 1411.28 & 1683.99 \\
\hline 2019 & 1217.88 & 1211.57 & 1175.40 & 1196.53 & 1069.19 & 1229.63 \\
\hline 2020 & 1599.17 & 1588.20 & 1497.18 & 1558.21 & 1321.94 & 1471.93 \\
\hline Median & 994.83 & 992.75 & 1019.94 & 984.32 & 906.13 & 1025.07 \\
\hline Mean & 1023.72 & 1036.11 & 1012.69 & 1023.00 & 913.93 & 1029.25 \\
\hline Max & 1599.17 & 1588.20 & 1497.18 & 1558.21 & 1411.28 & 1683.99 \\
\hline \multicolumn{7}{|l|}{ Min } \\
\hline & 541.12 & 541.84 & 630.46 & 542.13 & 530.43 & 644.18 \\
\hline
\end{tabular}


Annual rainfall [mm] for orographic catchments (CHIRPS)

\begin{tabular}{ccccccc}
\hline Year & Baringo & Bogoria & Nakuru & Solai & Elementaita & Naivasha \\
\hline Range & & & & & & \\
& 1058.05 & 1046.36 & 866.72 & 1016.08 & 880.85 & 1039.81 \\
& & & & & & \\
$\begin{array}{c}\text { Standard } \\
\text { Deviation }\end{array}$ & 211.72 & 225.50 & 184.18 & 223.11 & 178.86 & 207.54 \\
\hline
\end{tabular}

Table A2: Mean annual lake area $\left[\mathrm{km}^{2}\right]$

Mean annual lake area $\left[\mathrm{km}^{2}\right]$

\begin{tabular}{|c|c|c|c|c|c|c|}
\hline Year & Baringo & Bogoria & Nakuru & Solai & Elementaita & Naivasha \\
\hline 1984 & 147.31 & 32.14 & 41.00 & 3.26 & 16.52 & 141.12 \\
\hline 1985 & 142.43 & N/A & 40.32 & 5.38 & N/A & 138.85 \\
\hline 1986 & 140.86 & 31.38 & 36.81 & 3.84 & 16.64 & 131.68 \\
\hline 1987 & 132.70 & 31.43 & 33.51 & 4.12 & 15.12 & 129.84 \\
\hline 1988 & N/A & N/A & N/A & N/A & N/A & N/A \\
\hline 1989 & 132.35 & 33.11 & 35.75 & N/A & 18.06 & 116.76 \\
\hline 1990 & N/A & N/A & N/A & N/A & N/A & N/A \\
\hline 1991 & N/A & N/A & N/A & N/A & N/A & N/A \\
\hline 1992 & 133.86 & 32.00 & N/A & 5.48 & 16.94 & N/A \\
\hline 1993 & N/A & N/A & N/A & N/A & N/A & N/A \\
\hline 1994 & 119.27 & 32.06 & N/A & 6.14 & N/A & N/A \\
\hline 1995 & 118.31 & 31.89 & 33.10 & 5.89 & N/A & 123.13 \\
\hline 1996 & N/A & N/A & N/A & N/A & N/A & N/A \\
\hline 1997 & N/A & N/A & N/A & N/A & N/A & N/A \\
\hline 1998 & N/A & N/A & N/A & N/A & N/A & N/A \\
\hline 1999 & 126.41 & 34.38 & 41.40 & 6.23 & 19.83 & 129.01 \\
\hline 2000 & 124.95 & 33.78 & 37.19 & 5.42 & 17.61 & 126.19 \\
\hline 2001 & 120.05 & 33.63 & 35.88 & 6.05 & 18.40 & 124.26 \\
\hline 2002 & 119.15 & 33.24 & 36.16 & 4.98 & 17.54 & 123.52 \\
\hline 2003 & 121.40 & 33.02 & 37.38 & 5.73 & 17.21 & 123.03 \\
\hline 2004 & 125.24 & 33.12 & 38.35 & 6.26 & 17.15 & N/A \\
\hline 2005 & 125.79 & 32.41 & 36.51 & 5.58 & 16.44 & N/A \\
\hline 2006 & 126.00 & 31.51 & N/A & 5.08 & 16.52 & N/A \\
\hline 2007 & 127.20 & 33.07 & 38.12 & 7.16 & 17.82 & N/A \\
\hline 2008 & 131.24 & 34.02 & 39.17 & 6.36 & 18.66 & 119.95 \\
\hline 2009 & 133.52 & 33.41 & 36.42 & 4.62 & 16.81 & 104.85 \\
\hline
\end{tabular}


Mean annual lake area $\left[\mathrm{km}^{2}\right]$

\begin{tabular}{ccccccc}
\hline Year & Baringo & Bogoria & Nakuru & Solai & Elementaita & Naivasha \\
\hline 2010 & 134.74 & 34.15 & 38.86 & 7.17 & 19.10 & 108.40 \\
2011 & 139.17 & 34.98 & 42.25 & 8.41 & 20.52 & 113.72 \\
2012 & 142.59 & 35.89 & 48.17 & 8.80 & 21.27 & N/A \\
2013 & 194.17 & 38.28 & 52.88 & 10.23 & 21.73 & 134.07 \\
2014 & 197.05 & 39.83 & 55.28 & 11.68 & 21.86 & 137.02 \\
2015 & 192.99 & 39.16 & 54.40 & 10.71 & 21.33 & 135.90 \\
2016 & 188.64 & 39.28 & 55.68 & 10.49 & 21.14 & 134.26 \\
2017 & 185.20 & 38.60 & 55.18 & 9.79 & 20.52 & 138.51 \\
2018 & 185.70 & 40.05 & 57.04 & 10.14 & 20.81 & 139.95 \\
2019 & 186.02 & 40.15 & 57.83 & 10.21 & 20.01 & 142.58 \\
2020 & 196.18 & 41.18 & 62.26 & 11.18 & 21.33 & 147.73 \\
\hline Median & 133.69 & 33.63 & 39.17 & 6.23 & 18.40 & 129.84 \\
Mean & 146.35 & 34.87 & 43.59 & 7.12 & 18.77 & 128.88 \\
Max & 197.05 & 41.18 & 62.26 & 11.68 & 21.86 & 147.73 \\
Min & 118.31 & 31.38 & 33.10 & 3.26 & 15.12 & 104.85 \\
Range & 78.74 & 9.80 & 29.16 & 8.42 & 6.74 & 42.88 \\
\hline Deviation & 28.28 & 3.16 & 9.01 & 2.46 & 2.02 & 11.21 \\
\hline Mard & & & & & & \\
\hline & & & & & & \\
\hline
\end{tabular}

1540

Table A3: Mean annual lake levels [m]

Mean annual lake level [m]

\begin{tabular}{ccccccc}
\hline Year & Baringo & Bogoria & Nakuru & Solai & Elementaita & Naivasha \\
\hline 1984 & 973.36 & 993.32 & 1760.87 & 1505.88 & 1776.21 & 1886.27 \\
1985 & 972.99 & N/A & 1760.77 & 1508.47 & N/A & 1885.86 \\
1986 & 972.88 & 993.12 & 1760.29 & 1506.66 & 1776.22 & 1884.60 \\
1987 & 972.31 & 993.13 & 1759.85 & 1507.01 & 1775.86 & 1884.28 \\
1988 & N/A & N/A & N/A & N/A & N/A & N/A \\
1989 & 972.28 & 993.58 & 1760.14 & N/A & 1776.60 & 1882.02 \\
1990 & N/A & N/A & N/A & N/A & N/A & N/A \\
1991 & N/A & N/A & N/A & N/A & N/A & N/A \\
1992 & 972.39 & 993.28 & N/A & 1508.58 & 1776.29 & N/A \\
1993 & N/A & N/A & N/A & N/A & N/A & N/A \\
1994 & 971.42 & 993.29 & N/A & 1509.27 & N/A & N/A \\
1995 & 971.36 & 993.25 & 1759.80 & 1509.01 & N/A & 1883.11 \\
1996 & N/A & N/A & N/A & N/A & N/A & N/A \\
1997 & N/A & N/A & N/A & N/A & N/A & N/A
\end{tabular}


Mean annual lake level [m]

\begin{tabular}{|c|c|c|c|c|c|c|}
\hline Year & Baringo & Bogoria & Nakuru & Solai & Elementaita & Naivasha \\
\hline 1998 & N/A & N/A & N/A & N/A & N/A & N/A \\
\hline 1999 & 971.89 & 993.97 & 1760.92 & 1509.36 & 1777.18 & 1884.13 \\
\hline 2000 & 971.79 & 993.78 & 1760.34 & 1508.52 & 1776.49 & 1883.64 \\
\hline 2001 & 971.47 & 993.74 & 1760.16 & 1509.18 & 1776.69 & 1883.31 \\
\hline 2002 & 971.42 & 993.62 & 1760.20 & 1508.03 & 1776.46 & 1883.18 \\
\hline 2003 & 971.56 & 993.56 & 1760.36 & 1508.70 & 1776.37 & 1883.10 \\
\hline 2004 & 971.81 & 993.59 & 1760.49 & 1509.39 & 1776.36 & N/A \\
\hline 2005 & 971.85 & 993.39 & 1760.25 & 1508.67 & 1776.19 & N/A \\
\hline 2006 & 971.86 & 993.15 & N/A & 1508.13 & 1776.19 & N/A \\
\hline 2007 & 971.94 & 993.58 & 1760.47 & 1510.27 & 1776.59 & N/A \\
\hline 2008 & 972.21 & 993.85 & 1760.61 & 1509.49 & 1776.79 & 1882.57 \\
\hline 2009 & 972.36 & 993.67 & 1760.23 & 1507.56 & 1776.28 & 1879.99 \\
\hline 2010 & 972.45 & 993.91 & 1760.58 & 1510.25 & 1777.00 & 1880.60 \\
\hline 2011 & 972.76 & 994.17 & 1761.05 & 1511.45 & 1777.48 & 1881.50 \\
\hline 2012 & 973.00 & 994.50 & 1762.01 & 1511.80 & 1777.87 & N/A \\
\hline 2013 & 978.93 & 995.68 & 1762.94 & 1513.10 & 1778.16 & 1885.02 \\
\hline 2014 & 979.52 & 996.65 & 1763.49 & 1514.41 & 1778.24 & 1885.54 \\
\hline 2015 & 978.61 & 996.13 & 1763.27 & 1513.53 & 1777.89 & 1885.34 \\
\hline 2016 & 977.78 & 996.22 & 1763.59 & 1513.33 & 1777.78 & 1885.05 \\
\hline 2017 & 977.24 & 995.78 & 1763.46 & 1512.70 & 1777.48 & 1885.80 \\
\hline 2018 & 977.33 & 996.86 & 1764.01 & 1513.01 & 1777.62 & 1886.06 \\
\hline 2019 & 977.36 & 996.93 & 1764.22 & 1513.08 & 1777.27 & 1886.53 \\
\hline 2020 & 979.59 & 998.11 & 1766.19 & 1513.96 & 1777.92 & 1887.47 \\
\hline Median & 972.38 & 993.74 & 1760.61 & 1509.36 & 1776.69 & 1884.28 \\
\hline Mean & 973.79 & 994.41 & 1761.50 & 1510.10 & 1776.94 & 1884.13 \\
\hline Max & 979.59 & 998.11 & 1766.19 & 1514.41 & 1778.24 & 1887.47 \\
\hline Min & 971.36 & 993.12 & 1759.80 & 1505.88 & 1775.86 & 1879.99 \\
\hline Range & 8.23 & 4.99 & 6.40 & 8.53 & 2.38 & 7.48 \\
\hline $\begin{array}{l}\text { Standard } \\
\text { Deviation }\end{array}$ & 2.85 & 1.43 & 1.72 & 2.41 & 0.72 & 1.95 \\
\hline
\end{tabular}

Table A4: Mean annual lake volume variation [ $\left.\mathrm{km}^{3}\right]$

Mean annual lake volume variation $\left[\mathrm{km}^{3}\right]$

\begin{tabular}{ccccccc}
\hline Year & Baringo & Bogoria & Nakuru & Solai & Elementaita & Naivasha \\
\hline 1984 & 0.311 & 0.008 & 0.040 & 0.002 & 0.007 & 0.304
\end{tabular}


Mean annual lake volume variation $\left[\mathrm{km}^{3}\right]$

\begin{tabular}{|c|c|c|c|c|c|c|}
\hline Year & Baringo & Bogoria & Nakuru & Solai & Elementaita & Naivasha \\
\hline 1985 & 0.258 & N/A & 0.036 & 0.013 & N/A & 0.268 \\
\hline 1986 & 0.242 & 0.002 & 0.017 & 0.005 & 0.006 & 0.182 \\
\hline 1987 & 0.166 & 0.002 & 0.002 & 0.006 & 0.001 & 0.164 \\
\hline 1988 & N/A & N/A & N/A & N/A & N/A & N/A \\
\hline 1989 & 0.163 & 0.016 & 0.012 & N/A & 0.013 & 0.068 \\
\hline 1990 & N/A & N/A & N/A & N/A & N/A & N/A \\
\hline 1991 & N/A & N/A & N/A & N/A & N/A & N/A \\
\hline 1992 & 0.176 & 0.006 & N/A & 0.013 & 0.007 & N/A \\
\hline 1993 & N/A & N/A & N/A & N/A & N/A & N/A \\
\hline 1994 & 0.056 & 0.007 & N/A & 0.017 & N/A & N/A \\
\hline 1995 & 0.049 & 0.006 & 0.000 & 0.016 & N/A & 0.110 \\
\hline 1996 & N/A & N/A & N/A & N/A & N/A & N/A \\
\hline 1997 & N/A & N/A & N/A & N/A & N/A & N/A \\
\hline 1998 & N/A & N/A & N/A & N/A & N/A & N/A \\
\hline 1999 & 0.112 & 0.029 & 0.042 & 0.018 & 0.024 & 0.157 \\
\hline 2000 & 0.100 & 0.023 & 0.019 & 0.013 & 0.011 & 0.134 \\
\hline 2001 & 0.062 & 0.022 & 0.012 & 0.017 & 0.015 & 0.118 \\
\hline 2002 & 0.055 & 0.018 & 0.014 & 0.011 & 0.011 & 0.113 \\
\hline 2003 & 0.075 & 0.016 & 0.020 & 0.016 & 0.010 & 0.111 \\
\hline 2004 & 0.096 & 0.017 & 0.025 & 0.018 & 0.009 & 0.117 \\
\hline 2005 & 0.091 & 0.010 & 0.016 & 0.014 & 0.006 & 0.113 \\
\hline 2006 & 0.085 & 0.003 & N/A & 0.011 & 0.006 & 0.089 \\
\hline 2007 & 0.143 & 0.017 & 0.024 & 0.024 & 0.013 & 0.080 \\
\hline 2008 & 0.175 & 0.025 & 0.029 & 0.019 & 0.017 & 0.087 \\
\hline 2009 & 0.173 & 0.019 & 0.015 & 0.009 & 0.008 & 0.042 \\
\hline 2010 & 0.184 & 0.027 & 0.029 & 0.024 & 0.021 & 0.030 \\
\hline 2011 & 0.235 & 0.036 & 0.047 & 0.033 & 0.030 & 0.057 \\
\hline 2012 & 0.260 & 0.048 & 0.090 & 0.036 & 0.039 & 0.099 \\
\hline 2013 & 1.197 & 0.092 & 0.136 & 0.048 & 0.045 & 0.168 \\
\hline 2014 & 1.319 & 0.130 & 0.165 & 0.062 & 0.046 & 0.242 \\
\hline 2015 & 1.146 & 0.109 & 0.153 & 0.052 & 0.039 & 0.228 \\
\hline 2016 & 0.965 & 0.112 & 0.173 & 0.050 & 0.037 & 0.248 \\
\hline 2017 & 0.874 & 0.095 & 0.164 & 0.044 & 0.030 & 0.251 \\
\hline 2018 & 0.942 & 0.134 & 0.197 & 0.048 & 0.033 & 0.309 \\
\hline 2019 & 0.946 & 0.141 & 0.207 & 0.048 & 0.026 & 0.305 \\
\hline 2020 & 1.402 & 0.190 & 0.329 & 0.057 & 0.040 & 0.471 \\
\hline
\end{tabular}


Mean annual lake volume variation $\left[\mathrm{km}^{3}\right]$

\begin{tabular}{ccccccc}
\hline Year & Baringo & Bogoria & Nakuru & Solai & Elementaita & Naivasha \\
\hline Median & 0.175 & 0.022 & 0.029 & 0.018 & 0.015 & 0.126 \\
Mean & 0.402 & 0.047 & 0.075 & 0.026 & 0.020 & 0.167 \\
Max & 1.402 & 0.190 & 0.329 & 0.062 & 0.046 & 0.471 \\
Min & 0.049 & 0.002 & 0.000 & 0.002 & 0.001 & 0.030 \\
Range & 1.353 & 0.188 & 0.329 & 0.060 & 0.045 & 0.441 \\
Standard & 0.443 & 0.053 & 0.084 & 0.018 & 0.014 & 0.102 \\
Deviation & & & & & & \\
\hline
\end{tabular}

